\title{
Extensões dos modelos de regressão quantílica bayesianos
}

\author{
Bruno Ramos dos Santos \\ TESE APRESENTADA \\ $\mathrm{AO}$ \\ Instituto de Matemática e Estatística \\ $\mathrm{DA}$ \\ Universidade De SÃo Paulo \\ PARA \\ OBTENÇÃO DO TÍTULO \\ $\mathrm{DE}$ \\ DOUTOR EM CIÊNCIAS \\ Programa: Estatística \\ Orientador: Prof. Dr. Heleno Bolfarine
}

Durante o desenvolvimento deste trabalho o autor recebeu auxílio financeiro da CAPES/FAPESP.

São Paulo, abril de 2016 


\section{Extensões dos modelos de regressão quantílica Bayesianos}

Esta versão definitiva da tese contém as correções e alterações sugeridas pela Comissão Julgadora durante a defesa realizada por Bruno Ramos dos Santos em 29/4/2016.

Comissão Julgadora:

- Prof. Dr. Heleno Bolfarine (orientador) - IME-USP

- Prof ${ }^{a}$. Dra ${ }^{a}$. Marcia D’Elia Branco - IME-USP

- Prof. Dr. Victor Hugo Lachos D'Ávila - UNICAMP

- Prof. Dr. Jorge Luiz Bazán Guzmán - ICMC-USP

- Prof ${ }^{a}$. Dra . Vera Lucia Damasceno Tomazella - UFSCAR 


\section{Agradecimentos}

Ao professor Heleno Bolfarine pela orientação e por me indicar os caminhos pelos quais essa tese seguiu; pela confiança e interesse no meu trabalho; pelas animadas partidas de tênis no CEPE, que me ajudavam a descontrair em meio aos compromissos do curso.

À professora Silvia Nagib Elian, cuja orientação no meu mestrado foi essencial para minha formação enquanto pesquisador.

À professora Silvia Ferrari, cuja disciplina Estatística Avançada I e a convivência durante o doutorado foram muito importantes para o meu desenvolvimento na pesquisa.

Ao professor Alan Gelfand, que possibilitou a minha visita à Duke University durante o doutorado; pelos conselhos da vida acadêmica; pela indicação ao professor Surya Tokdar, que me supervisionou e orientou, e que me mostrou uma nova abordagem para modelos de regressão quantílica.

À Fundação de Amparo à Pesquisa do Estado de São Paulo (FAPESP), através dos processos 2012/20267-9 e 2013/04419-6, que deu o apoio financeiro necessário para o cumprimento de todas as etapas dessa pesquisa.

Aos amigos de Duke, Allie, David, Christoph, Jacopo, Lutz, Maria, MaryBeth, Nicole, Monika, Thais, Tsuyoshi, que me ajudaram a passar esse longo período longe do Brasil e tornaram essa ida para os Estados Unidos muito mais agradável.

Aos amigos do IME, que estiveram presente em toda essa caminhada de quatro anos, Ariadne, Daniel, Gilberto, Glauce, Joelson, Maikel, Plinio, Tatá, Vinicius, pela companhia de estudo nos finais de semana, pelas conversas no café, pela companhia no bandejão e pela sempre pronta ajuda em qualquer tipo de problema que eu tivesse durante a tese.

Aos amigos da FFLCH, Ana Flávia, Danilo, Bruna, Edu, Camila, Everaldo, Ugo, pelos momentos de descontração e pelas trocas de experiências sempre enriquecedoras.

Aos meus pais e meus irmãos, pelo amor, pelo apoio contínuo em todas as minhas decisões e por me fazerem lembrar a todo momento que mesmo distantes estaremos sempre juntos.

Por fim, à Anouch, pelo amor e companheirismo em todos os momentos. Agradeço por me mostrar que, mesmo na incerteza, devemos continuar caminhando certos de que haverá sempre um amanhã. 


\section{Resumo}

SANTOS, B. R. Extensões dos modelos de regressão quantílica Bayesianos. 2016. 115 f. Tese (Doutorado) - Instituto de Matemática e Estatística, Universidade de São Paulo, São Paulo, 2016.

Esta tese visa propor extensões dos modelos de regressão quantílica bayesianos, considerando dados de proporção com inflação de zeros, e também dados censurados no zero. Inicialmente, é sugerida uma análise de observações influentes, a partir da representação por mistura localização-escala da distribuição Laplace assimétrica, em que as distribuições a posteriori das variáveis latentes são comparadas com o intuito de identificar possíveis observações aberrantes. Em seguida, é proposto um modelo de duas partes para analisar dados de proporção com inflação de zeros ou uns, estudando os quantis condicionais e a probabilidade da variável resposta ser igual a zero. Além disso, são propostos modelos de regressão quantílica bayesiana para dados contínuos com um componente discreto no zero, em que parte dessas observações é suposta censurada. Esses modelos podem ser considerados mais completos na análise desse tipo de dados, uma vez que a probabilidade de censura é verificada para cada quantil de interesse. E por último, é considerada uma aplicação desses modelos com correlação espacial, para estudar os dados da eleição presidencial no Brasil em 2014. Nesse caso, os modelos de regressão quantílica são capazes de incorporar essa informação espacial a partir do processo Laplace assimétrico. Para todos os modelos propostos foi desenvolvido um pacote do software $\mathrm{R}$, que está exemplificado no apêndice.

Palavras-chave: Regressão quantílica bayesiana; Observações aberrantes; Modelo de duas partes; Dados censurados; Modelo espacial; Distribuição Laplace assimétrica. 


\section{Abstract}

This thesis aims to propose extensions of Bayesian quantile regression models, considering proportion data with zero inflation, and also censored data at zero. Initially, it is suggested an analysis of influential observations, based on the location-scale mixture representation of the asymmetric Laplace distribution, where the posterior distribution of the latent variables are compared with the goal of identifying possible outlying observations. Next, a two-part model is proposed to analyze proportion data with zero or one inflation, studying the conditional quantile and the probability of the response variable being equal to zero. Following, Bayesian quantile regression models are proposed for continuous data with a discrete component at zero, where part of these observations are assumed censored. These models may be considered more complete in the analysis of this type of data, as the censoring probability varies with the quantiles of interest. For last, it is considered an application of these models with spacial correlation, in order to study the data about the last presidential election in Brazil in 2014. In this example, the quantile regression models are able to incorporate spatial dependence with the asymmetric Laplace process. For all the proposed models it was developed a $\mathrm{R}$ package, which is exemplified in the appendix.

Keywords: Bayesian quantile regression; Outliers; Two-part model; Censored data; Spatial model; Asymmetric Laplace distribution. 


\section{Sumário}

Lista de Figuras $\quad$ vi

1 Introdução 1

2 Sobre regressão quantílica bayesiana e outliers $\quad 4$

2.1 Introdução . . . . . . . . . . . . . . . . . . . . . . . . . . . . . . 4

2.2 Regressão quantílica Bayesiana ． . . . . . . . . . . . . . . . . . 7

2.3 Observações outliers dados os ajustes de regressão quantílica bayesiana . . . 10

2.3.1 Probabilidade média a posteriori . . . . . . . . . . . . . . . . . . . . 12

2.3.2 Divergência de Kullback-Leibler . . . . . . . . . . . . . . . . . . . . . 14

2.4 Estudos de simulação . . . . . . . . . . . . . . . . . . . . . . . . 15

2.4 .1 Simulação $1 \ldots \ldots$. . . . . . . . . . . . . . . . 16

2.4 .2 Simulação $2 \ldots \ldots \ldots$. . . . . . . . . . . . . . . 17

2.5 Aplicação . . . . . . . . . . . . . . . . . . . . . 21

2.6 Discussão final . . . . . . . . . . . . . . . . . . . . . . . 26

3 Análise bayesiana para dados de proporção com inflação de zeros ou uns $\begin{array}{ll}\text { usando regressão quantílica } & 28\end{array}$

3.1 Introdução . . . . . . . . . . . . . . . . . . . . . . . . . . . . . 28

3.2 Modelos de regressão quantílica para dados de proporção . . . . . . . . . . . 31

3.2.1 Exemplos com misturas de distribuição beta . . . . . . . . . . . . . . 34

3.3 Modelos de duas partes . . . . . . . . . . . . . . . . . . 36

3.4 Estudos de simulação . . . . . . . . . . . . . . . . . . . . . . . . . . . . . . . 39

3.4 .1 Simulação $1 \ldots \ldots$. . . . . . . . . . . . . . . . 40

3.4 .2 Simulação $2 \ldots \ldots \ldots$. . . . . . . . . . . . . . . . . . . . 41

3.5 Análise de acesso à eletricidade no Brasil . . . . . . . . . . . . . . . . . . . . 42

3.6 Discussão e conclusão . . . . . . . . . . . . . . . . . . . . . . . . . . . . 45

4 Regressão quantílica bayesiana para dados contínuos com um componente discreto no zero $\quad 49$

4.1 Introdução . . . . . . . . . . . . . . . . . . . . . . . 50

4.2 Revisão do modelo de duas partes . . . . . . . . . . . . . . . . . . 51 
4.3 Regressão quantílica bayesiana para dados contínuos com uma massa pontual no zero . . . . . . . . . . . . . . . . . . . . . . . . . 54

4.4 Estudo de simulação para a probabilidade de censura . . . . . . . . . . . . 57

4.5 Aplicações . . . . . . . . . . . . . . . . . . . . . . . . . . . . 61

4.5.1 Dados sobre oferta de trabalho de mulheres . . . . . . . . . . . 61

4.5.2 Gastos com bens duráveis no Brasil . . . . . . . . . . . . . . . . . 65

4.6 Considerações finais . . . . . . . . . . . . . . . . . . . . . . . . . . . . . 69

5 Análise das eleições presidenciais no Brasil via regressão quantílica baye$\begin{array}{ll}\text { siana espacial } & 71\end{array}$

5.1 Introdução . . . . . . . . . . . . . . . . . . . . . . . 72

5.2 Regressão quantílica espacial bayesiana . . . . . . . . . . . . . . . . . 74

5.3 Regressão quantílica bayesiana espacial para dados de proporção . . . . . . . 76

5.3 .1 Ajuste do modelo . . . . . . . . . . . . . . . 78

5.3.2 Processo Preditivo Laplace assimétrico . . . . . . . . . . . . . . . . . 80

5.4 Eleição presidencial no Brasil . . . . . . . . . . . . . . . . . . . . . . . . . . 81

5.5 Discussão . . . . . . . . . . . . . . . . . . . . . . . 88

6 Conclusão e estudos futuros $\quad 89$

6.1 Considerações finais . . . . . . . . . . . . . . . . . . . . . . . . 89

6.2 Trabalhos futuros . . . . . . . . . . . . . . . . . . . . 90

A Manual sobre pacote baquantreg $\quad \mathbf{9 2}$

$\begin{array}{ll}\text { Referências Bibliográficas } & 102\end{array}$ 


\section{Lista de Figuras}

2.1 (a) Função $T(\tau)$, que é parte da variância de uma variável com distribuição Laplace assimétrica. (b) Estimativas a posteriori para $\sigma$ no modelo analisado na seção de aplicação, em que a linha sólida representa a média a posteriori, enquanto que as linhas pontilhadas representam o intervalo de credibilidade de $95 \%$. . . . . . . . . . . . . . . . . . . . .

2.2 Exemplo de como parte da probabilidade em (2.6) é calculada, em que a área sob as linhas pontilhadas em cinza é a probabilidade de interesse.

2.3 (a) Distribuição das probabilidades de serem outliers para todas observações em uma réplica selecionada aleatoriamente no estudo de simulação 1. (b) Distribuição da probabilidade de ser outlier média para cada réplica do estudo de simulação 1 .

2.4 Distribuição das estimativas $\hat{\beta}_{1}(\tau)$ no estudo de simulação 2 nos diferentes cenários para $\tau=\{0,1,0,5,0,9\} \ldots \ldots \ldots \ldots$

2.5 Distribuição das estimativas $\hat{\beta}_{2}(\tau)$ no estudo de simulação 2 nos diferentes cenários para $\tau=\{0,1,0,5,0,9\}$.

2.6 Variação percentual para o índice de Gini nos 26 estados brasileiros e o Distrito Federal, em comparação com 1991. (a) 2000, (b) 2010 . . . . . . . . . . . . .

2.7 Estimativas a posteriori para os parâmetros da regressão quantílica propostos no modelo (2.8), em que a linha sólida representa as médias a posteriori obtidas das cadeias MCMC e as linhas pontilhadas representam o intervalo de credibilidade de $95 \%$, para os quantis $\tau=0,1, \ldots, 0,9 \ldots \ldots$. . . .

2.8 Probabilidades de cada observação ser um outlier para $\tau=\{0.1,0.5,0.9\}$, considerando o modelo em $(2.8) \ldots \ldots \ldots$. . . . . . . . . . . . 24

$2.9 K L\left(f_{i}\right)$ para $\tau=\{0.1,0.5,0.9\}$, considerando o modelo em $(2.8) \ldots$. . .

3.1 Gráficos para exemplo dos dados com bimodalidade. (a) Histograma dos dados. (b) Estimativas a posteriori e intervalos de credibilidade de $95 \%$ para $\beta(\tau), \tau=\{0.1,0.2, \ldots, 0.9\}$.

3.2 Gráfico com as frequências da proporções de domicílios com acesso à eletricidade em uma amostra de cidades no Brasil . . . . . . . . . . . . . . . . . . 
3.3 Estimativas e intervalos de credibilidade de $95 \%$ para o modelo (3.8), para $\tau=0,1, \ldots, 0,9 \ldots \ldots \ldots \ldots \ldots \ldots \ldots \ldots$

3.4 Quantis estimados para valores predeterminados das variáveis preditoras. . . 47

4.1 Gráfico para $P(C=1 \mid Y=0)$ para diferentes $\tau^{\prime}$ 's como função da probabilidade $p=P(Y=0)$. (a) $x^{\prime} \beta(\tau)=-1$, (b) $x^{\prime} \beta(\tau)=1 \ldots \ldots$. . . . .

4.2 Densidade estimada para as médias a posteriori das probabilidades de ser censurada para observações censuradas e também observações não-censuradas. 59

4.3 Densidades estimadas para as médias a posteriori dos parâmetros $\beta_{2}, \gamma_{1}, \gamma_{2}$ no estudo de simulação. . . . . . . . . . . . . . . . . . . .

4.4 Densidades da probabilidade de uma observação ser censurada para $\tau=$

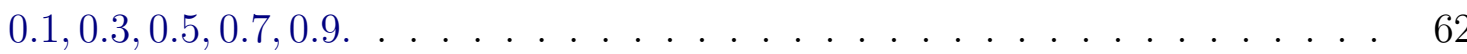

4.5 Média a posteriori e intervalos de credibilidade de $95 \%$ para $\gamma_{i}, i=1, \ldots, 6$. .

4.6 Densidade da variável $x_{1}$ separando por dois grupos de acordo com as respectivas probabilidade de censura em comparação com a probabilidade média em um dado quantil, para $\tau=0,1$ e $\tau=0,5$. As linhas sólidas são para o grupo acima da probabilidade média, enquanto as linhas pontilhadas são referentes ao grupo abaixo da probabilidade média. . . . . . . . . . . . . . . .

4.7 Densidade da variável $x_{3}$ separando por dois grupos de acordo com as respectivas probabilidade de censura em comparação com a probabilidade média em um dado quantil, para $\tau=0,5$ e $\tau=0,9$. As linhas sólidas são para o grupo acima da probabilidade média, enquanto as linhas pontilhadas são referentes ao grupo abaixo da probabilidade média.

4.8 Distribuição de gastos com bens duráveis no Brasil com dados da POF, com uma massa pontual no zero, em reais. . . . . . . . . . . . . . . . .

4.9 Estimativas da média a posteriori e intervalos de credibilidade de $90 \%$ para $\beta(\tau) \ldots \ldots \ldots \ldots \ldots \ldots \ldots \ldots \ldots \ldots \ldots \ldots \ldots \ldots \ldots \ldots \ldots$

4.10 Comparações para as probabilidades das observações serem censuradas dada a variável indicadora Cartão de Crédito. (a) Densidades estimadas para $\tau=0,5$, sim = linha sólida, não = linha pontilhada. (b) Perfis da probabilidades para $\tau=0,1,0,2, \ldots, 0,7 \ldots \ldots \ldots \ldots \ldots$

5.1 Proporção de votos para a presidenta reeleita Dilma Rousseff em cada município do Brasil. . . . . . . . . . . . . . . . . . . . . . . . . . . . .

5.2 Proporção de votos para a presidenta reeleita Dilma Rousseff em cada município do Estado de São Paulo. . . . . . . . . . . . . . . . . . .

5.3 Estimativa da mediana condicional da proporção de votos para a candidata Dilma Rousseff, segundo o modelo de regressão quantílica espacial bayesiano

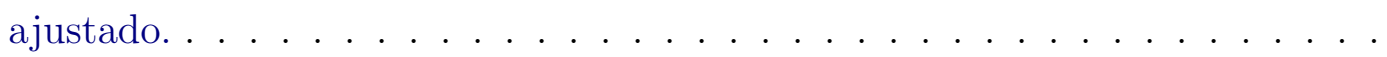

5.4 Distribuição das variáveis explicativas do modelo e também do tamanho da população nos municípios do Estado de São Paulo. 
5.5 Estimativas pontuais e intervalares considerando o modelo de regressão quantílica bayesiano com dependência espacial e sem dependência espacial. Intervalos de credibilidade de $90 \%$. . . . . . . . . . . . . . . . . . . . 86

A.1 Gráfico com o sumário dos parâmetros da regressão quantílica . . . . . . . . 94

A.2 Gráfico com as estimativas a posteriori para sigma . . . . . . . . . . . . 95

A.3 Gráfico com as probabilidades de uma observação ser outlier a posteriori . 95

A.4 Gráfico da divergência de Kullback-Leibler para observações aberrantes . . . 96

A.5 Gráfico da cadeias das variáveis latentes. . . . . . . . . . . . . . . . . . . 97

A.6 Gráfico com a comparação da densidade de uma variável latente com todas as outras no modelo . . . . . . . . . . . . . . . . . . . . . 97

A.7 Gráfico com a comparação da densidade da probabilidade de censura dada a variável cartão de crédito. . . . . . . . . . . . . . . . . . . . . . . . 99 


\section{Capítulo 1}

\section{Introdução}

Na Estatística, uma possível via de análise em diferentes áreas do conhecimento é a análise da associação entre duas ou mais variáveis, a partir dos modelos de regressão. Nesse tipo de estudo, uma variável é chamada de variável resposta ou variável dependente, enquanto que as outras são chamadas de variáveis preditoras ou independentes. E para a construção e a análise desses modelos são necessárias algumas suposições.

Inicialmente, a distribuição normal era considerada indiferentemente como distribuição da variável resposta para diversos problemas, mesmo quando o suporte da variável resposta não correspondia com o suporte da distribuição normal. Isso acontecia principalmente devido à facilidade de uso dessa distribuição, dada a ligação com a estimação de mínimos quadrados, e a fácil obtenção dos estimadores. Nessa configuração, o modelo de regressão busca explicar a relação entre a média condicional da variável resposta dadas as variáveis explicativas. Essa abordagem é bastante útil, por exemplo, se o interesse é a previsão de novas observações, onde a média condicional pode ser considerada um bom estimador segundo alguns critérios. Ou mesmo quando o interesse é só obter uma estimativa dos efeitos das variáveis preditoras na média da variável resposta.

Além da suposição da normalidade, outras distribuições também podem ser utilizadas. Os modelos lineares generalizados organizados por McCullagh e Nelder (1989) são um bom exemplo. Mais recentemente, Rigby e Stasinopoulos (2005) propõem uma abordagem mais 
ampla, modelando além da média condicional como função de outras variáveis, também outras quantidades de interesse, como parâmetros de escala e curtose. Nessas propostas, são necessárias então ferramentas para comparar o ajuste de um mesmo banco de dados para diferentes suposições da variável resposta, com a finalidade de encontrar aquele modelo que melhor se ajusta aos dados. Inclusive, uma intensa área de pesquisa atualmente é buscar essas novas distribuições de probabilidade, assim como maneiras de se comparar os diferentes ajustes.

No entanto, a média condicional pode não ser a melhor medida para resumir a distribuição da variável resposta. Inclusive, não é uma certeza que essa distribuição deva ser resumida em apenas uma quantidade, tal como, a média condicional. Nesse sentido, novas abordagens estão sendo propostas na literatura, como regressão da densidade (Dunson et al., 2007), regressão expectílica ${ }^{1}$ (Schnabel e Eilers, 2009), e a regressão quantílica proposta por Koenker e Bassett (1978), que é o principal interesse desse texto. Nessas abordagens de modelos de regressão os autores buscam estudar mais do que a média condicional.

Essa tese está interessada em extensões de modelos de regressão quantílica bayesianos e tem quatro contribuições principais: a sugestão da análise da representação por mistura de localização-escala da distribuição Laplace assimétrica, a qual permite o estudo de observações outliers; a proposta de uso desses modelos para analisar dados de proporção com inflação de zeros ou uns; o estudo dos quantis condicionais para observações com inflação de zeros e dados censurados; o uso dos modelos de regressão quantílica espaciais bayesianos para dados de proporção. Cada uma dessas contribuições é comentada brevemente a seguir, conforme a organização da tese.

No Capítulo 2, os modelos de regressão quantílica bayesianos são introduzidos considerando a distribuição Laplace assimétrica, dando especial atenção à representação dessa distribuição por mistura de localização-escala, em que a variável latente adicionada ao processo proporciona uma possibilidade de análise de valores discrepantes, i.e., é possível comparar a distribuição a posteriori dessas variáveis latentes para observar pontos que estão muito distantes dos demais. Anteriormente na literatura sobre modelos de regressão quantílica

\footnotetext{
${ }^{1}$ Tradução do inglês, Expectile regression.
} 
bayesianos, essa variável latente não era incluída na análise do ajuste, sendo utilizada somente como variável auxiliar no estudo dos outros parâmetros de maior interesse no modelo.

Em seguida, no Capítulo 3, são introduzidos modelos de regressão quantílica bayesianos para dados de proporção com inflação de zeros ou uns. Tendo em vista a distribuição Laplace assimétrica, com suporte no conjunto $\mathbb{R}$, a propriedade de equivariância para transformações monótonas da função quantílica é utilizada para defender o uso desses modelos em dados de proporção. Considerando a inflação de zeros (ou uns), um modelo de duas partes é proposto para explicar a probabilidade da variável resposta ser igual a zero (ou um), ao mesmo tempo que se estuda os quantis condicionais dos valores contínuos entre zero e um.

Adiante, no Capítulo 4, supondo dados censurados e com inflação de zeros, são introduzidos modelos que consideram essa informação da censura e a probabilidade de uma observação ser igual a zero, sendo esta distinta para diferentes quantis de interesse. Os modelos de regressão quantílica bayesianos apresentados nesse capítulo propõem o estudo dos quantis condicionais para gastos com bens duráveis no Brasil, um exemplo bastante estudado na literatura de econometria. Além disso, dados sobre oferta de trabalho de mulheres na GrãBretanha são revisitados, mostrando outros resultados considerando essa nova abordagem proposta aqui nesta tese.

Por último, no Capítulo 5, a partir dos dados das últimas eleições para presidente no Brasil, que terminou com um resultado muito próximo, modelos de regressão quantílica espaciais bayesianos são utilizados para ilustrar o ganho de informação na análise ao utilizar esses modelos. Nessa aplicação em especial, o efeito das variáveis preditoras na variável resposta, proporção de votos para a presidenta eleita, pode ser estudado tendo em vista essa dependência espacial.

Sugestões de estudos futuros e algumas conclusões são discutidas no Capítulo 6. No apêndice, é apresentado o pacote desenvolvido a partir dessa tese, com exemplo das rotinas construídas e instruções para o uso destas. Todos os modelos propostos nessa tese são ilustrados no apêndice. 


\title{
Capítulo 2
}

\section{Sobre regressão quantílica bayesiana e}

\author{
outliers
}

Nesse capítulo, os modelos de regressão quantílica bayesianos são apresentados considerando a sua evolução desde a sua primeira proposta, assim como a importância de certos parâmetros envolvidos no processo inferencial. Usando uma representação da distribuição de Laplace assimétrica como uma mistura de uma distribuição normal e uma distribuição exponencial, é discutida a relevância da presença do parâmetro de escala para controlar a variância no modelo. Além disso, as distribuições a posteriori das variáveis latentes adicionadas devido à representação por mistura são utilizadas para identificar observações aberrantes condicional aos ajustes dos modelos de regressão quantílica, a partir da comparação entre essas distribuições a posteriori. Essas ideias são ilustradas com estudos de simulação e também com um banco de dados sobre o índice de Gini nos estados brasileiros nos anos com informação do censo.

\subsection{Introdução}

A regressão quantílica não pode mais ser considerada como uma novidade no conjunto de modelos de regressão, já que tem sido estudada intensivamente na literatura e pode ser encontrada atualmente nos principais programas estatísticos. Essa técnica foi introduzida 
por Koenker e Bassett (1978) como um problema de minimização, em que os quantis condicionais da variável resposta eram a solução do problema. Inicialmente, essas quantidades foram chamadas pelos autores de "quantis da regressão", ao invés de regressão quantílica. De fato, esse segundo termo é o nome do livro de Koenker (2005), que traz diversos exemplos de aplicações, e também apresenta resultados assintóticos, que permitem a construção de intervalos de confiança e testes de hipótese usando diferentes procedimentos inferenciais.

Inicialmente, esse método frequentista não era ligado a nenhuma distribuição de probabilidade, já que a estimação dos parâmetros era possível a partir de algoritmos de programação linear, enquanto métodos inferenciais, como testes de hipótese e intervalos de confiança poderiam se basear em resultados assintóticos e bootstrap, por exemplo. Koenker e Machado (1999) conectaram a distribuição Laplace assimétrica a esses modelos, nos quais eles definiram o teste de razão de verossimilhança usando a suposição dessa distribuição.

Yu e Moyeed (2001) introduziram modelos de regressão quantílica bayesianos, assumindo na verossimilhança a distribuição Laplace assimétrica, mas fixando o parâmetro de escala igual a um. Nessa primeira proposta, eles usaram uma distribuição a priori imprópria para os parâmetros da regressão, mas mostrando que ainda assim era possível obter uma distribuição a posteriori própria. Depois, Kozumi e Kobayashi (2011) adotaram uma mistura de localização-escala da distribuição Laplace assimétrica para construir um algoritmo Markov Chain Monte Carlo (MCMC) mais flexível para obter amostras da distribuição a posteriori. Khare e Hobert (2012) provaram que esse novo algoritmo de amostragem converge numa taxa geométrica.

Recentemente, Sriram et al. (2013) demonstraram a consistência a posteriori para estimativas de quantis sob a suposição da distribuição Laplace assimétrica, considerando-a como modelo mal especificado. De fato, quando esses modelos são construídos para o mesmo banco de dados, o individuo considera que para cada quantil de interesse uma verossimilhança diferente deve ser propriamente combinada com a distribuição a priori, para produzir uma distribuição a posteriori. Isto faz com que a suposição de má especificação do modelo seja ainda mais plausível. Usando uma ideia similar, Yang et al. (2015) argumentam que fixando o parâmetro $\sigma$, é necessário fazer apenas uma pequena modificação na matriz de covariân- 
cias a posteriori dos parâmetros de regressão, de forma a obter intervalos de confiança mais plausíveis. Entretanto, ainda que concordemos com o resultado da má especificação, neste capítulo é discutido porque não é razoável fixar $\sigma$, mas sim aprender de sua distribuição $a$ posteriori.

Na literatura de modelos semi-paramétricos e não-paramétricos, também existem propostas de modelos de regressão quantílica bayesianos. Usando processos de Dirichlet, os autores Kottas e Gelfand (2001) sugerem um modelo de regressão da mediana, enquanto que Kottas e Krnajajić (2009) e Taddy e Kottas (2010) estudam modelos para todos os quantis. Planos quantílicos que não se cruzam, uma preocupação com modelos de regressão, são propostos por Reich et al. (2011) e Tokdar e Kadane (2011), considerando bases de polinômios de Bernstein e funções de processos gaussianos, respectivamente. De uma forma interessante, essas propostas são capazes de produzir estimativas de quantis, sem se basear na distribuição de Laplace assimétrica.

Sobre observações aberrantes, na literatura frequentista, Santos e Elian (2015) propuseram medidas de influência para identificar observações que podem afetar o ajuste do modelo. Eles consideraram a função de afastamento da verossimilhança para determinar se uma observação deveria ser considerada influente ou não. No processo, o modelo é ajustado novamente para cada observação, com o intuito de obter estimativas do modelo sem cada um dos pontos. Isto pode se tornar computacionalmente desafiador para dados com grandes dimensões. Alternativamente, é proposto nesse capítulo, a partir da abordagem bayesiana, a comparação entre as distribuições para cada variável latente $v_{i}$ de cada observação, com a finalidade de encontrar estes pontos mais distantes dos outros.

O capítulo está organizado da seguinte maneira. Na Seção 2.2, é dada uma introdução dos modelos de regressão quantílica bayesianos, discutindo alguns parâmetros que usualmente não recebem muita atenção na literatura. Na Seção 2.3, é proposto o uso da distribuição a posteriori da variável latente $v_{i}$ como uma medida de distância entre as observações, sugerindo uma possível maneira para identificar outliers na amostra. Além disso, na Seção 2.4, dois estudos de simulação são apresentados para checar como os métodos propostos variam com diferentes cenários, seja com zero, um ou dois outliers. Em seguida, as propostas 
são ilustradas com uma aplicação na Seção 2.5, em que se argumenta sobre a presença de mais de uma observação aberrante em dados sobre índices de Gini em estados brasileiros. Para concluir, alguns comentários finais são feitos na Seção 2.6.

\subsection{Regressão quantílica Bayesiana}

Em modelos de regressão quantílica considerando somente termos lineares, o maior interesse está no seguinte modelo

$$
Q_{y}(\tau \mid x)=x^{\prime} \beta(\tau)
$$

que basicamente diz que o quantil de ordem $\tau$ de $Y$ dado $X$ segue um modelo linear com coeficientes $\beta(\tau)$. Um primeiro modelo a produzir tais estimativas foi sugerido por Koenker e Bassett (1978). Nele os autores propuseram, dada uma amostra de $n$ pares $\mathcal{D}_{i}=$ $\left(y_{i}, X_{i}\right)$, minimizar utilizando algoritmos de programação linear a seguinte soma absoluta ponderada

$$
\sum_{i=1}^{n} \rho_{\tau}\left(y_{i}-x_{i}^{\prime} \beta\right)
$$

em que $\rho_{\tau}(u)=u(\tau-\mathbb{I}(u<0))$ e $I($. $)$ é a função indicadora ${ }^{1}$.

No paradigma bayesiano, Yu e Moyeed (2001) usaram a distribuição Laplace assimétrica na verossimilhança, com densidade

$$
f(y \mid \mu, \sigma, \tau)=\frac{\tau(1-\tau)}{\sigma} \exp \left\{-\rho_{\tau}\left(\frac{y-\mu}{\sigma}\right)\right\}
$$

devido ao fato de seu parâmetro de localização, $\mu \in \mathbb{R}$, ser o quantil de ordem $\tau$ da distribuição. De fato, o estimador de máxima verossimilhança, quando é feita a substituição de $\mu$ por $x^{\prime} \beta$, é semelhante ao estimador obtido pela minimização em (2.1), para o modelo frequentista.

Ainda sobre a distribuição Laplace assimétrica, a sua média e variância podem ser escritas

\footnotetext{
${ }^{1}$ Para mais explicações desses modelos segundo a abordagem frequentista, ver Santos (2012).
} 
como

$$
E(Y)=\mu+\frac{\sigma(1-2 \tau)}{\tau(1-\tau)}, \quad \operatorname{Var}(Y)=\sigma^{2} T(\tau)
$$

em que $\sigma>0$ é o parâmetro de escala e $T(\tau)=\left(1-2 \tau+2 \tau^{2}\right) /\left((1-\tau)^{2} \tau^{2}\right)$. A função $T(\tau)$, da qual depende a variância de $Y$ é apresentada na Figura 2.1(a). É possível ver que essa função tem formato de U, então para $\sigma$ fixado a variância é grande de forma relativa para maiores e menores quantis. Em sua primeira proposta, Yu e Moyeed (2001) assumiram que $\sigma=1$, automaticamente aumentando a variabilidade nas caudas, e prosseguiram a análise do modelo amostrando da distribuição a posteriori para $\beta(\tau)$.

Assumindo uma distribuição a priori para $\sigma$, como por exemplo, a distribuição gama inversa, pode-se proceder no processo inferencial de uma forma mais completa, porque a distribuição a posteriori para $\sigma$ já leva em consideração essa variação dos dados e a variação devido à distribuição Laplace assimétrica na verossimilhança. Na Figura 2.1(b), são apresentadas as estimativas das médias da distribuição a posteriori de $\sigma$ para diferentes quantis, $\tau=0.1,0.2, \ldots, 0.9$, na aplicação que será estudada na Seção 2.5. É fácil ver que as estimativas para $\sigma$ se adaptam, de acordo com o quantil de interesse e com a função $T(\tau)$, e que fixando $\sigma$, como foi feito por Yu e Moyeed (2001) e sugerido por Yang et al. (2015), tal resultado é desperdiçado.

Ainda sobre regressão quantílica bayesiana, Kozumi e Kobayashi (2011) propuseram uma representação por mistura localização-escala da distribuição Laplace assimétrica, combinando uma distribuição normal condicional numa distribuição exponencial com média $\sigma$, da seguinte forma

$$
\begin{aligned}
Y \mid v & \sim N\left(\mu+\theta v, \psi^{2} \sigma v\right), \\
v & \sim \mathcal{E}(\sigma)
\end{aligned}
$$

em que $\theta=(1-2 \tau) /(\tau(1-\tau)), \psi^{2}=2 /(\tau(1-\tau))$. A distribuição marginal de $Y$ é Laplace assimétrica com parâmetros $\mu, \sigma$ e $\tau$. Fazendo a substituição $\mu=x^{\prime} \beta(\tau)$, é possível obter o 


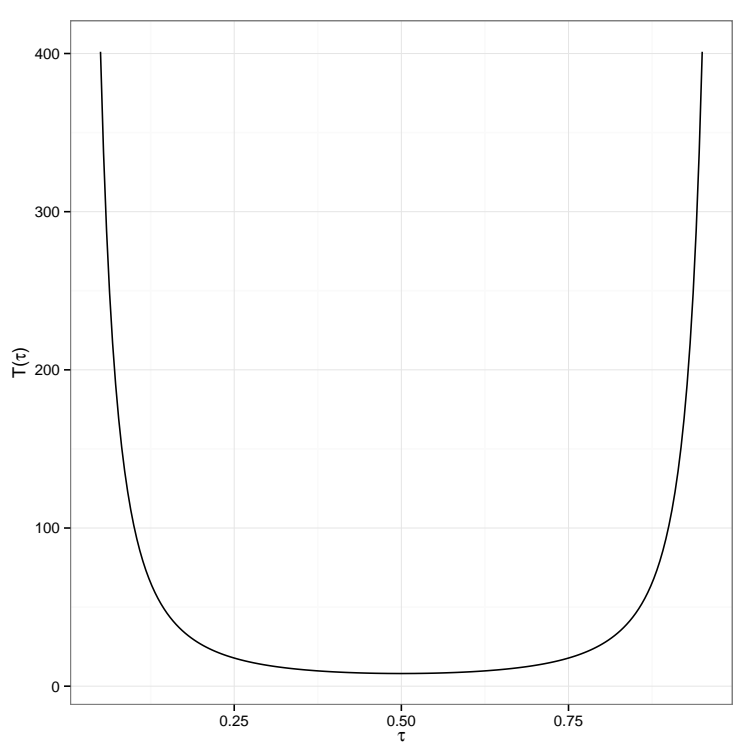

(a)

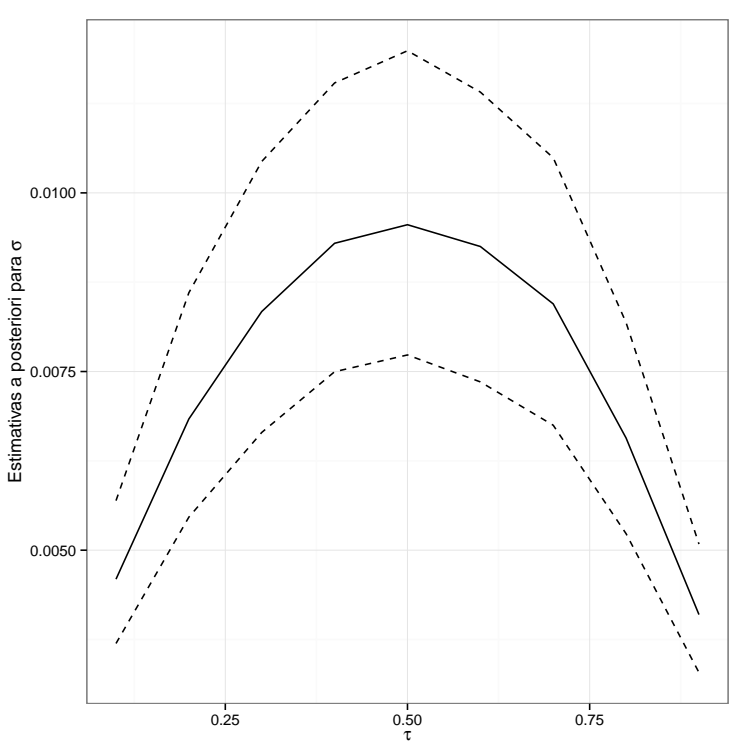

(b)

Figura 2.1: (a) Função T( $\tau)$, que é parte da variância de uma variável com distribuição Laplace assimétrica. (b) Estimativas a posteriori para $\sigma$ no modelo analisado na seção de aplicação, em que a linha sólida representa a média a posteriori, enquanto que as linhas pontilhadas representam o intervalo de credibilidade de $95 \%$.

seguinte modelo hierárquico, tendo em vista as distribuições a priori de $\beta(\tau)$ e $\sigma$

$$
\begin{aligned}
Y \mid v & \sim N\left(\mu+\theta v, \psi^{2} \sigma v\right), \\
v & \sim \mathcal{E}(\sigma) \\
\beta(\tau) & \sim N\left(b_{0}, B_{0}\right), \\
\sigma & \sim \mathcal{G I}\left(n_{0} / 2, s_{0} / 2\right) .
\end{aligned}
$$

As distribuições a posteriori de $\beta(\tau)$ e $\sigma$ ficam da seguinte forma

$$
\begin{aligned}
\beta(\tau) \mid D, \sigma, v & \sim N\left(b_{1}, B_{1}\right), \\
\sigma \mid D, \beta(\tau), v & \sim \mathcal{G I}\left(n_{1} / 2, s_{1} / 2\right),
\end{aligned}
$$


em que

$$
\begin{aligned}
& B_{1}=\left(\frac{1}{\psi^{2} \sigma} X^{\prime} D(v) X+B_{0}\right)^{-1} \\
& b_{1}=B_{1}\left[\frac{1}{\psi^{2} \sigma}\left(X^{\prime} D(v)(Y-\theta v)\right)+B_{0}^{-1} b_{0}\right] \\
& n_{1}=n_{0}+3 n \\
& s_{1}=s_{0}+2 \sum_{i=1}^{n} v_{i}+\sum_{i=1}^{n} \frac{\left(y_{i}-x_{i}^{\prime} \beta(\tau)-\theta v_{i}\right)^{2}}{\psi^{2} v_{i}}
\end{aligned}
$$

e $D(v)$ é uma matriz diagonal com as variáveis latentes em sua diagonal principal.

É evidente que em comparação com a proposta de Yu e Moyeed (2001), esse novo algoritmo MCMC é mais eficiente por amostrar da distribuição a posteriori dos parâmetros da regressão quantílica com distribuição normal, e também por modelar o parâmetro $\sigma$ com uma distribuição a priori, ao invés de fixar o seu valor igual a um.

Além disso, a variável latente $v_{i}$, que por construção poderia se dizer que tem distribuição a priori, também necessita de ser atualizada no algoritmo MCMC. A distribuição condicional completa de cada $v_{i}$ é proporcional a

$$
v_{i}^{\nu-1} \exp \left\{-\frac{1}{2}\left(\delta_{i}^{2} v_{i}^{-1}+\zeta^{2} v_{i}\right)\right\},
$$

que é o núcleo de uma distribuição Gaussiana Inversa Generalizada. Os detalhes dos cálculos desse hiperparâmetros estão na próxima seção. Como cada $v_{i}$ tem a sua própria distribuição a posteriori, que depende do valor do resíduo de cada observação, logo esta informação pode ser utilizada para comparar observações, e até mesmo para identificar possíveis outliers.

\subsection{Observações outliers dados os ajustes de regressão quantílica bayesiana}

Devido à representação por mistura localização-escala da distribuição Laplace assimétrica, a variável latente $v_{i}$ é adicionada no esquema da modelagem para cada observação. 
Antes de atualizar a sua informação com os dados, cada $v_{i}$ tem distribuição exponencial de média $\sigma$, que com a verossimilhança produz uma distribuição a posteriori Gaussiana Inversa Generalizada como em (2.2) com parâmetros,

$$
\nu=\frac{1}{2}, \quad \delta_{i}^{2}=\frac{\left(y_{i}-x_{i}^{\prime} \beta(\tau)\right)^{2}}{\psi^{2} \sigma}, \quad \zeta^{2}=\frac{2}{\sigma}+\frac{\theta^{2}}{\psi^{2} \sigma}
$$

Dentre os parâmetros da distribuição a posteriori de $v_{i}$, somente $\delta_{i}^{2}$ que varia para cada observação. E o seu valor é igual ao resíduo ao quadrado ponderado do ajuste. É possível ver que para maiores valores de $\delta_{i}^{2}$, mantendo os outros parâmetros fixos, a distribuição $a$ posteriori da variável latente tem maior valor esperado. Logo, observações mais extremas apresentam uma distribuição a posteriori mais distante de zero.

Isso é possível dizer a partir do valor esperado a posteriori de $v_{i}$, que é definido como

$$
E\left(v_{i} \mid \beta(\tau), \sigma, Y, v_{(-i)}\right)=\frac{\delta_{i}^{2}}{\zeta^{2}} \frac{K_{3 / 2}\left(\delta_{i}^{2} \zeta^{2}\right)}{K_{1 / 2}\left(\delta_{i}^{2} \zeta^{2}\right)},
$$

em que $K_{\nu}(u)$ representa a função de Bessel modificada do terceiro tipo ${ }^{2}$, já que segundo Karlis (2002)

$$
E\left(v_{i}^{r} \mid \beta(\tau), \sigma, Y, v_{(-i)}\right)=\left(\frac{\delta_{i}^{2}}{\zeta^{2}}\right)^{r} \frac{K_{1 / 2+r}\left(\delta_{i}^{2} \zeta^{2}\right)}{K_{1 / 2}\left(\delta_{i}^{2} \zeta^{2}\right)}
$$

Para demonstrar que maiores valores de $\delta_{i}^{2}$ resultam em maiores valores esperados, é necessário considerar as seguintes propriedades dessas funções (ver Barndorff-Nielsen, 1978)

$$
K_{1 / 2+r}(u)=\sqrt{\frac{\pi}{2 u}} \exp (-u)\left(1+\sum_{i=1}^{r} \frac{(r+i) !}{(r-i) ! i !}(2 u)^{-i}\right) \text { e } K_{1 / 2}(u)=\sqrt{\frac{\pi}{2 u}} \exp (-u)
$$

Dessa forma, é possível escrever a razão da esperança a posteriori entre duas variáveis latentes $v_{i}$ e $v_{j}$, supondo a seguinte relação entre os parâmetros associados a essas variáveis latentes respectivamente, $\delta_{i}^{2}>\delta_{j}^{2}$, já retirando os termos em comum, como

$$
\frac{E\left(v_{i} \mid \beta(\tau), \sigma, Y, v_{(-i)}\right)}{E\left(v_{j} \mid \beta(\tau), \sigma, Y, v_{(-j)}\right)}=\frac{\delta_{i}^{2}}{\delta_{j}^{2}} \frac{K_{3 / 2}\left(\delta_{i}^{2} \zeta^{2}\right)}{K_{3 / 2}\left(\delta_{j}^{2} \zeta^{2}\right)} \frac{K_{1 / 2}\left(\delta_{j}^{2} \zeta^{2}\right)}{K_{1 / 2}\left(\delta_{i}^{2} \zeta^{2}\right)} .
$$

\footnotetext{
${ }^{2}$ Tradução de Modified Bessel function of third kind
} 
Utilizando as propriedades em (2.4), é possível obter que

$$
\frac{K_{3 / 2}\left(\delta_{i}^{2} \zeta^{2}\right)}{K_{3 / 2}\left(\delta_{j}^{2} \zeta^{2}\right)} \frac{K_{1 / 2}\left(\delta_{j}^{2} \zeta^{2}\right)}{K_{1 / 2}\left(\delta_{i}^{2} \zeta^{2}\right)}=\frac{1+\frac{1}{\delta_{i}^{2} \zeta^{2}}}{1+\frac{1}{\delta_{j}^{2} \zeta^{2}}}
$$

Tal resultado pode ser substituído na expressão (2.5) para obter que

$$
\begin{aligned}
\frac{E\left(v_{i} \mid \beta(\tau), \sigma, Y, v_{(-i)}\right)}{E\left(v_{j} \mid \beta(\tau), \sigma, Y, v_{(-j)}\right)} & =\frac{\delta_{i}^{2} \frac{1+\frac{1}{\delta_{i}^{2} \zeta^{2}}}{\delta_{j}^{2}}}{1+\frac{1}{\delta_{j}^{2} \zeta^{2}}} \\
& =\frac{\delta_{i}^{2}}{\delta_{j}^{2}} \frac{\delta_{i}^{2} \zeta^{2}+1}{\delta_{i}^{2} \zeta^{2}} \frac{\delta_{j}^{2} \zeta^{2}}{\delta_{j}^{2} \zeta^{2}+1} \\
& =\frac{\delta_{i}^{2} \zeta^{2}+1}{\delta_{j}^{2} \zeta^{2}+1} \\
& >1,
\end{aligned}
$$

i.e., o valor esperado da variável latente é maior quanto maior o valor do parâmetro $\delta_{i}^{2}$.

Dada essa informação, propõe-se utilizar essa diferença para identificar pontos como possíveis outliers, i.e., observações que demonstram um padrão extremo que não pode ser explicado pelo modelo de regressão quantílica. Estes pontos frequentemente causam viés nas estimativas dos parâmetros, então poderia ser discutido inclusive se esses pontos devem ser considerados no ajuste dos modelos.

A proposta desse capítulo é medir a distância entre uma observação com as demais, comparando a distribuição a posteriori da variável latente de duas formas diferentes. Primeiramente, propõe-se medir a probabilidade média da distribuição condicional a posteriori da variável latente de ser maior que as outras respectivas variáveis latentes. Em seguida, propõe-se utilizar a divergência de Kullback-Leibler para verificar a diferença entre as distribuições a posteriori condicionais das variáveis baseadas nas amostras MCMC.

\subsubsection{Probabilidade média a posteriori}

Seja a variável $O_{i}$, que recebe valor igual a 1 quando a $i$-ésima observação é um outlier, e 0 caso contrário. Então, uma proposta para o cálculo da probabilidade de uma observação 
ser um outlier é

$$
P\left(O_{i}=1\right)=\frac{1}{n-1} \sum_{j \neq i} P\left(v_{i}>v_{j} \mid \mathcal{D}\right) .
$$

Um exemplo de uma das parcelas dessa soma é apresentada na Figura 2.2. A probabilidade proposta em (2.6) calcula o valor médio dessa probabilidade quando todas observações são consideradas.

Para pontos que não sejam observações aberrantes, essa probabilidade deve ser pequena, próxima de zero. Dada a ordenação natural dos resíduos, devido ao fato dos parâmetros da distribuição a posteriori dependerem somente dos resíduos como em (2.3), é esperado que algumas observações apresentem valores maiores para essa probabilidade em comparação com outras observações. Porém, o que deve ser considerado como ponto aberrante devem ser aquelas observações com um valor alto para $P\left(O_{i}=1\right)$, e possivelmente um valor que seja particularmente distante dos outros.

A probabilidade em (2.6) pode ser aproximada dadas as amostras MCMC, da seguinte forma

$$
P\left(O_{i}=1\right)=\frac{1}{M} \sum_{l=1}^{M} \mathbb{I}\left(v_{i}^{(l)}>\max _{k \in 1: M} v_{j}^{(k)}\right)
$$

em que $M$ é o tamanho da amostra de $v_{i}$ após o período de burn-in e $v_{i}^{(l)}$ é a l-ésima observação dessa cadeia.

Um ponto importante sobre essa proposta de calcular a probabilidade de uma observação ser um outlier é que esse resultado depende do quantil de interesse. Logo, uma observação pode ser considerada como um ponto extremo para um quantil, mas não para outro. Isto traz mais informação sobre a variação dos dados, já que há uma maior flexibilidade em determinar possíveis outliers. Outra possibilidade seria considerar um ponto outlier somente se for uma observação distante das outras em todos os quantis. No entanto, nesse trabalho somente a primeira opção será considerada, em que a análise é feita separadamente para cada quantil. 


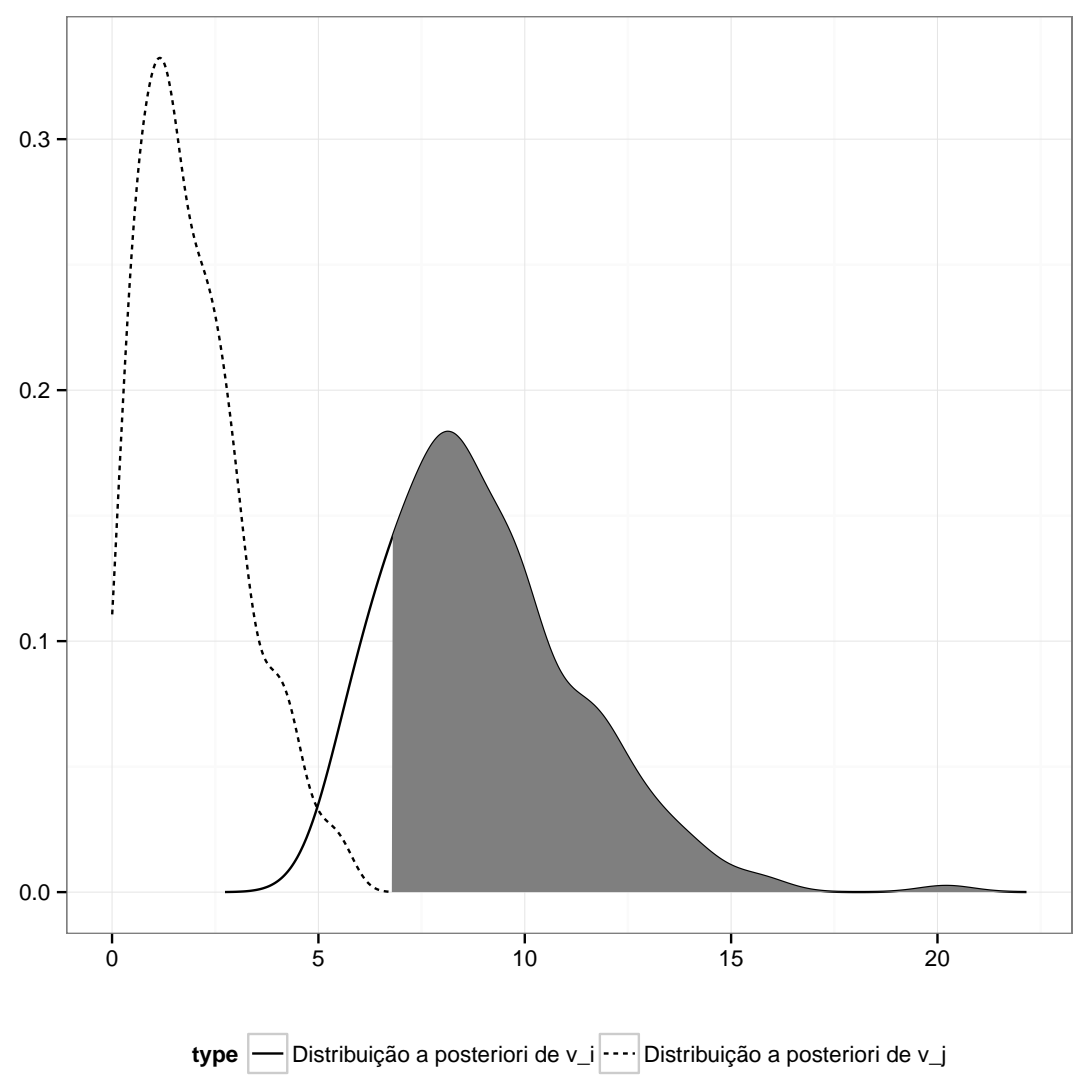

Figura 2.2: Exemplo de como parte da probabilidade em (2.6) é calculada, em que a área sob as linhas pontilhadas em cinza é a probabilidade de interesse.

\subsubsection{Divergência de Kullback-Leibler}

Como uma segunda proposta para estudar essas diferenças entre as distribuições a posteriori das diferentes variáveis latentes no modelo, a divergência proposta por Kullback e Leibler (1951) pode ser utilizada, inclusive como uma medida mais precisa para se medir essa distância entre as variáveis latentes na abordagem de modelos de regressão quantílica bayesianos. Essa divergência é definida como

$$
K\left(f_{i}, f_{j}\right)=\int \log \left(\frac{f_{i}(x)}{f_{j}(x)}\right) f_{i}(x) d x
$$

em que no modelo $f_{i}$ pode ser a distribuição condicional a posteriori de $v_{i}$ e $f_{j}$ a distribuição condicional a posteriori de $v_{j}$. De forma similar à probabilidade proposta na subseção anterior, essa divergência pode ser resumida por um valor médio considerando a distância 
para todas as outras observações, i.e.

$$
K L\left(f_{i}\right)=\frac{1}{n-1} \sum_{j \neq i} K\left(f_{i}, f_{j}\right)
$$

Essa proposta pode ser vista como uma ratificação da probabilidade anterior, usando uma medida mais precisa de distância entre as variáveis latentes a posteriori. É esperado que quando uma observação apresenta um maior valor para essa divergência, também deve apresentar uma probabilidade alta de ser um outlier. Por um lado, existe a probabilidade no intervalo $(0,1)$, que pode dar uma ideia se uma observação deve ser tratada como muito extrema. Por outro lado, há a divergência de Kullback-Leibler, um valor positivo, que sempre pode ser comparado de forma relativa entre as observações, i.e., ao invés de considerar o seu valor absoluto, considera-se quantas vezes maior é o valor de uma observação comparado com as outras.

Nesse caso, baseado nas amostras MCMC de cada distribuição a posterior das variáveis latentes, é possível estimar as densidades em (2.7) usando um kernel normal, e a integral pode ser aproximada usando a regra trapezoidal.

\subsection{Estudos de simulação}

Nessa seção, são propostos dois estudos de simulação com o intuito de entender como as medidas definidas na seção anterior variam de acordo com a presença ou não de uma observação aberrante com variáveis explicativas no caso multivariado. No primeiro estudo, é analisada a distribuição da probabilidade da observação ser um outlier na ausência de observações desse tipo. No segundo estudo, são discutidos resultados para os casos em que há mais de um outlier, mostrando medidas-resumo tanto para a probabilidade como para a divergência de Kulback- Leibler. 


\subsubsection{Simulação 1}

Neste estudo de simulação, o objetivo é gerar um cenário em que não há observações aberrantes. O objetivo do estudo é analisar o comportamento da distribuição da probabilidade da observação ser um outlier nessa situação. Não é apresentado nenhum resultado para a divergência de Kulback-Leibler, já que essa quantidade não é limitada e depende da escala dos dados.

O seguinte modelo linear é considerado

$$
Y_{i}=\beta_{0}+\beta_{1} x_{1 i}+\beta_{2} x_{2 i}+\beta_{3} x_{3 i}+\epsilon_{i}, \quad i=1, \ldots, n,
$$

em que $\beta_{0}=0, \beta_{1}=1, \beta_{2}=-1, \beta_{3}=2, \epsilon_{i} \sim N(0,4)$, e as três variáveis explicativas são distribuídas de acordo com uma distribuição uniforme entre 0 e 10. Dois tamanhos de amostra são utilizados nesse estudo, $n=100,300$. Cada amostra foi replicada 250 vezes para produzir as medidas-resumo que são discutidas a seguir. Três quantis foram considerados, $\tau=0.25,0.50,0.75$.

Os resultados para esse estudos podem ser vistos na Figura 2.3. À esquerda da figura, são mostradas as probabilidades para uma das réplicas, que foi escolhida aleatoriamente, e onde pode ser visto que a probabilidade varia entre 0 e 0.03 , aproximadamente. Como esperado, com a ausência de uma observação extrema, não foram observados maiores valores para essa probabilidade, já que as distribuições a posteriori das variáveis latentes devem estar relativamente próximas, dado que os resíduos devem ser relativamente pequenos.

Comparando as médias de todas essas probabilidades em cada replicação, obtém-se a distribuição apresentada na Figura 2.3(b). Entre os diferentes quantis estudados, as probabilidades na mediana condicional apresentaram menores valores comparados com os quantis 0,25 e 0,75. Para diferentes tamanhos de amostra, as probabilidades decrescem assim que o tamanho da amostra aumenta. 


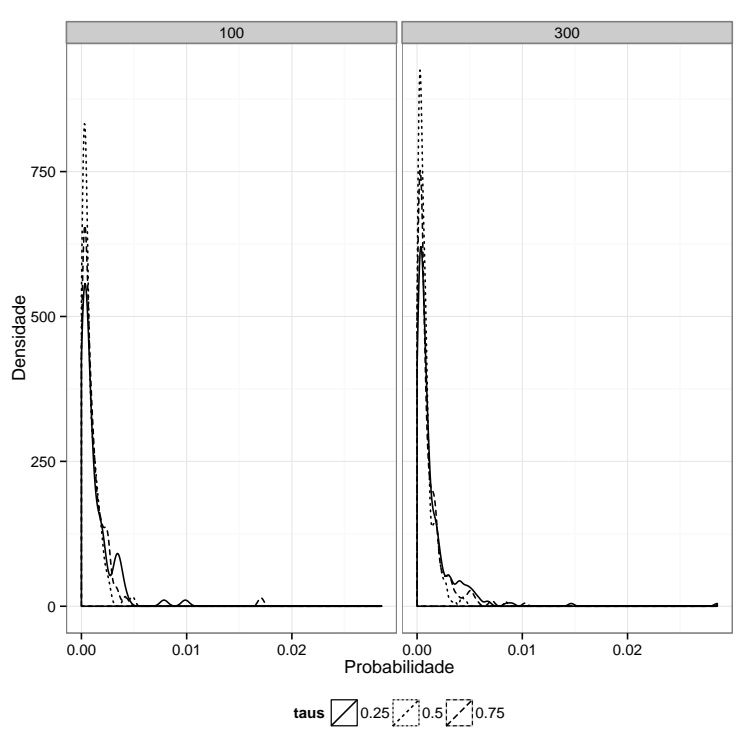

(a)

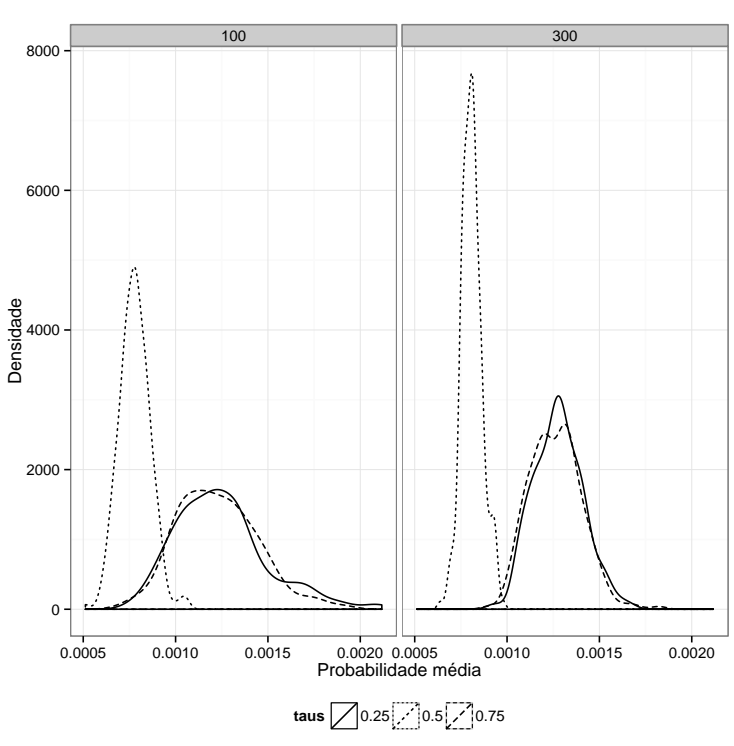

(b)

Figura 2.3: (a) Distribuição das probabilidades de serem outliers para todas observações em uma réplica selecionada aleatoriamente no estudo de simulação 1. (b) Distribuição da probabilidade de ser outlier média para cada réplica do estudo de simulação 1.

\subsubsection{Simulação 2}

Para o segundo estudo de simulação, são adicionados até dois pontos outliers e são verificadas então algumas medidas para analisar a presença desse tipo de observação. Novamente as amostras são replicadas 250 vezes. O interesse é checar também nesse caso qual a influência de um ponto aberrante no outro, quando mais de um deles está presente. Para isso, são comparados os resultados quando somente um destes são adicionados no modelo, e em seguida quando ambos são colocados. Foi considerado a mesma configuração do estudo anterior, com os mesmos valores para os parâmetros, porém aqui somente o tamanho de amostra 100 foi utilizado.

As duas observações outliers tem os seguintes valores para a variável resposta e para as suas respectivas variáveis explicativas

$$
\begin{aligned}
& y^{*}=30, \quad x_{1}^{*}=\bar{x}_{1}, \quad x_{2}^{*}=20, \quad x_{3}^{*}=\bar{x}_{3} \\
& y^{\star}=0, \quad x_{1}^{\star}=20, \quad x_{2}^{\star}=\bar{x}_{2}, \quad x_{3}^{\star}=\bar{x}_{3},
\end{aligned}
$$


em que $\bar{x}_{i}$ representa a média para a $i$-ésima variável explicativa sem a adição do possível valor outlier. Pode-se argumentar que $y^{*}$ deve ser considerado um outlier porque ambos valores da variável resposta e de $x_{2}^{*}$ são definitivamente muito maiores que o esperado, em especial dado o fato do coeficiente para $x_{2}$ ser negativo. Além disso, por razões similares $y^{\star}$ também deve ser considerado como uma observação aberrante, uma vez que $x_{1}^{\star}$ está fora do intervalo $(0,10)$ e produz um valor para a variável resposta menor que o esperado.

Para a apresentação dos resultados, foram os utilizadas as seguintes notações que estão dispostas na Tabela 2.1, em que $\times$ representa a presença da observação extrema naquela cenário.

Tabela 2.1: Notação para os diferentes cenários no estudo de simulação 2, em que $\times$ representa a presença do outlier $*$ ou $\star$ no cenário indicado.

\begin{tabular}{lll} 
& \multicolumn{2}{c}{ Outlier } \\
\cline { 2 - 3 } & $*$ & $\star$ \\
\hline Cenário 1 & & \\
Cenário 2 & & $\times$ \\
Cenário 3 & $\times$ & $\times$ \\
Cenário 4 & $\times$ & \\
\hline \hline
\end{tabular}

Os resumos para as probabilidades em todos os cenários são apresentados na Tabela 2.2. É fácil ver que quando cada outlier é adicionado de forma separada no modelo então sua respectiva probabilidade é sempre alta, maior que 0,40 em média. Para muitos cenários, $y^{*}$ sempre apresenta maior probabilidade em comparação com $y^{\star}$. Para ambos outliers, a probabilidade diminui com a presença do outro, mas ainda mostram valores muito maiores que zero. De forma geral, essas probabilidades são menores para o quantil 0,5.

Um fato interessante é que, quando são analisados os resultados para a divergência de Kullback-Leibler, as maiores disparidades são observadas nos modelos para a mediana condicional. Na Tabela 2.3, são apresentadas as médias relativas da divergência para ambos pontos outliers, i.e., a razão média entre a divergência entre os pontos extremos e uma observação selecionada ao acaso na amostra. Em geral, é possível ver que essas razões são sempre maiores que 9, aproximadamente.

Outro interessante aspecto dessas medidas é como elas apresentam conclusões diferentes 
Tabela 2.2: Resumo dos resultados para as probabilidades de ser outlier em cada cenário.

\begin{tabular}{|c|c|c|c|c|c|c|c|c|c|}
\hline \multirow[b]{2}{*}{$\tau$} & \multirow[b]{2}{*}{ Cenário } & \multicolumn{4}{|c|}{ Outlier $*$} & \multicolumn{4}{|c|}{ Outlier $\star$} \\
\hline & & Média & Mediana & $2,5 \%$ & $97,5 \%$ & Média & Mediana & $2,5 \%$ & $97,5 \%$ \\
\hline \multirow{3}{*}{0,1} & 2 & & & & & 0,505 & 0,488 & 0,228 & 0,783 \\
\hline & 3 & 0,981 & 0,984 & 0,957 & 0,994 & 0,452 & 0,436 & 0,197 & 0,721 \\
\hline & 4 & 1,000 & 1,000 & 0,998 & 1,000 & & & & \\
\hline \multirow{3}{*}{0,5} & 2 & & & & & 0,433 & 0,431 & 0,265 & 0,631 \\
\hline & 3 & 0,656 & 0,657 & 0,506 & 0,809 & 0,273 & 0,266 & 0,159 & 0,419 \\
\hline & 4 & 0,780 & 0,781 & 0,636 & 0,914 & & & & \\
\hline \multirow{3}{*}{0,9} & 2 & & & & & 0,987 & 0,992 & 0,948 & 1,000 \\
\hline & 3 & 0,810 & 0,823 & 0,596 & 0,935 & 0,765 & 0,778 & 0,543 & 0,911 \\
\hline & 4 & 0,841 & 0,852 & 0,656 & 0,961 & & & & \\
\hline
\end{tabular}

Tabela 2.3: Resumo dos resultados para a média relativa da divergência de Kullback-Leibler em cada cenário.

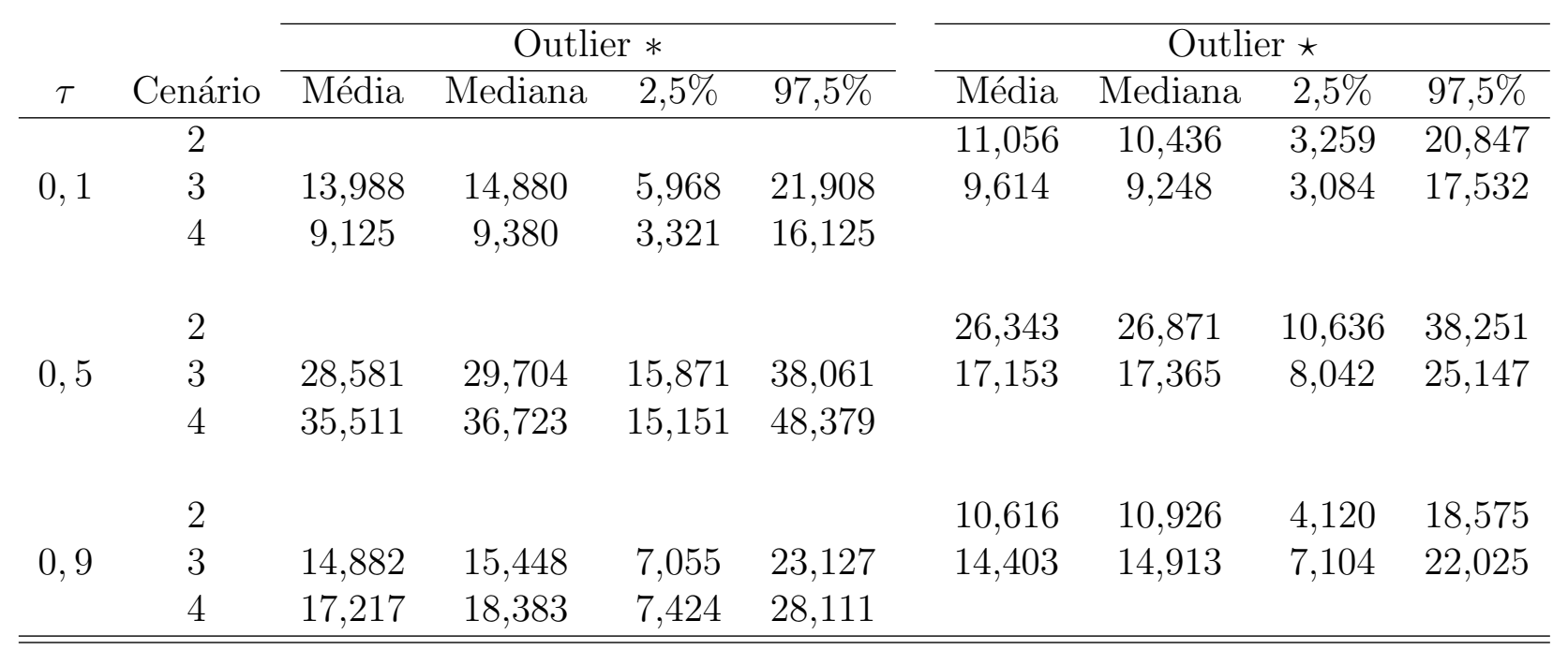




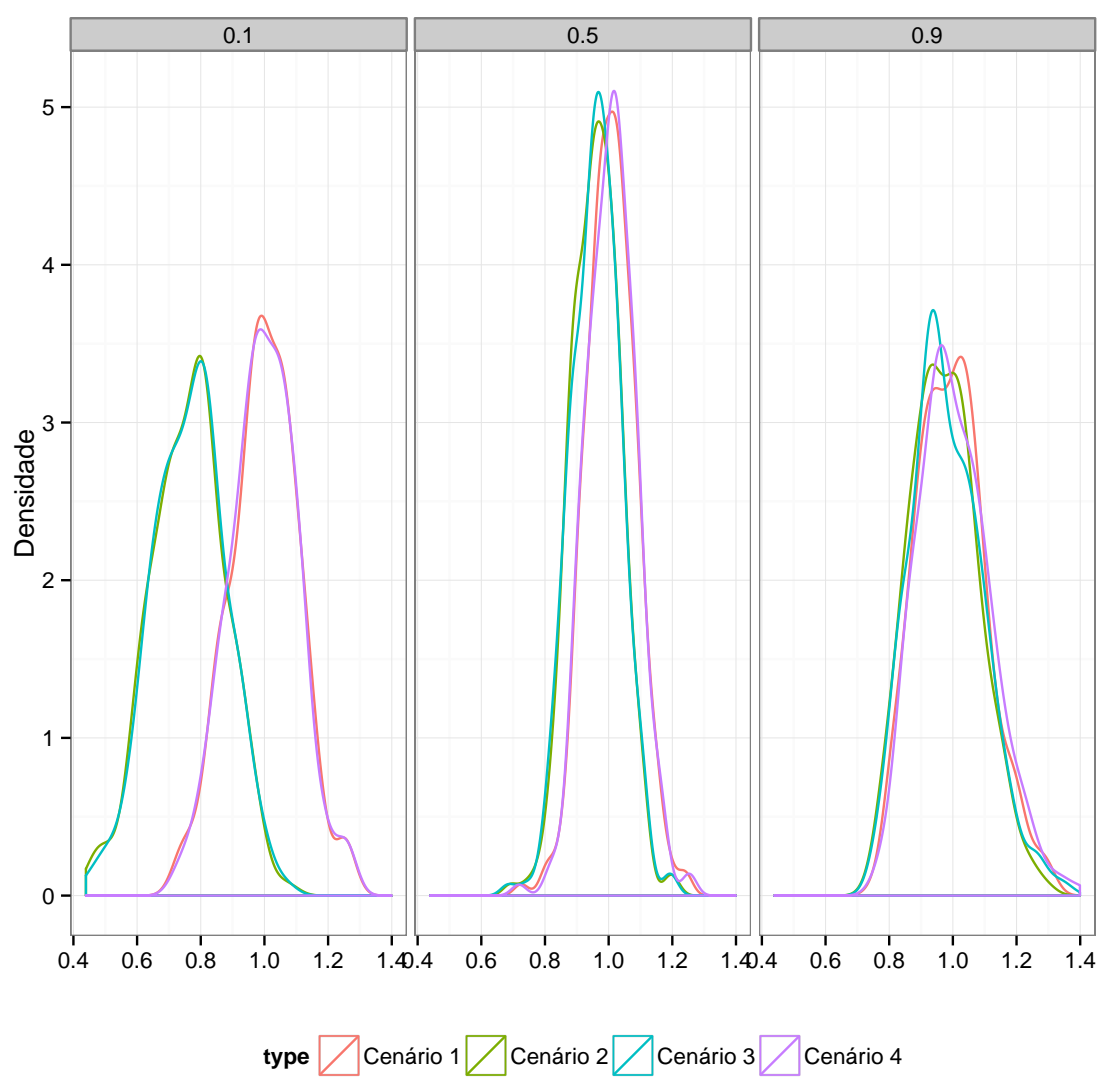

Figura 2.4: Distribuição das estimativas $\hat{\beta}_{1}(\tau)$ no estudo de simulação 2 nos diferentes cenários para $\tau=\{0,1,0,5,0,9\}$.

em respeito a esses outliers, $y^{*}$ e $y^{\star}$. Por exemplo, no quantil 0,1, nos modelos somente com um outlier, a probabilidade é maior para $y^{\star}$, enquanto que a divergência apresenta maiores valores para $y^{*}$. Por outro lado, no quantil 0,9 a divergência é maior para $y^{\star}$, ainda que $y^{*}$ apresente maiores valores da probabilidade de ser um outlier.

Além disso, são apresentadas as distribuições das estimativas para $\beta_{1}(\tau)$ e $\beta_{2}(\tau)$ nas Figuras 2.4 e 2.5, respectivamente. Para $\beta_{1}(\tau)$, é possível ver que as estimativas são somente influenciadas pela presença de $y^{\star}$, nos cenários 2 e 3 . E ainda assim, somente nos menores quantis, por exemplo, no quantil 0,1.

Por outro lado, para $\beta_{2}(\tau)$, a presença de $y^{*}$ adiciona um vício nas estimativas dos maiores quantis, somente nos cenários que este está presente, i.e., nos cenários 3 e 4.

Para $\beta_{3}(\tau)$, nenhum dos outliers apresentou um desafio para as suas estimativas, já que em todos os cenários a distribuição $\hat{\beta}_{3}(\tau)$ não foi afetada por essas observações. 


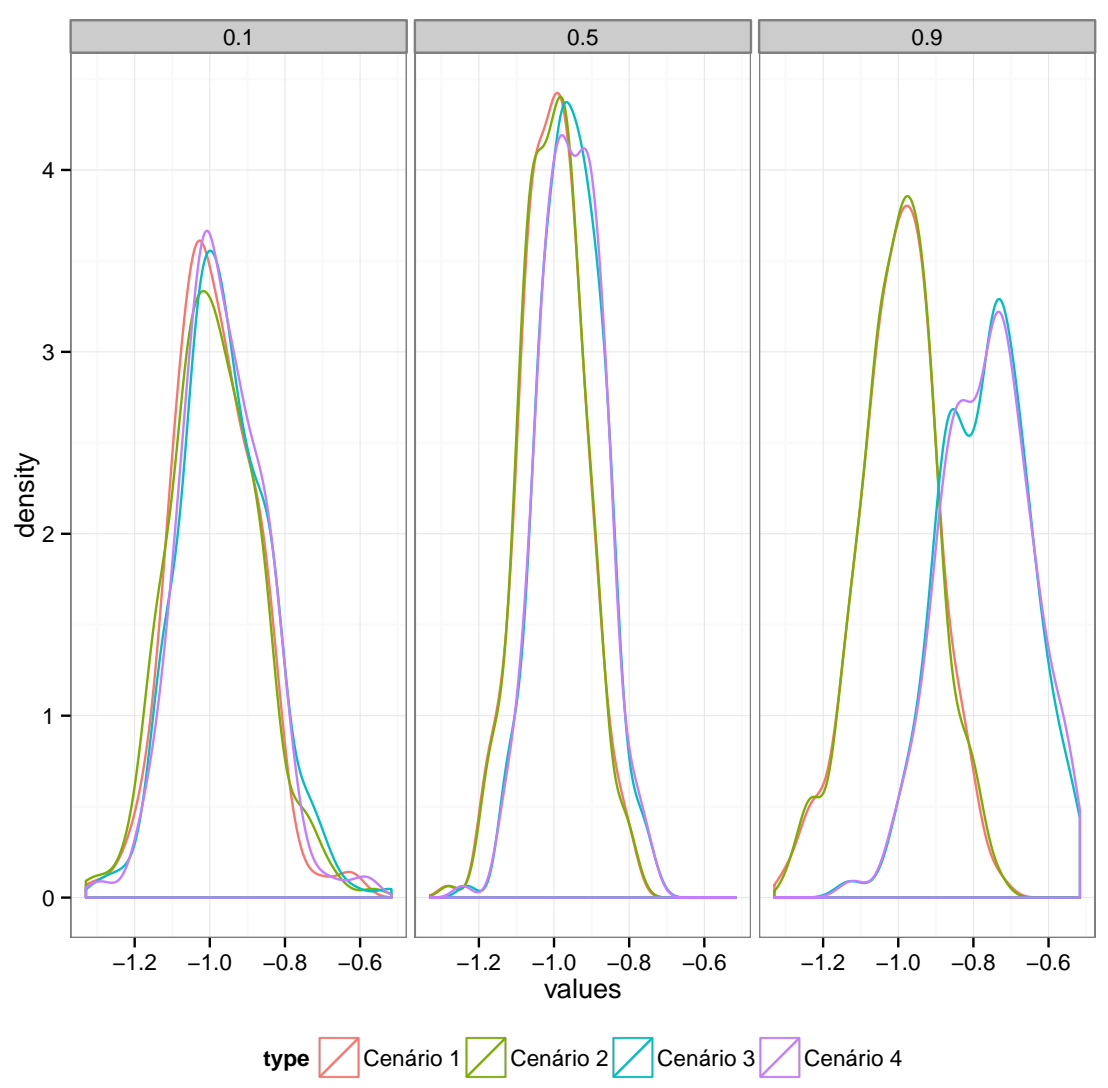

Figura 2.5: Distribuição das estimativas $\hat{\beta}_{2}(\tau)$ no estudo de simulação 2 nos diferentes cenários para $\tau=\{0,1,0,5,0,9\}$.

\subsection{Aplicação}

Com o interesse em usar modelos de regressão quantílica bayesianos para analisar possíveis observações extremas, consideramos dados sobre os índices de Gini nos estados brasileiros nos anos de 1991, 2000 e 2010, anos que ocorreram os últimos censos e para os quais estão disponíveis os dados da pesquisa. Esse banco de dados apresenta a informação de 26 estados e o Distrito Federal, completando 81 observações.

Considerando informações agregadas do país, o Brasil é usualmente considerado como um país ainda altamente desigual, quando comparado com países europeus, por exemplo. Usando o índice de Gini, que é um indicador de desigualdade de renda, é possível ver que, ao menos, houve um avanço na distribuição de renda entre 1991 e 2010, quando essa medida diminui para diversos estados, como mostrado na Figura 2.6, apesar do aumento para alguns estados, iniciado em 2000. 


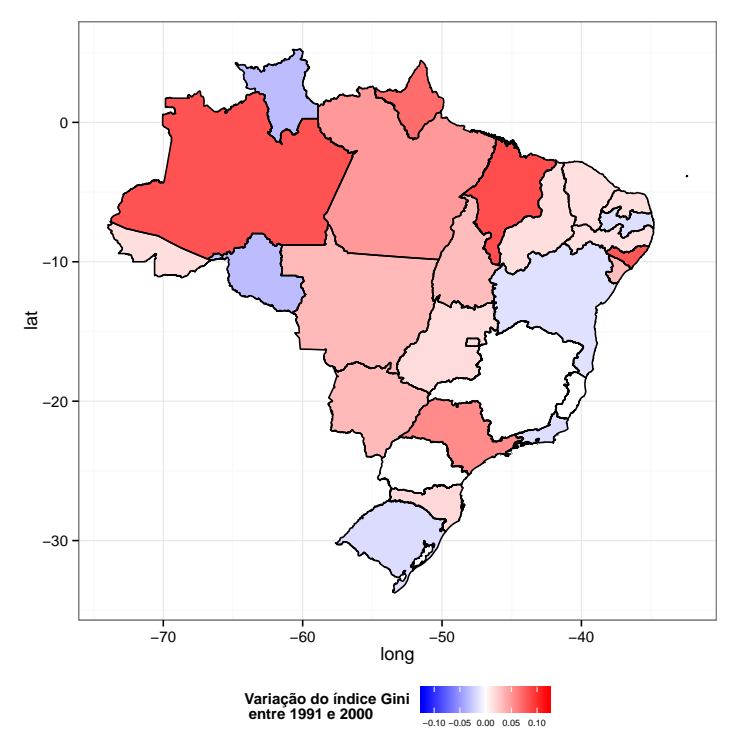

(a)

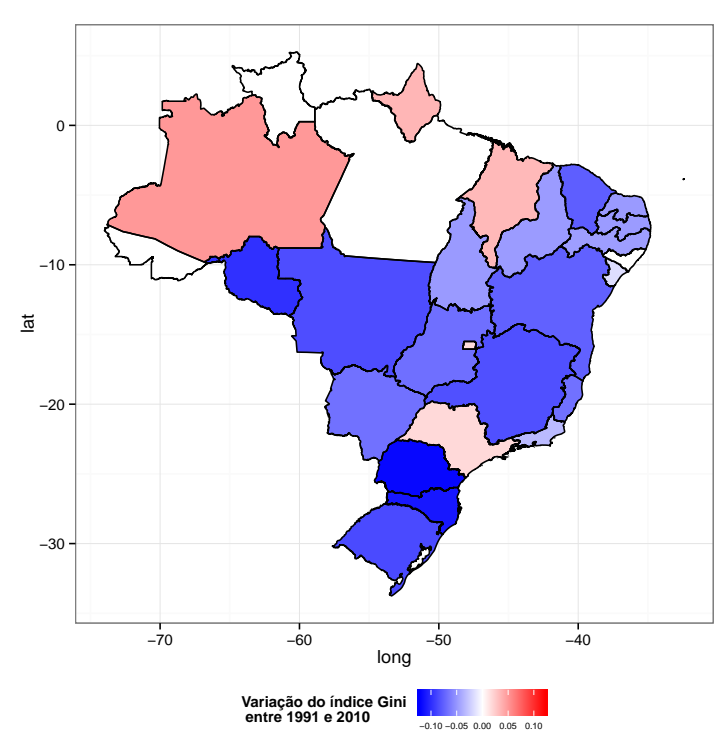

(b)

Figura 2.6: Variação percentual para o indice de Gini nos 26 estados brasileiros e o Distrito Federal, em comparação com 1991. (a) 2000, (b) 2010.

O seguinte modelo foi proposto para estudar os quantis condicionais do índice de Gini

$$
Q_{Y_{i}}\left(\tau \mid x_{i}\right)=\beta_{0}(\tau)+\beta_{1}(\tau) \mathrm{EDUC}_{i}+\beta_{2}(\tau) \mathrm{INCPC}_{i}+\beta_{3}(\tau) \mathrm{Y}_{2000}+\beta_{4}(\tau) \mathrm{Y}_{2010}
$$

em que EDUC é referente aos anos de educação de cada estado e INCPC é a renda per capita de cada estado, e duas variáveis indicadoras foram utilizadas para controlar a diferença entre os três anos, usando 1991 como referência. Decidiu-se por não transformar a variável, conforme será discutido no próximo capítulo, porque mesmo nos quantis mais extremos, os quantis condicionais ficaram bastante afastados dos limites 0 e 1 .

As estimativas a posteriori foram obtidas usando uma cadeia de Markov de tamanho 3000, descartando as primeiras 1000 como burn-in. Foi utilizada a priori uma distribuição normal $N(0,100 I)$ para $\beta(\tau)$, em que $I$ representa a matriz identidade. Para $\sigma$, foi adotada uma distribuição a priori $G I(3 / 2,0.1 / 2)$. A média a posteriori e seus respectivos intervalos de credibilidade para $\sigma$ nos diferentes quantis podem ser vistos na Figura 2.1(b), em que claramente pode-se ver que a forma das estimativas a posteriori, assim como os intervalos de credibilidade, tem a forma inversa da função $T(\tau)$, apresentada na Seção 2.2. Diante desses resultados, defendemos a importância de se usar uma distribuição a priori para $\sigma$, ao 


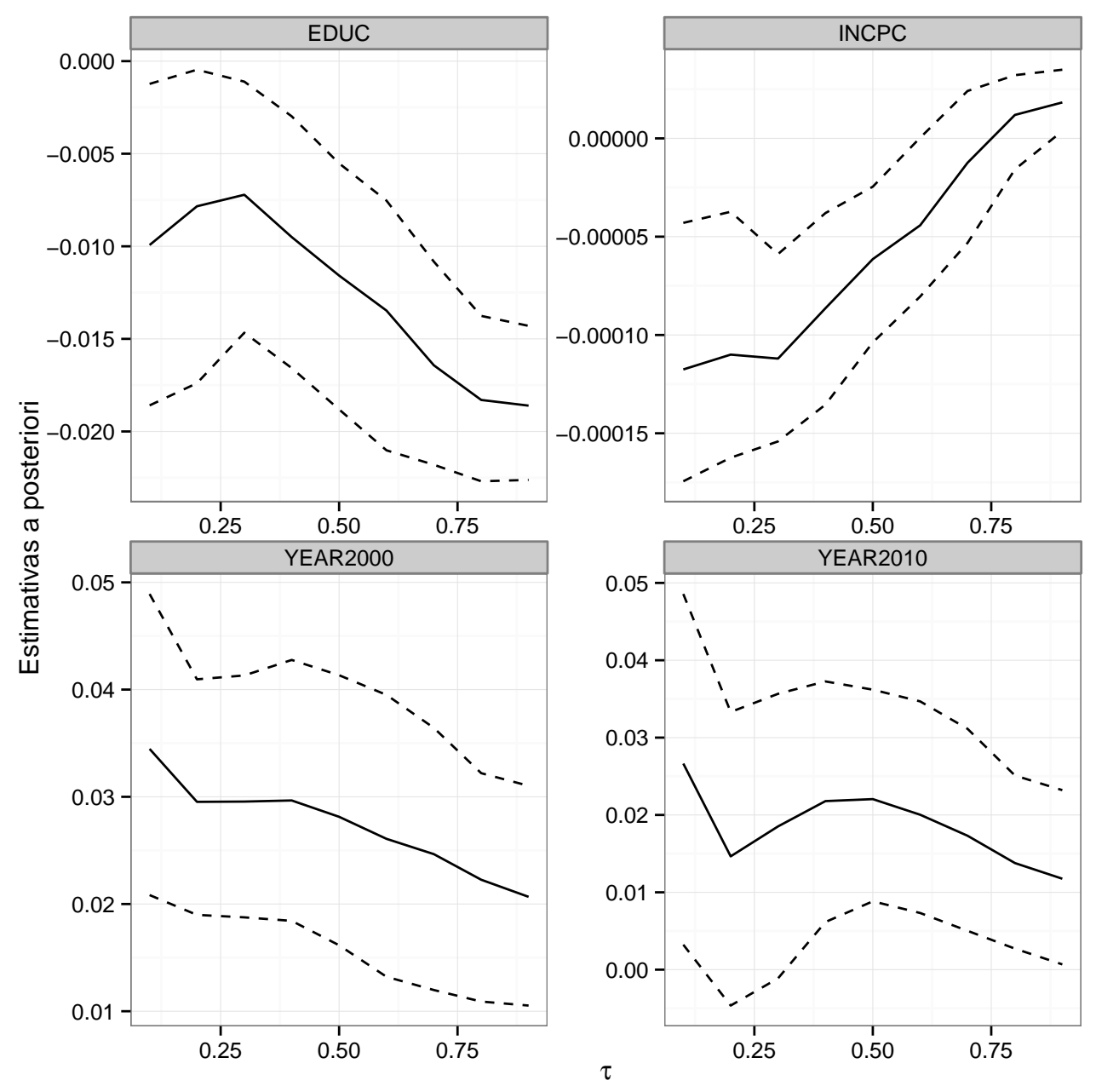

Figura 2.7: Estimativas a posteriori para os parâmetros da regressão quantílica propostos no modelo (2.8), em que a linha sólida representa as médias a posteriori obtidas das cadeias $M C M C$ e as linhas pontilhadas representam o intervalo de credibilidade de $95 \%$, para os quantis $\tau=0,1, \ldots, 0,9$.

invés de fixar o seu valor, sob o argumento que a distribuição a posteriori naturalmente se adapta às diferentes fontes de variação no processo de modelagem. A média a posteriori e os intervalos de credibilidade de $95 \%$ para $\beta(\tau)$ são apresentados na Figura 2.7.

Para a variável anos de educação, as estimativas para $\beta_{1}(\tau)$ são negativas para todos quantis e com maiores valores absolutos para $\tau$ 's mais próximos de 1. Para a variável renda per capita, as estimativas para o respectivo parâmetro são também negativas, mas não significante para maiores quantis, $\tau \geqslant 0,6$. Ambas variáveis indicadoras para anos do censo apresentaram estimativas similares, apesar de apresentarem uma evolução diferente, como mostrado na Figura 2.6. Controlando com outras variáveis, é estimado que o índice de Gini nos anos de 2000 e 2010 em comparação com 1991 sejam maiores, com essa diferença sendo 


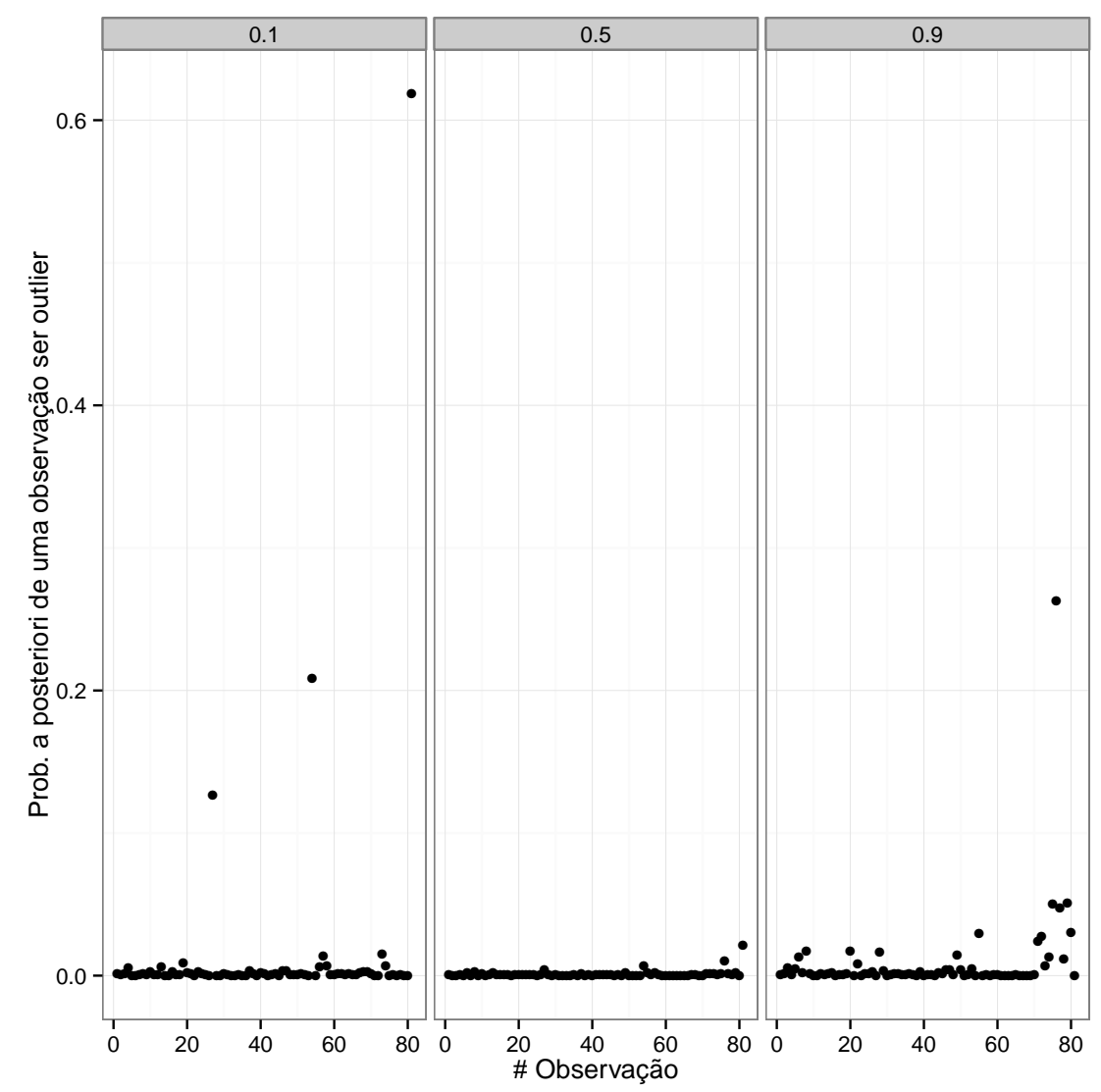

Figura 2.8: Probabilidades de cada observação ser um outlier para $\tau=\{0.1,0.5,0.9\}$, considerando o modelo em (2.8)

menor para maiores quantis.

Se a probabilidade proposta na Seção 2.3 é calculada para todas observações, a Figura 2.8 é obtida. E para a divergência de Kullback-Leibler os resultados são apresentados na Figura 2.9. Aqui os resultados de somente três quantis são apresentados, ainda que outros quantis tenham sido analisados. No quantil 0,1, as observações que se separaram demais das outras foram \#27, \#54 e \#81, sendo as três observações do Distrito Federal. Para o quantil 0,9, a observação \#76 é a mais distante das demais, e este ponto se refere ao estado de Santa Catarina no ano de 2010. Comparando as Figuras 2.8 e 2.9, é possível ver que as mesmas observações se destacam em cada uma das medidas.

No primeiro caso, as três observações do Distrito Federal têm os maiores valores de renda per capita com $\mathrm{R} \$ 917, \mathrm{R} \$ 1,204$, e $\mathrm{R} \$ 1,717$ nos anos de 1991, 2000 e 2010, respectivamente. Ordenando essa variável, na amostra verifica-se que esse valores são o oitavo, o segundo e o primeiro colocados nessa lista, respectivamente. Também para os anos de educação, estes 


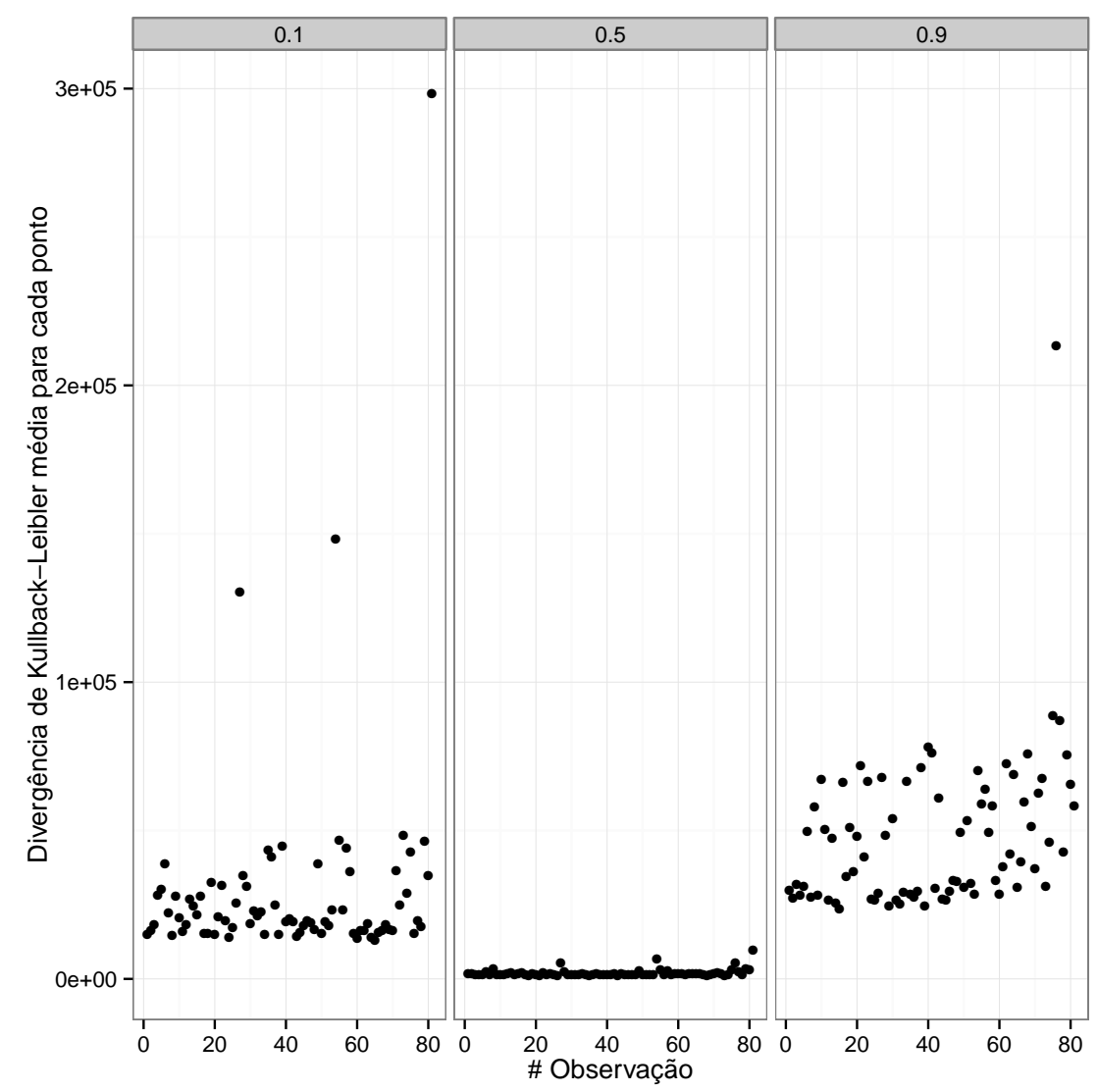

Figura 2.9: $K L\left(f_{i}\right)$ para $\tau=\{0.1,0.5,0.9\}$, considerando o modelo em (2.8)

pontos apresentam altos valores considerando a amostra, ao passo que o efeito de renda per capita nos menores quantis é estimado ser negativo como mostrado na Figura 2.7, assim como o efeito de anos de educação. Contudo, os índices de Gini estão entre os maiores no banco de dados. Assim, é razoável que essas observações sejam marcadas como outliers nos menores quantis da distribuição condicional, já que para todas as três observações era mais provável que elas apresentassem menores valores para o índice Gini.

Além disso, a observação \#76 do estado de Santa Catarina, medido no ano de 2010, teve o menor índice de Gini da amostra, com 0,49. É importante notar que essa observação apresentou uma maior probabilidade de ser outlier somente nos maiores quantis. Pode ser argumentado que essa observação deva ser considerada um outlier, já que apresentou o menor valor de Gini apesar de ter acontecido no ano de 2010. Deve-se notar que os coeficientes estimados para a variável indicadora desse ano são positivos para todos os quantis, ainda que não significante para alguns quantis. Mais, esta observação apresenta uma grande diferença 
para o próximo menor valor da amostra, já que o segundo menor valor de índice Gini foi de 0,53. Tal diferença entre dois pontos não é visto em toda a amostra, fazendo que esse ponto seja ainda mais cotado como uma observação aberrante.

Essas observações de dois diferentes estados puderam ser consideradas outliers em diferentes partes da distribuição condicional do índice de Gini, e isto somente foi possível examinando suas variáveis latentes em cada quantil de interesse, como foi proposto nesse capítulo.

\subsection{Discussão final}

Modelos de regressão quantílica se tornaram uma ótima ferramenta na análise de regressão dada a sua flexibilidade em estudar os quantis condicionais da variável resposta. A versão bayesiana desse modelo, levando em consideração a suposição de má especificação, está bem estabelecida na literatura com a distribuição de Laplace assimétrica e sua representação por mistura, a qual propicia de forma direta um mecanismo para identificar observações que se afastam das demais segundo o modelo de regressão quantílica ajustado, enquanto que $\sigma$ ajuda a controlar a variabilidade dos dados de forma natural.

Nesse capítulo, foi apresentada como a distribuição a posteriori de $\sigma$ varia de acordo com $\tau$, e como essa informação é desperdiçada se um valor fixo é considerado para esse parâmetro, aumentando a variância para quantis mais extremos de forma desnecessária. Também foi estudado como a distribuição a posteriori das variáveis latentes $v_{i}$ oferecem evidências sobre observações muito extremas, que podem ser consideradas outliers. Essa sugestão foi demonstrada com dois estudos de simulação que mostraram que essa abordagem realmente é capaz de identificar esses pontos. Além disso, foi verificado que esses pontos podem afetar somente algumas estimativas para certos quantis, e não todos os quantis.

Num banco de dados sobre índices Gini de estados brasileiros, foi possível identificar observações extremas de dois estados diferentes que afetaram os ajustes da regressão quantílica em partes diferentes da distribuição condicional, um sendo nos menores quantis e outro nos 
maiores quantis. Isto só foi possível usando o método sugerido nesse capítulo que dá atenção de forma separada para cada quantil. Como estudo futuro nessa área seria interessante propor técnicas de diagnóstico com deleção de caso para esse tipo de modelo, considerando a abordagem bayesiana. 


\section{Capítulo 3}

\section{Análise bayesiana para dados de}

\section{proporção com inflação de zeros ou}

\section{uns usando regressão quantílica}

Nesse capítulo, modelos de regressão quantílica bayesianos para análise de dados de proporção são sugeridos. Também é considerado o caso em que os dados apresentam uma inflação de zeros ou uns utilizando uma abordagem com um modelo de duas partes. Para a segunda hipótese, assume-se que a variável resposta é gerada a partir de uma distribuição mista discreta-contínua com uma massa pontual no zero ou um. A regressão quantílica é então utilizada para explicar a distribuição condicional da parte contínua entre zero e um, enquanto que a probabilidade da mistura também é modelada como função de outras covariáveis. A performance do modelo proposto é analisada com dois estudos de simulação. O método é ilustrado com dados sobre proporção de domicílios com acesso à eletricidade no Brasil.

\subsection{Introdução}

$\mathrm{Na}$ análise de regressão é comum encontrar dados de proporção como variável resposta, por exemplo, a proporção da renda reservada para gastos com alimentação ou a proporção 
de óleo convertido para gasolina. Em tais situações, é factível utilizar uma transformação da variável resposta e seguir a análise da regressão linear considerando a distribuição normal para os erros, mas ao custo de perda da interpretação dos parâmetros no processo. Ferrari e Cribari-Neto (2004) sugeriram o uso da regressão beta para esse tipo de variáveis, reparametrizando os parâmetros de localização e escala, de forma a escrever a média como função de preditores lineares (ver Simas et al. (2010) para uma classe mais geral dos modelos de regressão beta).

Outro desdobramento desse tipo de dados acontece quando é observada uma quantidade considerável de pontos com resposta exatamente igual a zero e/ou um. Para esses casos, os modelos de regressão beta não serão ainda capazes de explicar a variável resposta de forma adequada. Considerando isso, Ospina e Ferrari (2012) introduziram os modelos de regressão beta inflacionados de zeros ou um, usando uma suposição de distribuição mista discretacontínua para os dados. Os autores assumem uma massa pontual em $c, c \in\{0,1\}$ e uma distribuição beta para todos valores entre zero e um. Com essa suposição, a densidade da variável resposta pode ser escrita da seguinte maneira

$$
g(y \mid x, z)=p \mathbb{I}(y=c)+(1-p) f(y \mid x) \mathbb{I}(0<y<1)
$$

em que $p=P(y=c \mid z), c=\{0,1\}, f(y \mid x)$ é a distribuição beta e $\mathbb{I}(a)$ é a função indicadora que é igual a um, quando a é verdadeiro, e zero, caso contrário. Em vez disso, se fosse considerado somente o caso em que $c=0$ e a distribuição normal para $f(y \mid x)$ em (3.1), o modelo de duas partes proposto por Cragg (1971) estaria definido.

A probabilidade $p$ da massa pontual em $c$ pode ser conectada a variáveis auxiliares $z$ por uma função de ligação $h($.$) , usualmente a função de distribuição acumulada da distribuição$ normal ou da distribuição logística. O conjunto de variáveis auxiliares $z$ e $x$ não precisam ser os mesmos, mas não há problemas se esse for o caso. É importante notar que a mistura apresentada em (3.1) é diferente daquela observada nos modelos de mistura como em Diebolt e Robert (1994), já que não há uma estrutura latente com relação a que parte do modelo pertence cada observação. 
Sobre a modelagem da parte contínua, a distribuição beta é muito flexível, assumindo diferentes formas dependendo dos valores dos parâmetros de localização e escala, porém o modelo de duas partes proposto por Ospina e Ferrari (2012) analisava somente uma característica da distribuição condicional da parte contínua, i.e., a média. Uma alternativa a essa abordagem é considerar a regressão quantílica de forma a obter uma visão mais completa da distribuição condicional, estudando os parâmetros da regressão para diferentes quantis.

Conforme discutido nos capítulos anteriores, a regressão quantílica foi introduzida por Koenker e Bassett (1978) e desde então tem sido utilizada em diversas aplicações (ver Koenker (2005); Yu et al. (2003) para mais referências). A regressão quantílica informa se os parâmetros da regressão mudam ou não quando passamos da mediana para um quantil mais perto da cauda superior da distribuição, por exemplo. Em esquemas homocedásticos, essa informação não é muito útil. Porém, quando a heterocedasticidade é uma suposição válida, então a regressão quantílica pode trazer toda uma nova concepção da distribuição condicional da variável resposta de interesse. Em estudo sobre a intensidade de ciclones tropicais, Elsner et al. (2008) analisando a ocorrência desses ciclones ao longo dos anos, notaram uma mudança significativa somente nos parâmetros da regressão para a cauda superior da distribuição dos ventos de ciclones ao longo dos anos, i.e., houve uma alteração significativa positiva somente nos ciclones mais fortes. Tal resultado tão interessante não teria sido revelado somente com a análise da média condicional.

Yu e Moyeed (2001) propuseram um modelo de regressão quantílica, considerando a distribuição Laplace assimétrica, que também pode ser considerada no modelo proposto aqui nesse capítulo. Combinando isso com uma priori imprópria para os parâmetros da regressão, Yu e Moyeed (2001) mostraram que uma posteriori própria poderia ser obtida. Eles procederam com a análise, obtendo amostras da distribuição a posteriori usando o método Metropolis- Hastings. Kozumi e Kobayashi (2011) consideram uma proposta mais interessante, que já foi mencionada no capítulo anterior, escrevendo a distribuição Laplace assimétrica a partir de uma representação por mistura de localização e escala. Dada a sua fácil implementação, essa abordagem foi estendida para diversos modelos de regressão quantílica, como modelos espaciais (Lum e Gelfand, 2012), seleção de variáveis (Alhamzawi e Yu, 2012, 
2013; Ji et al., 2012), e análise de dados longitudinais (Luo et al., 2012), para nomear alguns exemplos.

Nesse capítulo, mostramos como os modelos de regressão quantílica com a representação proposta por Kozumi e Kobayashi (2011) são relevantes para estudar os quantis condicionais de variáveis restritas ao intervalo [0,1], tais como proporção ou taxas. O modelo é estendido para o caso em que existe um número não desprezível de zeros ou uns, considerando o modelo de duas partes, como em (3.1), mas substituindo a distribuição beta pela distribuição Laplace assimétrica, com o intuito de capturar detalhes mais sutis da distribuição da parte contínua.

O capítulo está organizado da seguinte maneira. Na seção 3.2, é mostrado como a distribuição Laplace assimétrica é capaz de ser utilizada para analisar dados como proporções, reiterando a propriedade de equivariância da função quantílica e considerando um exemplo com dados simulados. Na Seção 3.3, o modelo de duas partes é definido usando a distribuição Laplace assimétrica para a parte contínua. Em seguida, na Seção 3.4, a performance dos modelos é testada com dois estudos de simulação. Por fim, uma aplicação com dados sobre acesso à eletricidade no Brasil é analisado na Seção 3.5, e uma breve discussão sobre os modelos é feita na Seção 3.6.

\subsection{Modelos de regressão quantílica para dados de pro- porção}

O modelo de regressão quantílica proposto por Koenker e Bassett (1978) é baseado no seguinte modelo linear,

$$
Y_{i}=x_{i}^{\prime} \beta+\epsilon_{i}, \quad i=1, \ldots, n,
$$

em que $\epsilon_{i}$ é o erro associado, para o qual se assume que tem o quantil de ordem $\tau$ igual a zero. Novamente, o estimador da regressão quantílica é obtido minimizando

$$
\sum_{i=1}^{n} \rho_{\tau}\left(y_{i}-x_{i}^{\prime} \beta\right)
$$


É importante reforçar que, inicialmente, não havia nenhuma suposição de distribuição para a variável resposta. Koenker e Machado (1999) consideraram a distribuição Laplace assimétrica para definir um teste de razão de verossimilhança, ainda que essa suposição não seja necessária para construir testes de hipóteses para os parâmetros da regressão, já que os mesmos podem ser obtidos a partir de resultados assintóticos e bootstrap, e a estimação dos parâmetros pode ser feita com algoritmos de programação linear.

Embora não tenha sido decisiva no paradigma frequentista, a distribuição Laplace assimétrica foi importante no modelo bayesiano, conforme foi apresentado no capítulo anterior. Relembrando que a densidade pode ser escrita da seguinte maneira

$$
f(y \mid \mu, \sigma, \tau)=\frac{\tau(1-\tau)}{\sigma} \exp \left\{-\rho_{\tau}\left(\frac{y-\mu}{\sigma}\right)\right\} .
$$

No contexto de regressão, se é feita a substituição do parâmetro de localização por um preditor linear das variáveis explicativas, i.e., $\mu=x_{i}^{\prime} \beta(\tau)$, é fácil ver que o estimador de máxima verossimilhança de $\beta(\tau)$ pode ser obtido minimizando (3.2), para um $\tau$ fixado. Com esse resultado, Yu e Moyeed (2001) propuseram um modelo de regressão quantílica, considerando uma priori imprópria para $\beta(\tau), \pi(\beta(\tau)) \propto 1$ e $\sigma=1$. Nesse caso, a estimativa utilizando o máximo a posteriori para $\beta(\tau)$ deve ser o mesmo que a estimativa frequentista. Yu e Moyeed (2001) provaram que a distribuição a posteriori obtida é própria e sugeriram um algoritmo de Metropolis-Hastings para amostrar da distribuição a posteriori dos parâmetros da regressão.

Como discutido no capítulo anterior, Kozumi e Kobayashi (2011) consideraram a representação por mistura de localização e escala da distribuição Laplace assimétrica de modo a introduzir um amostrador de Gibbs mais eficiente para os modelos de regressão quantílica. Para isso, eles introduziram uma variável latente e usaram um algoritmo de aumento de dados $^{1}$ para definir o MCMC. A mesma abordagem é utilizada aqui nesse capítulo, e Khare e Hobert (2012) mostraram que essa proposta converge a uma taxa geométrica.

Para dados de proporção, que estão limitados no intervalo [0,1], é necessário utilizar a

\footnotetext{
${ }^{1}$ Data augmentation, de Tanner e Wong (1987)
} 
propriedade de equivariância a transformações monótonas da função quantílica (ver Koenker, 2005).

Seja $h($.$) uma função contínua não-decrescente em \mathbb{R}$, então para qualquer variável aleatória $Y$

$$
Q_{h(Y)}(\tau \mid x)=h\left(Q_{Y}(\tau \mid x)\right)
$$

em que $Q_{Y}(\tau \mid X)$ representa o quantil condicional de $Y$ dado $X$ de ordem $\tau$. A prova dessa propriedade consiste no fato elementar que, para qualquer função $h$ contínua monótona,

$$
P(Y \leqslant y)=P(h(Y) \leqslant h(y))
$$

Então, é possível assumir que o quantil condicional da variável transformada segue o seguinte modelo linear

$$
Q_{h\left(Y_{i}\right)}\left(\tau \mid x_{i}\right)=x_{i}^{\prime} \beta(\tau)
$$

em que $h($.$) é a função de ligação, e h():.[0,1] \rightarrow \mathbb{R}$. Possibilidades para essa função são a função inversa da função de distribuição acumulada (f.d.a.) da distribuição normal ou da distribuição logística. Dessa forma, a função de verossimilhança aumentada pode ser escrita como

$$
L(\beta(\tau), \sigma, v) \propto \sigma^{-n / 2}\left(\prod_{i=1}^{n} v_{i}^{-1 / 2}\right) \exp \left\{-\sum_{i=1}^{n} \frac{h\left(y_{i}\right)-x_{i}^{\prime} \beta(\tau)-\theta v_{i}}{2 \psi^{2} \sigma v_{i}}\right\}
$$

Para completar a especificação do modelo Bayesiano, são assumidas as mesmas distribuições que foram propostas no capítulo anterior. O modelo hierárquico com a variável transformada pode ser descrito como

$$
\begin{aligned}
h\left(y_{i}\right) \mid v_{i}, \beta(\tau), \sigma & \sim N\left(x_{i}^{\prime} \beta(\tau)+\theta v_{i}, \psi^{2} \sigma v_{i}\right), \\
v_{i} & \sim \mathcal{E}(\sigma), \\
\beta(\tau) & \sim N\left(b_{0}, B_{0}\right), \\
\sigma & \sim \mathcal{G I}\left(n_{0}, s_{0}\right) .
\end{aligned}
$$


As distribuições a posteriori e o amostrador de Gibbs para obter as amostras da distribuição a posteriori são semelhantes aos obtidos no capítulo anterior e não serão repetidos aqui. A única alteração a ser feita é substituir $y_{i}$ pela variável resposta transformada $h\left(y_{i}\right)$ nos cálculos.

A transformação em (3.5) tem um propósito diferente daquele proposto usualmente em modelos de análise de regressão, em que se tenta obter a distribuição a partir daquela transformação. De fato, evitar esse tipo de transformação é uma motivação para o uso dos modelos de regressão beta de Ferrari e Cribari-Neto (2004) quando dados de proporção são de interesse. Aqui, o objetivo da transformação não é aproximar os dados da distribuição Laplace assimétrica, mas sim assegurar que na análise não serão consideradas densidades com valores fora do intervalo $[0,1]$ na verossimilhança. Essa atenção é especialmente importante quando estão sendo analisados os quantis condicionais perto de 0 ou 1, dependendo da assimetria dos dados. Além disso, a propriedade de equivariância é importante porque permite que possam ser feitas afirmações sobre os quantis condicionais na escala original dos dados, fazendo $Q_{Y_{i}}\left(\tau \mid x_{i}\right)=h^{-1}\left(Q_{h\left(Y_{i}\right)}\left(\tau \mid x_{i}\right)\right)$.

\subsubsection{Exemplos com misturas de distribuição beta}

Com o intuito de motivar o uso de modelos de regressão quantílica para dados de proporção, nessa subseção são apresentados resultados de estimação para esse tipo de dados considerando na verossimilhança a distribuição Laplace assimétrica. Um exemplo interessante, que também foi estudado em estudos de simulação por Yu et al. (2013), é considerado. Nele é apresentada uma distribuição bimodal para a variável resposta. Enquanto essa situação pode trazer problemas para a análise de regressão beta, para a regressão quantílica é mais uma evidência de como esse método pode ser atrativo. Ainda que, na regressão beta, modelos de mistura poderiam ser utilizados para evitar esse problema, essa solução não se compara com a facilidade com a qual os modelos de regressão são capazes de explicar essa variação dos dados.

Para gerar os dados, seja $Y$ distribuída de acordo com uma distribuição beta, parame- 


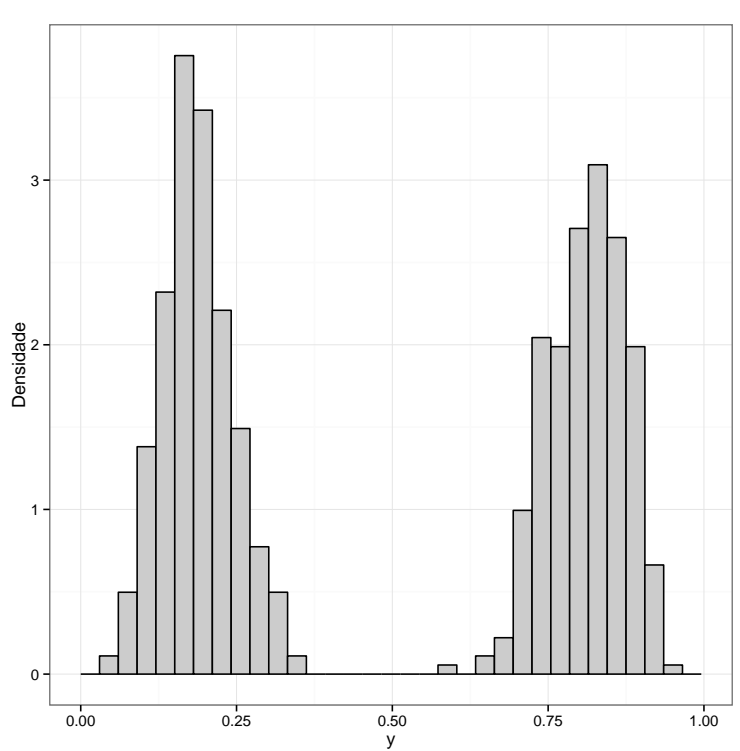

(a)

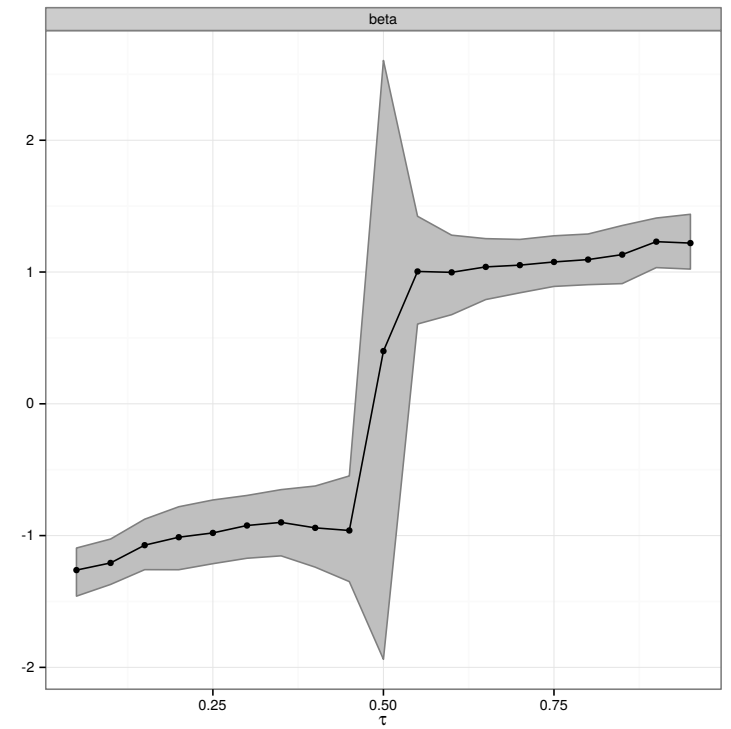

(b)

Figura 3.1: Gráficos para exemplo dos dados com bimodalidade. (a) Histograma dos dados. (b) Estimativas a posteriori e intervalos de credibilidade de $95 \%$ para $\beta(\tau), \tau=\{0.1,0.2, \ldots, 0.9\}$.

trizada a partir de sua média, $\mu$, e parâmetro de precisão $\phi$ (Ferrari e Cribari-Neto, 2004). A densidade nesse caso é definida como

$$
f\left(y_{i} ; \mu_{i}, \phi\right)=\frac{\Gamma(\phi)}{\Gamma\left(\mu_{i} \phi\right) \Gamma\left(\left(1-\mu_{i}\right) \phi\right)} y^{\mu_{i} \phi-1}(1-y)^{\left(1-\mu_{i}\right) \phi-1}, \quad 0<y_{i}<1 .
$$

Com essa parametrização, $E(Y)=\mu$ e $\operatorname{Var}(Y)=(\mu(1-\mu)) /(1+\phi)$. Para esse exemplo, foram geradas 600 observações com $\phi=100$ e de dois valores possíveis para $\mu_{i}$ com mesma probabilidade,

$$
\mu_{1}=\frac{\exp \left(-1-x_{i}\right)}{1+\exp \left(-1-x_{i}\right)}, \quad \mu_{2}=\frac{\exp \left(1+x_{i}\right)}{1+\exp \left(1+x_{i}\right)}
$$

A covariável $x_{i}$ foi gerada a partir de uma distribuição uniforme padrão.

Na Figura 3.1(a), é possível observar o histograma dessas observações. Essencialmente, uma mistura de duas distribuições beta está sendo considerada com médias $\mu_{1}$ e $\mu_{2}$. Dada a pequena probabilidade de cruzamento de valores entre essas duas distribuições, pode-se dizer que $\tau>0.5, \beta(\tau)=1$, enquanto que para $\tau<0.5, \beta(\tau)=-1$, considerando a f.d.a. da distribuição logística para a função de ligação $h($.$) em (3.5).$

Na Figura 3.1(b), são apresentadas as estimativas da média a posteriori para $\beta(\tau)$ da- 
das essas observações simuladas, assim como os intervalos de credibilidade, considerando a distribuição Laplace assimétrica na verossimilhança. É possível verificar que, mesmo que essa distribuição seja diferente da distribuição beta que gerou os dados, ainda assim o modelo recupera os verdadeiros valores de $\beta(\tau)$ para todos os valores, exceto 0,1 e 0,9 , porém mesmo nesses quantis as estimativas ficaram muito próximas. Esse exemplo recebe atenção especial nos estudos de simulação na Seção 3.4, em que são definidos os valores que foram considerados para os hiperparâmetros da distribuições a priori.

Sobre essa má-especificação do modelo, Sriram et al. (2013) mostraram que, sob certas condições para a verossimilhança, a distribuição Laplace assimétrica é uma boa candidata para aproximar os quantis condicionais da variável resposta. Além disso, a distribuição beta está contida nesse grupo de distribuições, que estão acordo com essas suposições.

\subsection{Modelos de duas partes}

A análise de regressão para dados de proporção, em que a variável resposta está limitada no intervalo $[0,1]$, frequentemente vai apresentar uma quantidade não desprezível de observações fora do intervalo aberto, i.e., observações com valor exatamente igual a 0 ou 1. Em um banco de dados sobre acesso à eletricidade, que será analisado posteriormente na Seção 3.5, a Figura 3.2 mostra a distribuição da proporção de domicílios com acesso a esse serviço. A linha vertical com um ponto no 1 representa a quantidade de cidades em que todos os domicílios tem acesso à eletricidade.

No contexto de regressão beta, Ospina e Ferrari (2012) sugeriram um modelo de regressão beta inflacionado de zeros-ou-uns para analisar esse tipo de dados. Reescrevendo a densidade do modelo estudado pelos autores, tem-se

$$
g(y \mid x, z)=p \mathbb{I}(y=c)+(1-p) f(y \mid x) \mathbb{I}(0<y<1)
$$

em que $p=P(y=c \mid z), c=\{0,1\}$. Usando a distribuição beta para a parte contínua, $f(y \mid x)$, é possível aprender sobre a média condicional, como uma função linear ou não-linear dos 


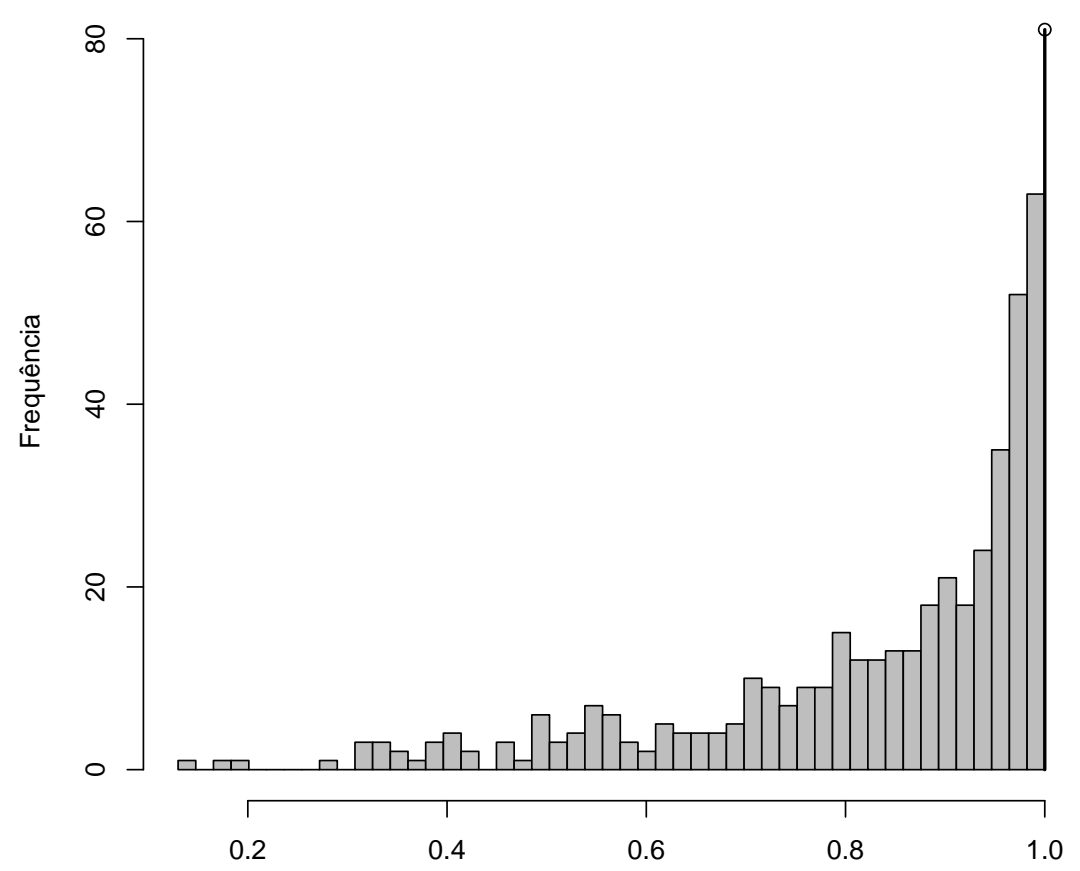

Figura 3.2: Gráfico com as frequências da proporções de domicilios com acesso à eletricidade em uma amostra de cidades no Brasil

preditores, dado que essa distribuição pode dar uma boa aproximação dos dados. Em vez disso, é sugerido aqui o uso da distribuição Laplace assimétrica, como ilustrado na seção anterior, com o objetivo de ganhar mais informação sobre a distribuição condicional dessas observações no intervalo $(0,1)$.

Tendo em vista o interesse em modelar $P(y=c \mid z), c=\{0,1\}$, também como uma função de covariáveis, é possível utilizar outra função de ligação $h_{p}(),. h_{p}:(0,1) \rightarrow \mathbb{R}$ e escrever

$$
h_{p}\left(p_{i}\right)=z_{i}^{\prime} \gamma
$$

Além disso, sejam os conjuntos $C=\left\{y_{i}: y_{i}=c\right\}, c=\{0,1\}$ e $D=\left\{y_{i}: 0<y_{i}<1\right\}$. Então, a função de verossimilhança aumentada para o modelo de duas partes, removendo algumas parâmetros condicionais da expressão para simplificação da notação, pode ser escrita 
como

$$
L(\beta(\tau), \gamma, \sigma, v)=\prod_{y_{i} \in C} h_{p}^{-1}\left(z_{i}^{\prime} \gamma\right) \prod_{y_{i} \in D}\left(1-h_{p}^{-1}\left(z_{i}^{\prime} \gamma\right)\right) f\left(y_{i}\right)
$$

em que

$$
f\left(y_{i}\right) \propto\left(\left(v_{i} \sigma\right)^{-1 / 2}\right) \exp \left\{-\frac{\left(y_{i}-x_{i}^{\prime} \beta(\tau)-\theta v_{i}\right)^{2}}{2 \psi^{2} \sigma v_{i}}\right\}
$$

Novamente, são assumidas uma distribuição normal a priori para $\beta(\tau)$, e gama inversa para $\sigma$. Para $\gamma$ também é considerada uma distribuição normal a priori. O modelo hierárquico completo, sem os parâmetros condicionais para $h\left(Y_{i}\right)$, segue dessas especificações da seguinte maneira

$$
\begin{aligned}
h\left(Y_{i}\right) & \sim p_{i} I\left(Y_{i} \in C\right)+\left(1-p_{i}\right) N\left(x_{i}^{\prime} \beta(\tau)+\theta v_{i}, \psi^{2} \sigma v_{i}\right) I\left(Y_{i} \in D\right), \\
v_{i} & \sim \mathcal{E}(\sigma), \\
h_{p}\left(p_{i}\right) & =z_{i}^{\prime} \gamma, \\
\beta(\tau) & \sim N\left(b_{0}, B_{0}\right), \\
\sigma & \sim \mathcal{G I}\left(n_{0}, s_{0}\right), \\
\gamma & \sim N\left(g_{0}, G_{0}\right) .
\end{aligned}
$$

É importante indicar que essa função de ligação $h($.$) não vai afetar a probabilidade p_{i}$ nessa representação do modelo de duas partes. Essa transformação assegura que os quantis condicionais estimados para a variável em sua escala original vão permanecer no intervalo $[0,1]$. Mais do que isso, a propriedade da equivariância descrita em (3.4) facilita a obtenção desses quantis. Pelo Teorema de Bayes, o interesse está na seguinte distribuição a posteriori

$$
\pi(\beta(\tau), \gamma, \sigma, v \mid y) \propto L(\beta(\tau), \gamma, \sigma, v) \pi(\beta(\tau)) \pi(\gamma) \pi(\sigma) \pi(v)
$$

Combinando a distribuição a priori com a função de verossimilhança, é possível escrever a 
distribuição condicional completa para todos os parâmetros como

$$
\begin{aligned}
\beta(\tau) \mid h(y), v, \gamma, \sigma & \sim N\left(b_{1}, B_{1}\right), \\
v_{i} \mid h(y), \beta(\tau), \gamma, \sigma & \sim \mathcal{G} \mathcal{I} \mathcal{G}\left(1 / 2, \hat{\delta}_{i}, \hat{\xi}_{i}\right), \\
\sigma \mid h(y), v, \beta(\tau), \gamma & \sim \mathcal{G} \mathcal{I}(\tilde{n} / 2, \tilde{s} / 2), \\
\pi(\gamma \mid h(y), v, \beta(\tau), \sigma) & \propto \prod_{i \in C} h^{-1}\left(z_{i}^{\prime} \gamma\right) \prod_{i \in D}\left(1-h^{-1}\left(z_{i}^{\prime} \gamma\right)\right) \exp \left\{-\frac{1}{2}\left(\gamma-g_{0}\right)^{\prime} G_{0}^{-1}\left(\gamma-g_{0}\right)\right\},
\end{aligned}
$$

Os detalhes das distribuições a posteriori para todos os parâmetros, com exceção de $\gamma$ são similares aos apresentados no capítulo anterior, então não serão repetidos.

Para $\gamma$, como sua distribuição a posteriori não apresenta uma forma padrão conhecida, é utilizado um algoritmo Metropolis-Hastings, usando como proposta no processo iterativo a distribuição normal multivariada centrada no atual valor de $\gamma$, i.e., no $k$-ésimo passo é sorteado $\gamma^{(k)}$ de $N\left(\gamma^{(k-1)}, \sigma_{\gamma}^{2} \Omega_{\gamma}\right)$, e esse novo valor é aceito com probabilidade

$$
\alpha\left(\gamma^{(k)}, \gamma^{(k-1)}\right)=\min \left\{1, \frac{\pi\left(\gamma^{(k)} \mid y, v, \beta(\tau), \sigma\right)}{\pi\left(\gamma^{(k-1)} \mid y, v, \beta(\tau), \sigma\right)}\right\}
$$

em que $\sigma_{\gamma}^{2}$ deve ser escolhido de forma a dar probabilidades de aceitação entre 0,15 e 0,50 (Gelman et al., 2003). Nos estudos de simulação e aplicação, $\Omega_{\gamma}$ foi definida como a matriz identidade, mas outras opções poderiam ser consideradas. Para todos os outros parâmetros, é possível gerar valores de suas distribuições condicionais, completando o algoritmo MCMC. No apêndice é apresentado como obter essas estimativas dos modelos a partir do pacote do $R$ desenvolvido para essa tese.

\subsection{Estudos de simulação}

Nessa seção, dois estudos de simulação são apresentados para ilustrar como a regressão quantílica pode ser útil para explicar certos aspectos da distribuição condicional da variável resposta, quando esta é limitada ao intervalo [0,1], ainda que a distribuição Laplace assimétrica esteja definida em toda a reta. 
Primeiro, é revisitado o exemplo dos dados bimodais, comparando com a abordagem frequentista, em que não há suposição de distribuição, já que o processo de estimação é um problema de minimização, como discutido na Seção 3.2. O segundo estudo de simulação verifica o método MCMC proposto para o modelo de duas partes.

\subsubsection{Simulação 1}

Considerando novamente a situação dos dados bimodais caracterizados na Seção 2.1, em que o seguinte modelo linear foi proposto para cada quantil.

$$
h\left(Q_{y_{i}}\left(\tau \mid x_{i}\right)\right)=\beta_{0}(\tau)+\beta_{1}(\tau) x_{i}
$$

em que $h($.$) é a função logito e x_{i}$ é gerado de acordo a distribuição uniforme padrão. São considerados aqui três tamanhos de amostra diferentes, $n=100,250,500$, com o intuito de checar as diferenças entre as performances entre a proposta frequentista e a abordagem bayesiana nesse cenário de amostras finitas. O processo de estimação frequentista requer a solução do problema de minimização em (3.2). Essas estimativas foram obtidas utilizando o pacote do R quantreg Koenker (2013). Foram consideradas as médias a posteriori para cada parâmetro a partir de cadeias de tamanho 2000 depois de descartar as primeiras 1000 para o período de aquecimento.

A Tabela 3.1 reporta os vícios e a raiz do erro quadrático médio (RMSE) para $\beta_{1}(\tau)$ depois que o estudo foi replicado 100 vezes em cada cenário considerando $\tau=0.10,0.25,0.75,0.90$. Ambos os métodos, bayesiano e frequentista, apresentaram maior viés nas caudas da distribuição, i.e., para os quantis 0,1 e 0,9. Na comparação entre os dois métodos, a abordagem bayesiana apresentou menor viés que o método frequentista em quase todos os casos. Além disso, para quase todos os casos, o método bayesiano apresentou menor RMSE, mostrando que, apesar do problema da má especificação do modelo na verossimilhança com a distribuição Laplace assimétrica, ainda é possível obter boas estimativas para os quantis condicionais com os dados de proporção. 
Tabela 3.1: Vícios e RMSE para $\beta_{1}(\tau)$ no estudo de simulação 1.

\begin{tabular}{|c|c|c|c|c|c|}
\hline \multirow[b]{2}{*}{ Tamanho amostral } & \multirow[b]{2}{*}{$\tau$} & \multicolumn{2}{|c|}{ Bayesiano } & \multicolumn{2}{|c|}{ Frequentista } \\
\hline & & Vício & RMSE & Vício & RMSE \\
\hline \multirow[t]{4}{*}{$\mathrm{n}=100$} & 0,10 & $-0,103$ & 0,200 & $-0,119$ & 0,230 \\
\hline & 0,25 & $-0,034$ & 0,184 & $-0,041$ & 0,198 \\
\hline & 0,75 & 0,041 & 0,227 & 0,043 & 0,235 \\
\hline & 0,90 & 0,112 & 0,241 & 0,113 & 0,273 \\
\hline \multirow[t]{4}{*}{$\mathrm{n}=250$} & 0,10 & $-0,093$ & 0,152 & $-0,100$ & 0,162 \\
\hline & 0,25 & $-0,019$ & 0,124 & $-0,019$ & 0,133 \\
\hline & 0,75 & 0,004 & 0,132 & 0,008 & 0,132 \\
\hline & 0,90 & 0,088 & 0,151 & 0,094 & 0,159 \\
\hline \multirow[t]{4}{*}{$\mathrm{n}=500$} & 0,10 & $-0,096$ & 0,135 & $-0,095$ & 0,137 \\
\hline & 0,25 & $-0,015$ & 0,091 & $-0,016$ & 0,095 \\
\hline & 0,75 & $-0,002$ & 0,074 & $-0,003$ & 0,073 \\
\hline & 0,90 & 0,071 & 0,104 & 0,072 & 0,107 \\
\hline
\end{tabular}

\subsubsection{Simulação 2}

Um segundo estudo de simulação foi conduzido para explorar a performance do algoritmo proposto para o modelo de duas partes sugerido na seção anterior. Foram consideradas as mesmas variáveis explicativas para as duas partes do modelo, da seguinte forma

$$
\begin{aligned}
h_{p}\left(p_{i}\right) & =\gamma_{0}+\gamma_{1} x_{i}, \\
h\left(q_{y_{i}}\left(\tau \mid x_{i}\right)\right) & =\beta_{0}(\tau)+\beta_{1}(\tau) x_{i},
\end{aligned}
$$

em que $p_{i}=P\left(y_{i}=0\right)$. Novamente $x_{i}$ foi gerada a partir da distribuição uniforme. A função logit foi considerada tanto para $h_{p}($.$) quanto para h($.$) e foram utilizados \gamma_{0}=1, \gamma_{1}=-4$. As variáveis respostas foram geradas de uma distribuição beta com densidade como em (3.7), $\operatorname{com} \phi=20$ e média igual a -1 .

Sobre os hiperparâmetros das distribuições a priori, foram utilizados $b_{0}=g_{0}=0, B_{0}=$ $G_{0}=100 I$. Para $\sigma$, foi considerada $\mathcal{G} \mathcal{I}(3 / 2,0.1 / 2)$. Para cada parâmetro, foi calculada a média a posteriori a partir de 10000 sorteios, onde foram descartados as primeiras 1000 observações para o período de aquecimento, e em seguida, foi selecionado somente a cada 9 iterações, com o intuito de diminuir a autocorrelação na amostra devido ao uso do passo 
Tabela 3.2: Resumo das estimativas a posteriori com relação a 100 réplicas do estudo de simulação 2.

\begin{tabular}{lcccccc}
\hline & & & \multicolumn{4}{c}{ Resumo das replicações } \\
\cline { 3 - 6 } Tamanho amostral & Parâmetro & Valor verdadeiro & Média & Mediana & $2,5 \%$ & $97,5 \%$ \\
\hline $\mathrm{n}=100$ & $\gamma_{0}$ & 1,00 & 0,887 & 0,853 & 0,081 & 1,836 \\
& $\gamma_{1}$ & $-4,00$ & $-3,875$ & $-3,818$ & $-6,273$ & $-2,176$ \\
& $\beta_{1}(0,25)$ & $-1,00$ & $-1,300$ & $-1,287$ & $-2,118$ & $-0,470$ \\
& $\beta_{1}(0,50)$ & $-1,00$ & $-1,138$ & $-1,141$ & $-1,776$ & $-0,512$ \\
& $\beta_{1}(0,75)$ & $-1,00$ & $-1,003$ & $-1,005$ & $-1,617$ & $-0,420$ \\
$\mathrm{n}=250$ & & & & & \\
& $\gamma_{0}$ & 1,00 & 0,991 & 0,949 & 0,503 & 1,623 \\
& $\gamma_{1}$ & $-4,00$ & $-4,059$ & $-4,013$ & $-5,543$ & $-2,846$ \\
& $\beta_{1}(0,25)$ & $-1,00$ & $-1,172$ & $-1,172$ & $-2,797$ & $-0,669$ \\
$\mathrm{n}=500$ & $\beta_{1}(0,50)$ & $-1,00$ & $-1,063$ & $-1,076$ & $-2,846$ & $-0,626$ \\
& $\beta_{1}(0,75)$ & $-1,00$ & $-0,943$ & $-0,961$ & $-2,798$ & $-0,556$ \\
& & & & & & \\
& $\gamma_{0}$ & 1,00 & 1,028 & 1,033 & 0,583 & 1,456 \\
& $\gamma_{1}$ & $-4,00$ & $-4,066$ & $-4,017$ & $-4,888$ & $-3,280$ \\
& $\beta_{1}(0,25)$ & $-1,00$ & $-1,267$ & $-1,256$ & $-1,593$ & $-0,956$ \\
& $\beta_{1}(0,50)$ & $-1,00$ & $-1,083$ & $-1,078$ & $-1,384$ & $-0,795$ \\
& $\beta_{1}(0,75)$ & $-1,00$ & $-0,954$ & $-0,957$ & $-1,234$ & $-0,665$ \\
\hline
\end{tabular}

Metropolis-Hastings no algoritmo MCMC.

Na Tabela 3.2, são apresentados os resumos das médias a posteriori para cada parâmetro, obtidos a partir de 100 replicações desse estudo de simulação. É possível observar que para os três tamanhos de amostra considerados, todas estimativas da média e mediana são razoavelmente próximas dos verdadeiros valores, enquanto que os intervalos de credibilidade construídos a partir das médias a posteriori das replicações sempre contém o verdadeiro valor dos parâmetros. Esse cenário em particular, em que a mesma variável é utilizada nas duas partes do modelo, não gerou problema para o algoritmo MCMC proposto.

\subsection{Análise de acesso à eletricidade no Brasil}

Nesta seção, são analisados dados sobre acesso à eletricidade no Brasil, considerando cidades das regiões Sudeste e Nordeste. Os dados estão disponíveis em http://www.atlasbrasil. org.br/2013/. De acordo com as Organização das Nações Unidas, dados de 2009 apontam que 1,5 bilhão de pessoas não tinham acesso à eletricidade no mundo. Em países em desen- 
volvimento, o acesso à energia pode ajudar a diminuir a pobreza, melhorar a saúde dos seus cidadãos e promover crescimento econômico, apenas para nomear alguns benefícios desse serviço. Tendo isso em vista, nessa aplicação o interesse está em analisar qual é a associação entre a proporção de domicílios com acesso à eletricidade e algumas variáveis sociodemográficas dessas cidades. Os dados são relativo à informação de 500 cidades e todas as variáveis foram medidas no censo de 2000.

A variável resposta, proporção de domicílios no município com acesso à eletricidade (PROP_ELEC), foi levemente alterada de forma a deixar mais informativo o modelo sobre a probabilidade da proporção de domicílios ser igual a zero. Valores próximos a 1, especificamente maiores que 0,995 foram arredondados para 1. Enquanto que a região Sudeste é uma das mais desenvolvidas do Brasil, a região Nordeste é uma das mais subdesenvolvidas. Para as cidades na amostra, na primeira região a proporção de domicílios com acesso à eletricidade varia entre 0,54 e 1, enquanto na segunda varia entre 0,14 e 1. Ainda dentre as cidades da amostra, 81 cidades apresentaram 100\% dos seus domicílios com acesso a esse serviço. Como covariáveis, foram incluídas região, $(\mathrm{REG}=0$ para Sudeste, $\mathrm{REG}=1$ for Nordeste), população (POP), renda per capita (INCPC), índice de desenvolvimento humano (IDH), densidade populacional (DENS). Todas as variáveis contínuas foram padronizadas antes de ajustar o modelo.

Primeiro, para a proporção que está entre 0 e 1, o seguinte modelo foi sugerido

$h\left(Q_{y_{i}}\left(\tau \mid x_{i}\right)\right)=\beta_{0}(\tau)+\beta_{1}(\tau) \mathrm{REG}_{i}+\beta_{2}(\tau) \mathrm{POP}_{i}+\beta_{3}(\tau) \mathrm{INCPC}_{i}+\beta_{4}(\tau) \mathrm{IDH}_{i}+\beta_{5}(\tau) \mathrm{DENS}_{i}$

em que $Q_{y_{i}}\left(\tau \mid x_{i}\right)$ é $\tau$-ésimo quantil condicional da proporção dos domicílios com acesso a eletricidade para a $i$-ésima cidade na amostra, $i=1, \ldots, 500$. Nessa aplicação, a função logito foi considerada para $h($.$) .$

Para a probabilidade que a proporção é igual a um, foi considerado

$$
\log \left(\frac{p_{i}}{1-p_{i}}\right)=\gamma_{0}+\gamma_{1} \mathrm{REG}_{i}+\gamma_{2} \mathrm{POP}_{i}+\gamma_{3} \mathrm{INCPC}_{i}+\gamma_{4} \mathrm{IDH}_{i}+\gamma_{5} \mathrm{DENS}_{i}
$$


Tabela 3.3: Estimativas a posteriori para os parâmetros no modelo (3.9)

\begin{tabular}{lccc}
\hline Covariável & Média & DP & 95\% \\
\hline Intercepto & $-3,94$ & 0,68 & {$[-5,30 ;-2,68]$} \\
REG & $-1,07$ & 1,02 & {$[-3,12 ; 0,79]$} \\
POP & 0,02 & 0,22 & {$[-0,41 ; 0,48]$} \\
INCPC & 0,71 & 0,42 & {$[-0,18 ; 1,46]$} \\
IDH & 2,55 & 0,76 & {$[1,13 ; 3,88]$} \\
DENS & 0,85 & 0,35 & {$[0,22 ; 1,58]$} \\
\hline
\end{tabular}

em que $p_{i}$ é a probabilidade que a proporção de domicílios com acesso à eletricidade da $i$-ésima cidade seja igual a 1 .

Para os hiperparâmetros da distribuição a priori, foram assumidos $b_{0}=g_{0}=0, B_{0}=$ $G_{0}=100 I$, resultando em distribuições normais achatadas a priori para os parâmetros da regressão para as duas partes do modelo. Para $\sigma$, foi utilizado $\mathcal{G} \mathcal{I}(3 / 2,0.1 / 2)$. As estimativas foram obtidas considerando a média a posteriori para cada parâmetro, depois de descartar as primeiras 5000 amostras e também coletando cada $15^{\circ}$ elemento de 20000 sorteios, resultando em 1000 observações a partir das quais foram calculadas as estimativas.

Na Tabela 3.3 é possível checar as estimativas para o modelo que analisa a probabilidade da proporção ser igual a 1. Considerando os intervalos de credibilidade obtidos, as covariáveis IDH e DENS podem ser consideradas significantes para explicar essa probabilidade. Cidades com maiores valores de IDH tem a probabilidade maior de atingir todos os seus domicílios com acesso à energia elétrica. De maneira similar, cidades com maior densidade populacional também tem maior probabilidade de oferecer esse serviço a todos os seus habitantes.

Além disso, os resultados para a parte contínua mostram como a regressão quantílica pode ser mais interessante do que o estudo somente da média condicional de variáveis limitadas no intervalo $[0,1]$. Na Figura 3.3, foi feito o gráfico da média a posteriori para $\beta_{j}(\tau)$, quando $\tau=0,1, \ldots, 0,9, j=0, \ldots, 5$, e os respectivos intervalos de credibilidade. Para ambas as variáveis IDH e DENS, as estimativas são positivas para todos os quantis, mas os coeficientes de cada variável se comportam de forma diferente. Por um lado, para IDH quando o quantil aumenta os efeitos associados a essa variável diminuem, significando que essa medida de desenvolvimento humano tem maior efeito nos menores quantis. Por outro lado, o coeficiente para densidade populacional aumenta conforme $\tau$ aumenta. Para POP, as estimativas desse 
parâmetro são significantes somente para os quantis acima da mediana. E para esses quantis, o tamanho da população é negativamente associado com a proporção de domicílios com acesso à eletricidade, significando que cidades menores tendem a ser melhor representadas no topo da distribuição condicional da variável resposta.

Sobre o uso de $h($.$) no modelo (3.8), assumindo um modelo linear para o quantil da$ variável transformada, como temos que $\left.h\left(Q_{y_{i}}\left(\tau \mid x_{i}\right)\right)=Q_{h\left(y_{i}\right)}\left(\tau \mid x_{i}\right)\right)$, é fácil recuperar os quantis condicionais da variável na sua escala original, como explicado na Seção 3.2. Para ilustrar isso, na Figura 3.4 foram apresentados os quantis ajustados pelo modelo na escala original de $Y$. Foram consideradas as duas regiões, quando a renda per capita e o tamanho da população são iguais a média amostral, e comparando diferentes valores das variáveis IDH e DENS, usando as suas médias amostrais, mas também o seu quantil amostral de ordem 0,9. É possível ver que as diferenças entre os quantis estimados para $Y$ variam mais para mudanças na densidade populacional do que para índice de desenvolvimento humano. Além disso, não há evidências aparentes de diferença entre os quantis estimados entre as duas regiões. Inclusive o coeficiente estimado não deve ser considerado significante, dado o intervalo de credibilidade encontrado. Apesar disso, essa variável foi mantida no modelo, assim como renda per capita.

Um fato interessante sobre esse exemplo se deve a como as variáveis IDH e DENS se comportam em ambas as partes do modelo. Ainda que ambas variáveis sejam significantes para descrever a probabilidade $p_{i}$, esses coeficientes variam de forma diferente ao longo dos quantis condicionais. Enquanto que para a primeira o efeito diminui conforme aumentamse os quantis, para a segunda variável acontece o contrário. Especificamente para a parte contínua, não seria possível alcançar tais conclusões, analisando somente a média condicional, reforçando o quão útil pode ser essa análise com base nos modelos de regressão quantílica.

\subsection{Discussão e conclusão}

Nesse capítulo, foram sugeridos modelos de regressão quantílica bayesianos para variáveis respostas limitadas ao intervalo [0,1], fazendo uso de ideias anteriores na área, com a suposi- 

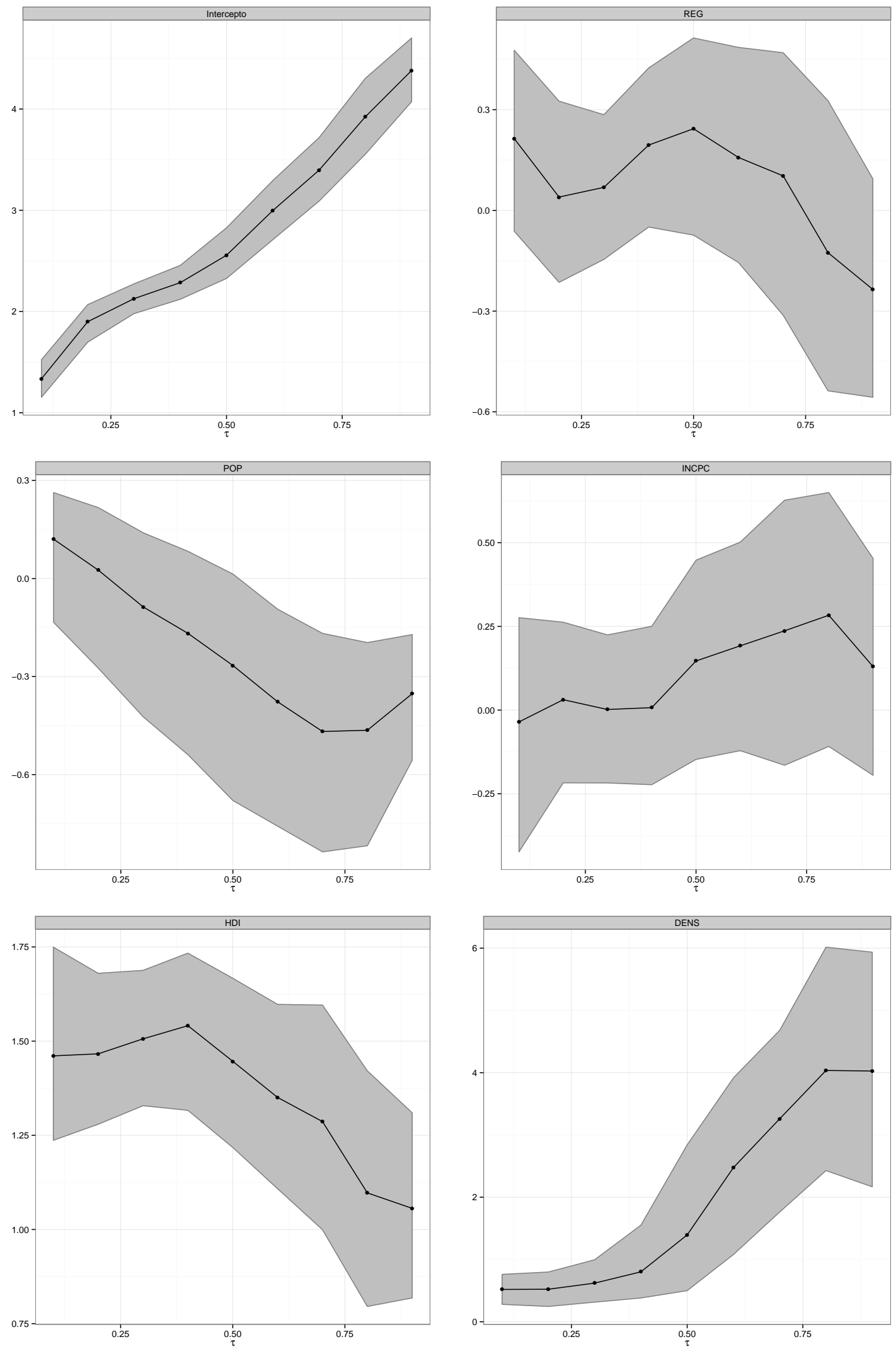

Figura 3.3: Estimativas e intervalos de credibilidade de 95\% para o modelo (3.8), para $\tau=$ $0,1, \ldots, 0,9$ 


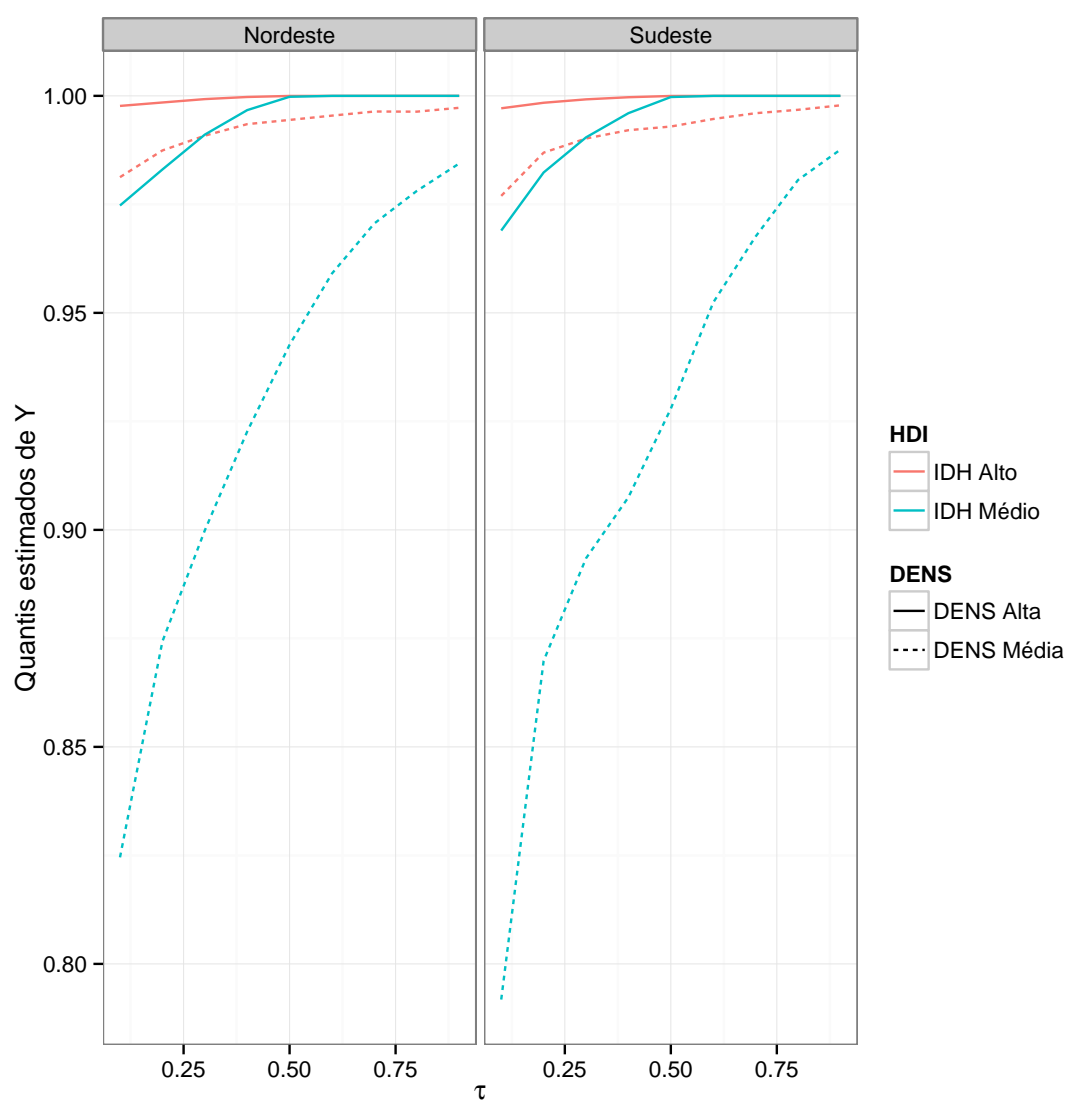

Figura 3.4: Quantis estimados para valores predeterminados das variáveis preditoras.

ção da distribuição Laplace assimétrica nos cálculos. Apesar dessa distribuição estar definida na reta, foi observado que a partir da propriedade de equivariância da função quantílica é possível modelar esse tipo de variável limitada usando modelos de regressão quantílica.

O modelo foi estendido para o caso em que uma proporção dos dados apresenta uma quantidade razoável de zeros ou uns. Foi proposto o uso de modelos de duas partes, em que modela-se a probabilidade dessa proporção ser igual a zero (ou um) como função de outras covariáveis, enquanto que os quantis condicionais da variável resposta entre 0 e 1 também são estudados. O método MCMC proposto apresentou bons resultados nos estudos de simulação.

O modelo proposto poderia ser estendido também para o caso em que existisse um número considerável de observações em ambos os limites da distribuição, de forma simultânea. Nesse cenário, poderia haver o interesse em se estimar tanto a probabilidade de $Y$ ser igual a um como também a probabilidade de $Y$ ser igual a zero, ao mesmo tempo em que o mo- 
delo analisa os quantis condicionais entre esses valores. Ainda que tal extensão não tenha sido apresentada aqui, as modificações necessárias para completar esse modelo podem ser obtidas de forma direta. O termo da verossimilhança seria levemente diferente e para obter as distribuições a posteriori passos similares teriam que ser seguidos, em comparação com o que foi apresentado nesse capítulo.

Ainda sobre a presença de observações tanto com valores iguais a 1 quanto 0 , poderia haver o interesse nos quantis condicionais de toda a distribuição, considerando a parte discreta e a parte contínua. De fato, uma simplificação na notação dos quantis condicionais foi feita, já que em todo o capítulo foram estudados somente os quantis da parte contínua. Assim, a notação deveria ter sido definida como $Q_{Y \mid Y \in(0,1)}(\tau \mid x)$ ao invés de somente $Q_{Y}(\tau \mid x)$, para $0<\tau<1$. Mas se forem adicionadas as probabilidades das massas pontuais, $p_{0}=P(y=0)>0$ e $p_{1}=P(y=1)>0$, então teríamos $0<p_{0}<\tau^{*}<1-p_{1}<1$, em $\tau^{*}$ 's são os quantis que são estudados pelo modelo de regressão quantílica na parte contínua. A seguinte conexão pode ser traçada entre os quantis condicionais da parte contínua de forma separada e de toda a distribuição

$$
Q_{y}\left(\frac{\tau^{*}}{1-p_{0}-p_{1}} \mid x\right)=Q_{y \mid y \in(0,1)}(\tau \mid x)
$$

em $0<p_{0}<\tau^{*}<1-p_{1}<1$ e $0<\tau<1$. Para cada coeficiente da regressão quantílica de interesse, a seguinte transformação pode ser feita $\beta_{i}\left(\tau^{*}\right)=\beta_{i}\left(\tau\left(1-p_{0}-p_{1}\right)\right)$. Nesse caso, não haveria conclusões a respeito da variação nos coeficientes da regressão para os quantis nos intervalos $\left[0, p_{0}\right]$ e $\left[1-p_{1}, 1\right]$. Uma possível abordagem, a qual pode ser apontada como um estudo futuro, seria combinar os resultados propostos aqui com os modelos de regressão quantílica para dados binários de Benoit e Van den Poel (2012) 


\section{Capítulo 4}

\section{Regressão quantílica bayesiana para dados contínuos com um componente}

\section{discreto no zero}

Neste capítulo, métodos de regressão quantílica bayesiana para variáveis resposta com distribuição mista com uma massa pontual no zero, em que se supõe que essas observações sejam censuradas à esquerda ou "zeros de verdade". Nós combinamos a informação fornecida pela análise de regressão quantílica para apresentar uma descrição mais completa da probabilidade de uma observação ser censurada dada que seu valor observado é igual a zero, ao mesmo tempo em que os quantis da parte contínua do modelo são estudados. Um algoritmo MCMC é proposto a partir dos métodos sugeridos no capítulo anterior para obter amostras da distribuição a posteriori. A partir de um estudo de simulação e duas aplicações com dados reais, é demonstrado que os métodos propostos são adequados para analisar a probabilidade de censura. O primeiro banco de dados é bastante conhecido na literatura de econometria sobre oferta de trabalho de mulheres na Grã-Bretanha e o segundo considera a análise estatística de gastos com bens duráveis, com base em informações do Brasil. 


\subsection{Introdução}

Na literatura de econometria, um problema bem conhecido acontece quando existe uma variável contínua não-negativa com uma massa pontual no zero. Tobin (1958) considerou o problema de gastos com bens duráveis, assumindo que todas observações com zero em gastos de um domicílio eram, na verdade, observações censuradas. Então, com o intuito de melhor entender a média condicional da variável resposta dada a renda do domicílio, por exemplo, a variável $Y^{\star}$, que é somente observável quando o seu valor é positivo, é adicionada no processo de modelagem. Dessa forma, considerando que os gastos são normalmente distribuídos, é possível utilizar a função de distribuição da normal acumulada para o cálculo da verossimilhança. Entretanto, Cragg (1971) ainda investigando os efeitos de variáveis explicativas na compra de bens duráveis, definiu um modelo de duas partes, em que uma parte do modelo estuda se o individuo fez a compra ou não e a outra parte tenta identificar o quanto é gasto em média condicionalmente a outras variáveis. Tal abordagem foi estudada no capítulo anterior no caso de dados definidos como uma proporção. Voltando ao exemplo dos bens duráveis, nota-se que essas duas abordagens tratam do mesmo problema usando suposições bem diferentes. Nesse capítulo, essas ideias são combinadas, sem depender somente da média condicional para fazer inferência sobre a distribuição contínua, mas sim utilizando a regressão quantílica para obter informação sobre os quantis condicionais.

Recentemente, houve um grande aumento de métodos que dão atenção a outras partes além da média condicional, frequentemente sem tentar descrever só com uma família de distribuições, (ver Kneib (2012) para uma discussão de tais modelos). Um desses modelos é a regressão quantílica, a qual é tema dessa tese.

Além disso, no capítulo anterior foram considerados dados de proporção com inflação de zeros ou uns e foi desenvolvido o modelo de duas partes usando um modelo de regressão quantílica bayesiana para explicar os quantis condicionais da parte contínua. Considerouse a propriedade de equivariância da função quantílica para se trabalhar com a variável transformada na modelagem, para igualar o suporte da distribuição Laplace assimétrica. Aqui, o objetivo é estender esses modelos nesse capítulo, mas concentrando-se somente no 
processo de inflação de zeros, em que assume-se que parte desses zeros são censurados. Examinando a distribuição contínua com seus quantis condicionais, pretende-se obter mais informação sobre a probabilidade de uma observação ser censurada, dado que a sua resposta é igual a zero.

Esse capítulo está organizado da seguinte maneira. Na Seção 4.2, é feita uma breve revisão dos modelos de duas partes, apenas para facilitar a leitura do capítulo, usando modelos de regressão quantílica e considerando o que foi exposto no capítulo anterior, mas adaptando para o caso da resposta não-negativa. Na Seção 4.3, o modelo de duas partes é estendido para permitir que observações iguais a zero possam ser ou censuradas ou zeros verdadeiros, definindo a probabilidade a posteriori de ser censurada dado que sua resposta é zero. Avançando, na Seção 4.4, é apresentado um estudo de simulação para comparar as probabilidades de censuras para observações com resposta zero. Duas aplicações do modelo em dados reais são discutidas, na Seção 4.5, para ilustrar o modelo proposto. Algumas considerações finais são feitas na Seção 4.6.

\subsection{Revisão do modelo de duas partes}

Se o interesse é modelar a variável resposta por uma mistura de duas distribuições, uma massa pontual no zero e uma distribuição contínua para a parte positiva, é possível utilizar o modelo de duas partes de Cragg (1971), já apresentado no capítulo anterior. A função densidade de probabilidade de $Y$ pode ser escrita como

$$
g(y)=p \mathbb{I}(Y=0)+(1-p) f(y) \mathbb{I}(Y>0) .
$$

Para o exemplo dos gastos com bens duráveis, esse modelo assume que uma pessoa decide se vai fazer a compra ou não no primeiro lugar e depois decide sobre o quanto vai gastar. Para cada parte do processo, a análise pode verificar tanto a importância de preditores para explicar a probabilidade de $Y$ ser igual a zero quanto ao resultado da parte positiva. Cragg (1971) considerou uma função de ligação probito para estudar a probabilidade $p$ 
e uma distribuição normal truncada para ajustar os valores maiores que zero. A partir dessas suposições, ou mesmo com outras distribuições para a parte contínua, é possível fazer inferência sobre a média condicional dos valores positivos. Porém, tendo em vista o exposto nessa tese, é importante checar se outras partes da distribuição condicional podem apresentar conclusões diferentes sobre a associação entre a variável resposta e suas variáveis explicativas. E nesse sentido, os modelos de regressão quantílica podem ser muito úteis.

No capítulo anterior, foi proposto utilizar a distribuição Laplace assimétrica para a parte contínua, para dados de proporção, quando a variável resposta é definida entre zero e um. A propriedade de equivariância foi considerada para modelar a resposta transformada para passar do suporte limitado das proporções para o conjunto $\mathbb{R}$, referente a distribuição Laplace assimétrica. E essa distribuição permite a inferência a posteriori sobre quantis condicionais da variável resposta, como provado por Sriram et al. (2013).

Da mesma maneira que no capítulo anterior, é possível adicionar variáveis explicativas para modelar a probabilidade $p_{i}$, fazendo $\eta\left(p_{i}\right)=z_{i}^{\prime} \gamma$, em que $\eta($.$) é uma função de ligação,$ podendo ser, por exemplo, o inverso da f.d.a. da distribuição normal, produzindo o modelo probito, ou o inverso da f.d.a. da distribuição logística, produzindo um modelo logístico. O conjunto de variáveis pode ser o mesmo ou diferente daquele usado para explicar a densidade contínua.

Com o intuito de igualar o suporte da distribuição Laplace assimétrica com os valores positivos nesses modelo, é preciso transformar a variável resposta com uma função nãodecrescente $h: \mathbb{R}^{+} \rightarrow \mathbb{R}$.

Sejam os conjuntos $J=\left\{y_{i}: y_{i}=0\right\}$, e $K=\left\{y_{i}: y_{i}>0\right\}$, a função de verossimilhança aumentada para o modelo de duas partes considerando a mistura localização-escala da distribuição Laplace assimétrica pode ser escrita como

$$
L(\beta(\tau), \gamma, \sigma)=\prod_{y_{i} \in J} \eta^{-1}\left(z_{i}^{\prime} \gamma\right) \prod_{y_{i} \in K}\left(1-\eta^{-1}\left(z_{i}^{\prime} \gamma\right)\right) f\left(h\left(y_{i}\right) \mid v_{i}\right) f\left(v_{i}\right)
$$

Para completar a especificação do modelo bayesiano, são assumidas distribuições a priori 
para os parâmetros, com uma distribuição normal para $\gamma$ e para $\beta(\tau)$, e uma distribuição gama inversa para $\sigma$. Dadas essas definições, é possível escrever o modelo hierárquico completo como

$$
\begin{aligned}
h\left(Y_{i}\right) \mid v_{i} & \sim p_{i} I\left(y_{i} \in J\right)+\left(1-p_{i}\right) N\left(x_{i}^{\prime} \beta(\tau)+\theta v_{i}, \psi^{2} \sigma v_{i}\right) I\left(y_{i} \in K\right), \\
v_{i} & \sim \mathcal{E}(\sigma) \\
p_{i} & =\eta\left(z_{i}^{\prime} \gamma\right), \\
\beta(\tau) & \sim N\left(b_{0}, B_{0}\right), \\
\sigma & \sim \mathcal{G} \mathcal{I}\left(n_{0}, s_{0}\right), \\
\gamma & \sim N\left(g_{0}, G_{0}\right) .
\end{aligned}
$$

As distribuições condicionais completas para todos os parâmetros, depois de combinadas a verossimilhança com a informação a priori, são

$$
\begin{aligned}
\beta(\tau) \mid y, v, \gamma, \sigma & \sim N\left(b_{1}, B_{1}\right), \\
v_{i} \mid h(y), \beta(\tau), \gamma, \sigma & \sim \mathcal{G} \mathcal{I} \mathcal{G}\left(1 / 2, \hat{\delta}_{i}, \hat{\xi}_{i}\right), \\
\sigma \mid y, v, \beta(\tau), \gamma & \sim \mathcal{G} \mathcal{I}(\tilde{n} / 2, \tilde{s} / 2), \\
\pi(\gamma \mid y, v, \beta(\tau), \sigma) & \propto \prod_{i \in J} \eta^{-1}\left(z_{i}^{\prime} \gamma\right) \prod_{i \in K}\left(1-\eta^{-1}\left(z_{i}^{\prime} \gamma\right)\right) \exp \left\{-\frac{1}{2}\left(\gamma-g_{0}\right)^{\prime} G_{0}^{-1}\left(\gamma-g_{0}\right)\right\} .
\end{aligned}
$$

Com exceção da diferença na definição de $h($.$) , as distribuições a posteriori aqui são$ similares às do capitulo anterior, por esse motivo não serão comentadas.

Por último, além de utilizar o passo Metropolis-Hastings no MCMC, se for considerado para $\eta$ a função de ligação probito, i.e., a inversa da f.d.a. da normal, então é possível utilizar o algoritmo de Albert e Chib (1993) para produzir amostras aleatórias para os parâmetros da probabilidade $\gamma$. Isso eliminaria o passo Metropolis-Hastings do algoritmo, já que todos os parâmetros poderiam ser atualizados com o amostrador de Gibbs. Por um lado, ao utilizar essa metodologia ganha-se eficiência computacional em utilizar o algoritmo Gibbs. Por outro lado, com o modelo logístico as interpretações dos parâmetros são mais interessantes tendo 
em vista as aplicações, e exatamente por esse motivo que a especificação com o MetropolisHastings foi utilizada nesse e no capítulo anterior.

\subsection{Regressão quantílica bayesiana para dados contí- nuos com uma massa pontual no zero}

Retornando ao problema de gastos com bens duráveis em um determinado período, é possível observar que uma proporção de domicílios pode não ter tido nenhum gasto desse tipo, tendo zero como total de gastos. Esse resultado pode ser analisado de duas formas diferentes em Tobin (1958) e Cragg (1971). Aqui o objetivo é combinar essas ideias, enquanto é feita também a inferência sobre os quantis condicionais desses gastos, por exemplo. Na literatura de biometria, Moulton e Halsey (1995) propuseram uma extensão do modelo do Cragg, considerando que uma observação zero, ou um limite inferior de detecção, podem fazer parte tanto da distribuição pontual quanto da parte contínua, sendo nesse caso uma observação censurada. Chai e Bailey (2008) consideraram uma formulação similar, porém mudando a distribuição da parte contínua e também a função de ligação para modelar $p_{i}$. Na literatura de análise de sobrevivência, uma situação análoga ocorre quando existe uma proporção da amostra que é assumida ter sido curada de uma possível doença. Como consequência, ao final do estudo de todas as observações que não foram afetadas pelo evento de interesse, algumas podem estar curadas e outras podem ser observações censuradas, i.e., que não foi observado por tempo suficiente para acontecer o evento de interesse.

Para esses modelos, que consideram os valores zero como parte censurados e parte zeros verdadeiros, a função densidade deve ser reescrita como

$$
g(y)=[p+(1-p) F(0)] \mathbb{I}(y=0)+(1-p) f(y) \mathbb{I}(y>0)
$$

em que $F($.$) é a f.d.a. da distribuição utilizada na parte contínua. Nos modelos de regressão$ quantílica, para as observações censuradas, a ideia proposta por Chib (1992) e adaptado 
para regressão quantílica por Kozumi e Kobayashi (2011), que amostra $Y^{*}$ usando

$$
Y^{\star} \sim N T_{(-\infty, 0]}\left(x^{\prime} \beta(\tau)+\theta v, \psi^{2} \sigma v\right)
$$

em $N T_{[a, b]}\left(\mu, \sigma^{2}\right)$ denota uma distribuição normal truncada, com média $\mu$ e variância $\sigma^{2}$ no intervalo $[a, b]$. Se uma variável latente $C$ é definida da seguinte maneira

$$
C= \begin{cases}1, & \text { se } Y \text { é censurada } \\ 0, & \text { caso contrário. }\end{cases}
$$

A probabilidade condicional da observação ser censurada dado que sua resposta é zero é igual a

$$
P(C=1 \mid Y=0)=\frac{(1-p) F(0)}{p+(1-p) F(0)},
$$

em que $F(0)$ depende dos parâmetros da distribuição Laplace assimétrica e pode ser definida como

$$
F(0 ; \beta(\tau), \sigma)= \begin{cases}\tau \exp \left\{-\frac{(1-\tau) x^{\prime} \beta(\tau)}{\sigma}\right\}, & \text { if } x^{\prime} \beta(\tau) \geqslant 0 \\ 1-(1-\tau) \exp \left\{\frac{\tau x^{\prime} \beta(\tau)}{\sigma}\right\}, & \text { if } x^{\prime} \beta(\tau)<0\end{cases}
$$

Para completar a especificação dessa variável que controla a censura dos dados, é fácil definir que $P(C=1 \mid Y>0)=0$ e $P(C=0 \mid Y>0)=1$. Se a probabilidade em (4.6) é calculada quando $\sigma=1$, e para dois possíveis valores de $x^{\prime}(\beta),-1$ e 1 , considerando valores diferentes para $p$, é possível obter as curvas na Figura 4.1. Comparando os dois possíveis valores, a probabilidade de ser censurada é maior quando o preditor linear é igual a -1, para o mesmo $\tau$. É fácil ver que essa probabilidade é limitada entre zero e $1-p$ e que essa característica é denotada na figura. Também, para o mesmo $p$ essa probabilidade é crescente em $\tau$, que é controlado por $F(0)$.

Essa variável latente, $C$, que indica o mecanismo de censura, é não-observável para todas as observações com resposta zero. Logo, é necessário um algoritmo de aumento de dados. As observações completas são $\left\{Y_{i}, C_{i}, v_{i}\right\}$, dentre as quais é observado somente $Y_{i}$.

Para os casos completos, os seguintes conjuntos podem ser definidos $C=\left\{y_{i}: y_{i}=\right.$ 


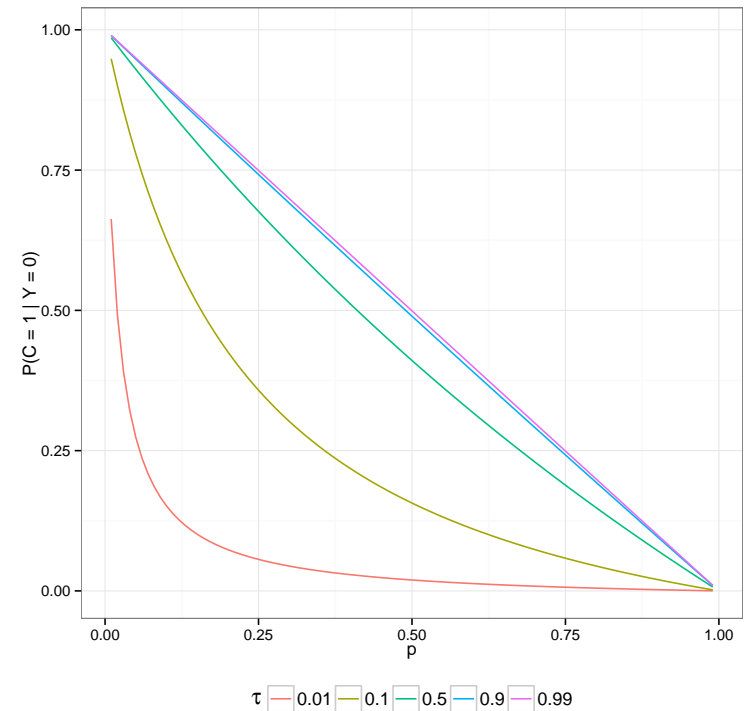

(a)

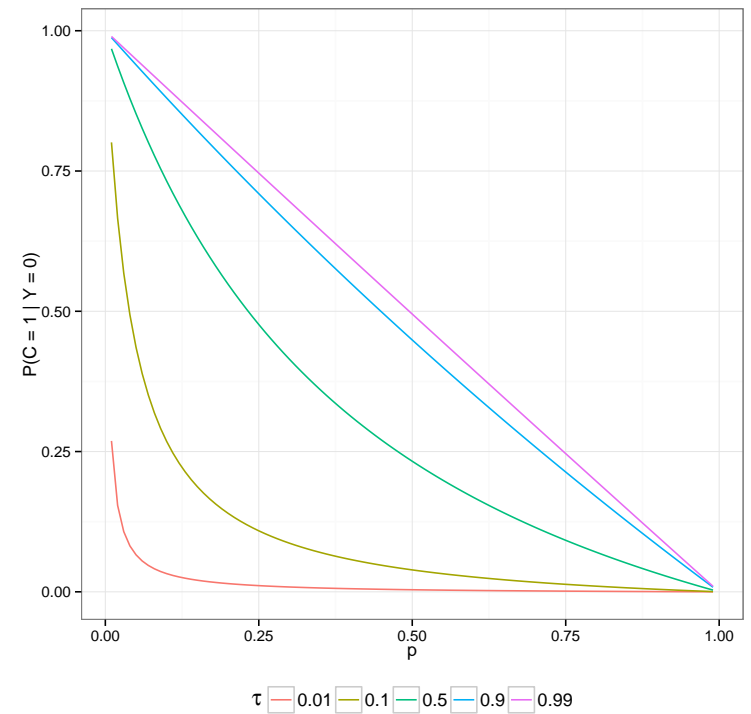

(b)

Figura 4.1: Gráfico para $P(C=1 \mid Y=0)$ para diferentes $\tau$ 's como função da probabilidade $p=P(Y=0)$. (a) $x^{\prime} \beta(\tau)=-1$, (b) $x^{\prime} \beta(\tau)=1$

0 e $\left.c_{i}=1\right\}, D=\left\{y_{i}: y_{i}=0\right.$ e $\left.c_{i}=0\right\}$ e $K=\left\{y_{i}: y_{i}>0\right\}$, de observações censuradas, não censuradas mas com resposta igual a zero, e observações com resposta maior que zero, respectivamente. Então, a função de verossimilhança para $\xi=(\beta(\tau), \gamma, \sigma)$, sem escrever os parâmetros condicionais para $F(0)$ e $f\left(y_{i} \mid v_{i}\right)$ para deixar a notação mais simples, pode ser escrita como

$$
L(\xi)=\prod_{y_{i} \in D} \eta^{-1}\left(z_{i}^{\prime} \gamma\right) \prod_{y_{i} \in C}\left(1-\eta^{-1}\left(z_{i}^{\prime} \gamma\right)\right) F(0) \prod_{y_{i} \in K}\left(1-\eta^{-1}\left(z_{i}^{\prime} \gamma\right)\right) f\left(y_{i} \mid v_{i}\right) f\left(v_{i}\right)
$$

Para as variáveis latentes, inicialmente $v_{i}$, no primeiro capítulo e no capítulo anterior, foi discutido como atualizar os seus valores no algoritmo MCMC. Para a variável $C_{i}$ é possível atualizar os seus valores a partir de sua distribuição condicional completa a posteriori,

$$
C_{i} \mid y, \beta(\tau), \sigma, v \sim \operatorname{Ber}\left(\frac{\left(1-p_{i}\right) F(0)}{p_{i}+\left(1-p_{i}\right) F(0)}\right)
$$

Note que essa distribuição depende dos valores atuais dos parâmetros relacionados a probabilidade $p_{i}$, mas também dos parâmetros relacionados à parte contínua. Essa propriedade interessante garante que uma certa observação, com sua resposta igual a zero, pode ter 
diferentes probabilidades de ser censurada a depender do quantil condicional e de sua probabilidade de ser igual a zero.

Com esse resultado, e considerando o procedimento de imputação sugerido em (4.5), então o modelo se torna um modelo de duas partes, o qual pode ser atualizado como discutido na seção anterior.

Uma estimativa a posteriori da probabilidade de ser censurada para cada observação pode ser calculada como

$$
P\left(C_{i}=1 \mid Y, v, \beta(\tau), \sigma, \gamma\right)=\sum_{k=b+1}^{M} \frac{C_{i}^{(k)}}{M-b}, \quad \forall i: y_{i} \in C \cup D
$$

em que $C_{i}^{(k)}$ é o $k$-ésimo termo da cadeia de Markov para a variável indicadora de censura para a $i$-ésima observação, $M$ é o tamanho da cadeia e $b$ é o tamanho do período burn-in.

\subsection{Estudo de simulação para a probabilidade de cen- sura}

Nessa seção, há o interesse em checar a performance do modelo com relação a sua capacidade de fazer afirmações sobre a probabilidade de uma observação ser censurada dado que sua resposta é igual a zero. Para realizar isso, um estudo de simulação foi replicado no qual são conhecidas quais observações foram censuradas e quais não foram, entre aquelas que tem a resposta igual a zero.

Foi considerado um modelo com duas covariáveis e com a seguinte estrutura

$$
\begin{aligned}
\log \left(\frac{p_{i}}{1-p_{i}}\right) & =\gamma_{0}+\gamma_{1} z_{i 1}+\gamma_{2} z_{i 2}, \\
Y_{i} & =\beta_{0}+\beta_{1} x_{i 1}+\beta_{2} x_{i 2}+\epsilon_{i},
\end{aligned}
$$

em que $\epsilon_{i} \sim N\left(0,0.5^{2}\right), \beta_{0}=-0.5, \beta_{1}=0$ e $\beta_{2}=1.5$. As variáveis $x_{i j}, j=1,2$, foram amostradas de uma distribuição uniforme padrão, e foi considerado $x_{i j}=z_{i j}$, i.e., o mesmo 
conjunto de covariáveis foi utilizado para explicar tanto a probabilidade $p_{i}$ quanto a parte contínua. Nesse estudo de simulação, foi considerado um cenário em que houvesse uma diferença grande entre as observações que fazem parte da massa pontual e aquelas censuradas. Dessa maneira, foram utilizados valores absolutos grandes para $\gamma_{1}$ e $\gamma_{2}$, inicialmente, 10 e -10, respectivamente. Definindo esses valores, a intenção é dar maior probabilidade $p_{i}$ para aqueles zeros verdadeiros. Em média, $50 \%$ da amostra era classificada como zero verdadeiro no início, e em seguida, outro $10 \%$ era classificada como zero depois de ser censurada. O tamanho de amostra no estudo foi igual a 500 e o estudo foi replicado 1000 vezes. Para os hiperparâmetros da priori, foram assumidos $b_{0}=g_{0}=0$ e $B_{0}=G_{0}=100 I$, em que $I$ é matriz identidade, e para $\sigma$ foi considerada $\mathcal{G I}(3 / 2,0.1 / 2)$, como em Kozumi e Kobayashi (2011). Todos os resultados foram baseados depois de descartadas as primeiras 500 amostras da posteriori e considerando as próximas 1500 amostras da posteriori, calculando a média a posteriori para cada parâmetro.

Para cada simulação, foi calculada a probabilidade de ser censurada para todas observações com $y_{i}=0$. Em seguida, essas probabilidades foram resumidas com a média para o grupo de observações censuradas e também para o grupo de observações não-censuradas, respectivamente, como

$$
\zeta_{C}=\sum_{y_{i} \in C} \frac{P\left(C_{i}=1 \mid Y_{i}=0\right)}{n_{C}} \quad \zeta_{D}=\sum_{y_{i} \in D} \frac{P\left(C_{i}=1 \mid Y_{i}=0\right)}{n_{D}}
$$

em que $n_{C}$ é o número de observações censuradas com $y_{i}=0$ e $n_{D}$ é o número de observações não-censuradas com $y_{i}=0$, e a $P\left(C_{i}=1 \mid Y_{i}=0\right)$ é calculada de acordo com (4.7).

Na Figura 4.2, há a densidade estimada para os $1000 \zeta_{C}$ e $\zeta_{D}$ obtidos, considerando três $\tau$ s diferentes: $0,25,0,50$ e 0,75. É possível ver que para observações não-censuradas a densidade é mais concentrada antes de 0,25, e que essa concentração é bem mais acentuada para o quantil 0,25. Para o grupo censurado, é possível ver que as probabilidades de ser censurada são definitivamente maiores que para o grupo não censurado, ainda que para o quantil condicional 0,25 é mais concentrado por volta de 0,3, mas com uma varição grande. Para o quantil condicional 0,75, essa probabilidade é concentrada principalmente por volta 


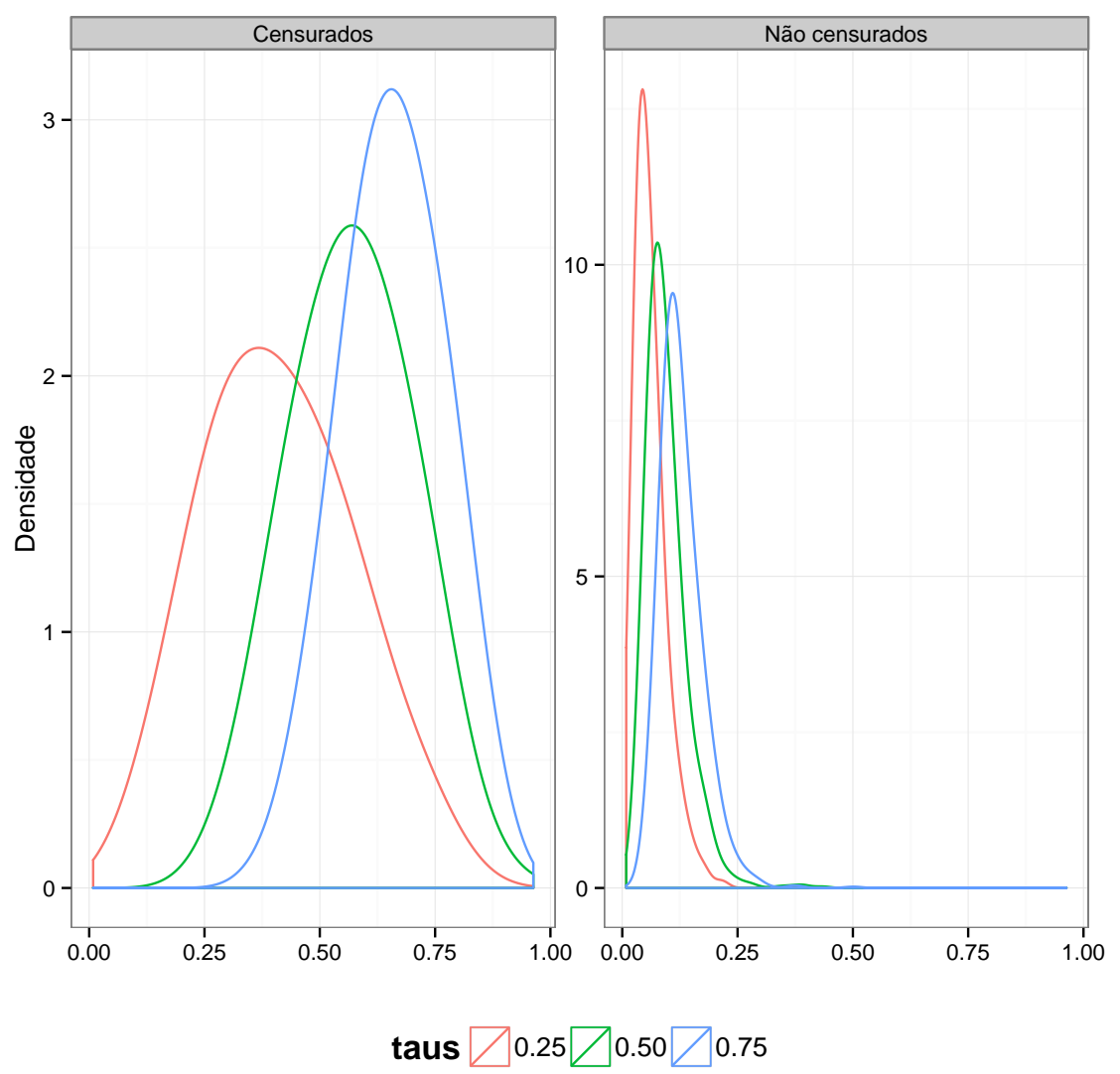

Figura 4.2: Densidade estimada para as médias a posteriori das probabilidades de ser censurada para observações censuradas e também observações não-censuradas.

de 0,70, logo dando alta probabilidade para essas observações censuradas. De forma geral, essas probabilidades $P\left(C_{i}=1 \mid Y=0\right)$ aumentam com o quantil de interesse, o que havia sido discutido na seção anterior.

Além do interesse na estimação da probabilidade $P(C=1 \mid Y=0)$, é importante checar se a incerteza sobre se uma observação é censurada ou não prejudica o processo de estimação dos outros parâmetros. Sobre o estudo de simulação, porém, há apenas um detalhe a ser discutido. O tamanho da cadeia MCMC nesse exemplo é pequeno para o passo MetropolisHastings. No entanto, esse tamanho de amostra era necessário para que pudessem ser feitas as replicações de interesse no estudo de simulação.

As densidades das 1000 estimativas a posteriori de $\gamma_{1}$ e $\gamma_{2}$, e $\beta_{2}$ estão apresentadas na Figura 4.3. É possível ver que para os três quantis, a estimação desses parâmetros não foi afetada por essa incerteza associada ao processo de censura. Em geral, esses parâmetros foram razoavelmente estimados. Nota-se, no entanto, alguns resultados interessantes sobre a 

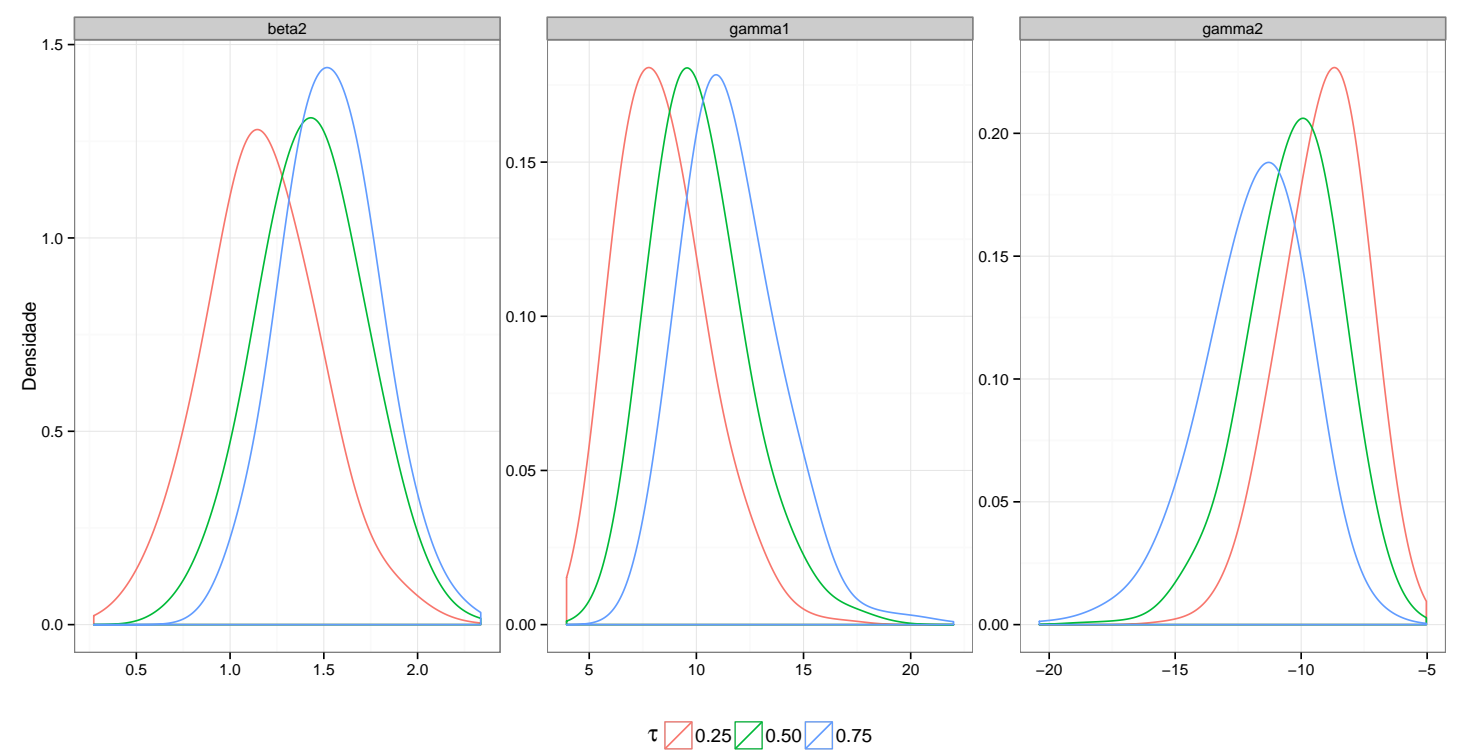

Figura 4.3: Densidades estimadas para as médias a posteriori dos parâmetros $\beta_{2}, \gamma_{1}, \gamma_{2}$ no estudo de simulação.

variância dessas estimativas. Devido ao pequeno erro do processo de censura para $\tau=0.75$, uma vez que a probabilidade média a posteriori de uma observação ser censurada é maior para esse quantil, então $\beta_{2}$ é melhor estimado, com valor médio próximo de 1,5 e também com menor variabilidade ao redor desse valor. Por outro lado, as estimativas para $\gamma_{2}$ apresentam um resultado similar, porém no quantil 0,25. Isto acontece devido ao fato que, nesse quantil, as observações que são zeros verdadeiros recebem maiores valores para $p_{i}$. Logo no processo iterativo da variável latente $C_{i}$, que é responsável por separar entre as observações censuradas e as observações não-censuradas, esta será atualizada para 1 em poucas oportunidades. Ainda assim, essa característica é observada numa menor escala para $\gamma_{1}$.

Por último, não foram adicionadas outras distribuições para o erro nesse estudo, no lugar da distribuição normal, já que acreditamos que tal mudança não providenciaria maiores informações sobre a efetividade do modelo. Além disso, considerar uma amostra maior seria útil, já que é esperado que erros de estimativas diminuiriam com amostras maiores. Mas uma vez que os resultados já foram satisfatórios, decidiu-se por não adicionar novos cenários para esse estudo. Além disso, adicionar mais variáveis para cada parte do modelo provavelmente dificultaria o processo de estimação, embora isso possa ser entendido com uma complicação com a qual os algoritmos poderiam lidar separadamente. 


\subsection{Aplicações}

O modelo proposto nesse capítulo é exemplificado com duas aplicações. Primeiramente, dados apresentados por Mroz (1987) são considerados como ilustração, uma vez que esse banco de dados foi utilizado para exemplificar o modelo de regressão quantílica Tobit em Kozumi e Kobayashi (2011). Em seguida, dados sobre gastos com bens duráveis no Brasil entre 2008 e 2009 são utilizados, tendo em vista a motivação desse tipo de dados em Tobin (1958) e Cragg (1971).

\subsubsection{Dados sobre oferta de trabalho de mulheres}

Analisando modelos empíricos sobre a oferta de trabalho de mulheres, Mroz (1987) organizou dados sobre 753 mulheres casadas, com idade entre 30 e 60 anos de idade. A variável resposta de interesse nesse caso é o número de horas trabalhadas por algum pagamento durante o ano de 1975, medido em 100h. Na amostra, que foi coletada do "Estudo de painel sobre dinâmicas da renda"1, 325 mulheres não trabalharam naquele ano, logo suas variáveis respostas são iguais a zero. Em Kozumi e Kobayashi (2011), os autores utilizaram esse banco de dados para ilustrar o modelo de regressão quantílica Tobit, em que essas observações iguais a zero são consideradas censuradas à esquerda. No modelo proposto aqui nesse capítulo, a probabilidade de uma observação ser censurada é combinada com a probabilidade de uma observação ser igual a zero para obter uma análise mais completa dessas mulheres que não trabalharam naquele ano. Como covariáveis, foram selecionadas renda que não é da mulher $\left(x_{1}\right)$, anos de educação $\left(x_{2}\right)$, anos de experiência $\left(x_{3}\right)$, idade da mulher $\left(x_{4}\right)$, número de crianças mais novas que 6 anos $\left(x_{5}\right)$, e o número de crianças com idade entre 6 e 18 anos de idade $\left(x_{6}\right)$. Depois de padronizar todas as covariáveis, foi considerado o seguinte modelo para a probabilidade e para os quantis condicionais

$$
\begin{aligned}
\log \left(\frac{p_{i}}{1-p_{i}}\right) & =\gamma_{0}+\gamma_{1} x_{i 1}+\gamma_{2} x_{i 2}+\gamma_{3} x_{i 3}+\gamma_{4} x_{i 4}+\gamma_{5} x_{i 5}+\gamma_{6} x_{i 6} \\
Q_{Y_{i}}\left(\tau \mid x_{i}\right) & =\beta_{0}+\beta_{1} x_{i 1}+\beta_{2} x_{i 2}+\beta_{3} x_{i 3}+\beta_{4} x_{i 4}+\beta_{5} x_{i 5}+\beta_{6} x_{i 6}
\end{aligned}
$$

\footnotetext{
${ }^{1}$ Panel Study of Income Dynamics
} 


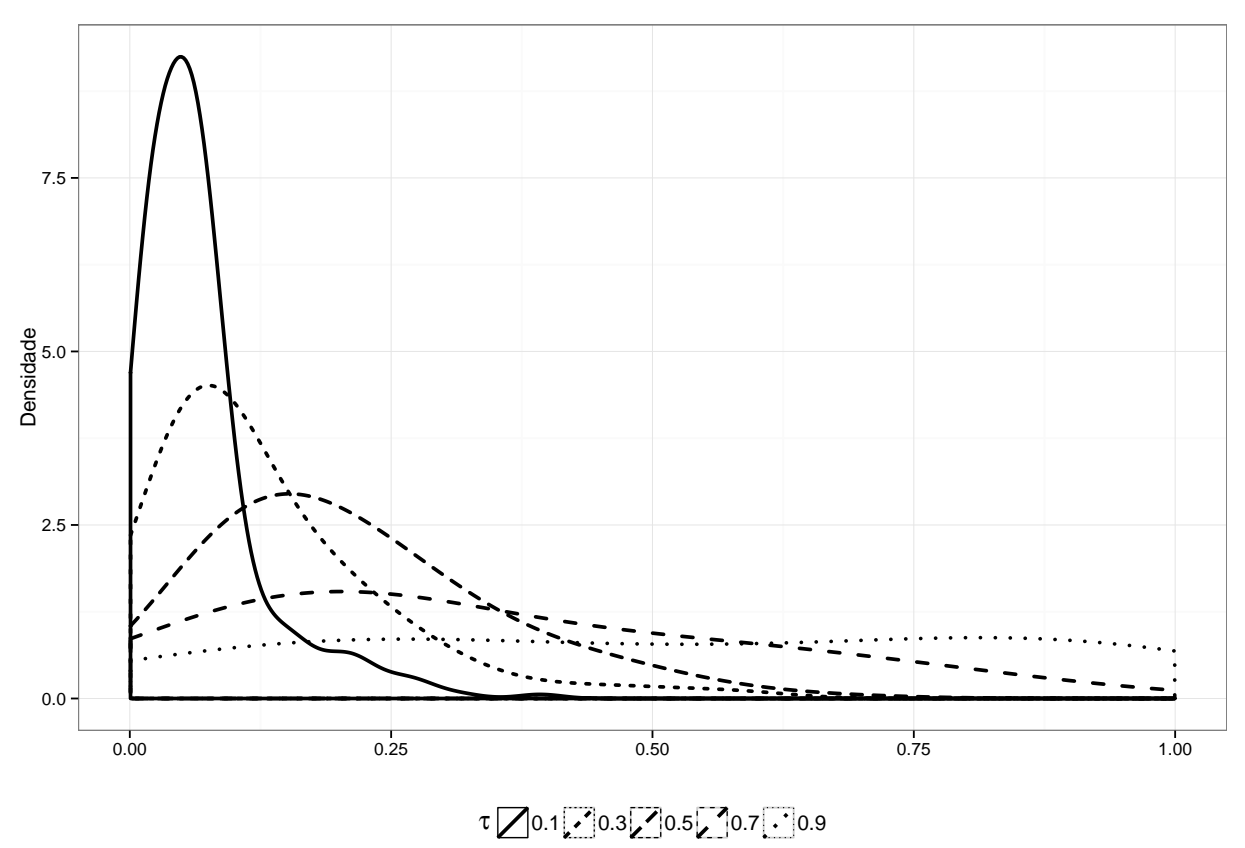

Figura 4.4: Densidades da probabilidade de uma observação ser censurada para $\tau=$ $0.1,0.3,0.5,0.7,0.9$.

Na Figura 4.4, são apresentadas as densidades das probabilidades das observações serem censuradas para distintos $\tau$ 's. Como mencionado anteriormente, essas probabilidades dependem de $\tau$, logo são esperadas essas diferentes formas dessas densidades. Estima-se que para $\tau=0.10$, essas probabilidades estão principalmente concentradas abaixo de 0,25 , enquanto que para $\tau=0,90$ essas probabilidades estão bem distribuídas entre 0 e 1 , com valor médio 0,53. Essas diferenças entre os quantis nas probabilidades de serem censuradas geram algumas variações nos intervalos de credibilidade para alguns $\gamma$ 's, como pode ser visto na Figura 4.5. Por exemplo, para $\gamma_{3}$ existe um aumento grande em valor absoluto para maiores $\tau$. Além disso, o efeito do número de crianças com mais de 6 anos de idade é estimado ser diferente de zero e negativo somente para maiores quantis, $\tau=0,8$ e $\tau=0,9$, enquanto que o coeficiente para a renda que não é da mulher pode ser considerado significante somente nos menores quantis. De forma geral, os coeficientes para $x_{1}, x_{4}$ e $x_{5}$, quando significantes, são estimados serem positivos. Por outro lado, as estimativas para as outras variáveis são negativas para explicar a probabilidade das horas de trabalho serem iguais a zero. Nesse momento, é importante notar que $\gamma$ também deveria estar indexado por $\tau$, porém isto não foi feito para deixar essa referência apenas para $\beta(\tau)$, que se refere aos parâmetros do modelo 


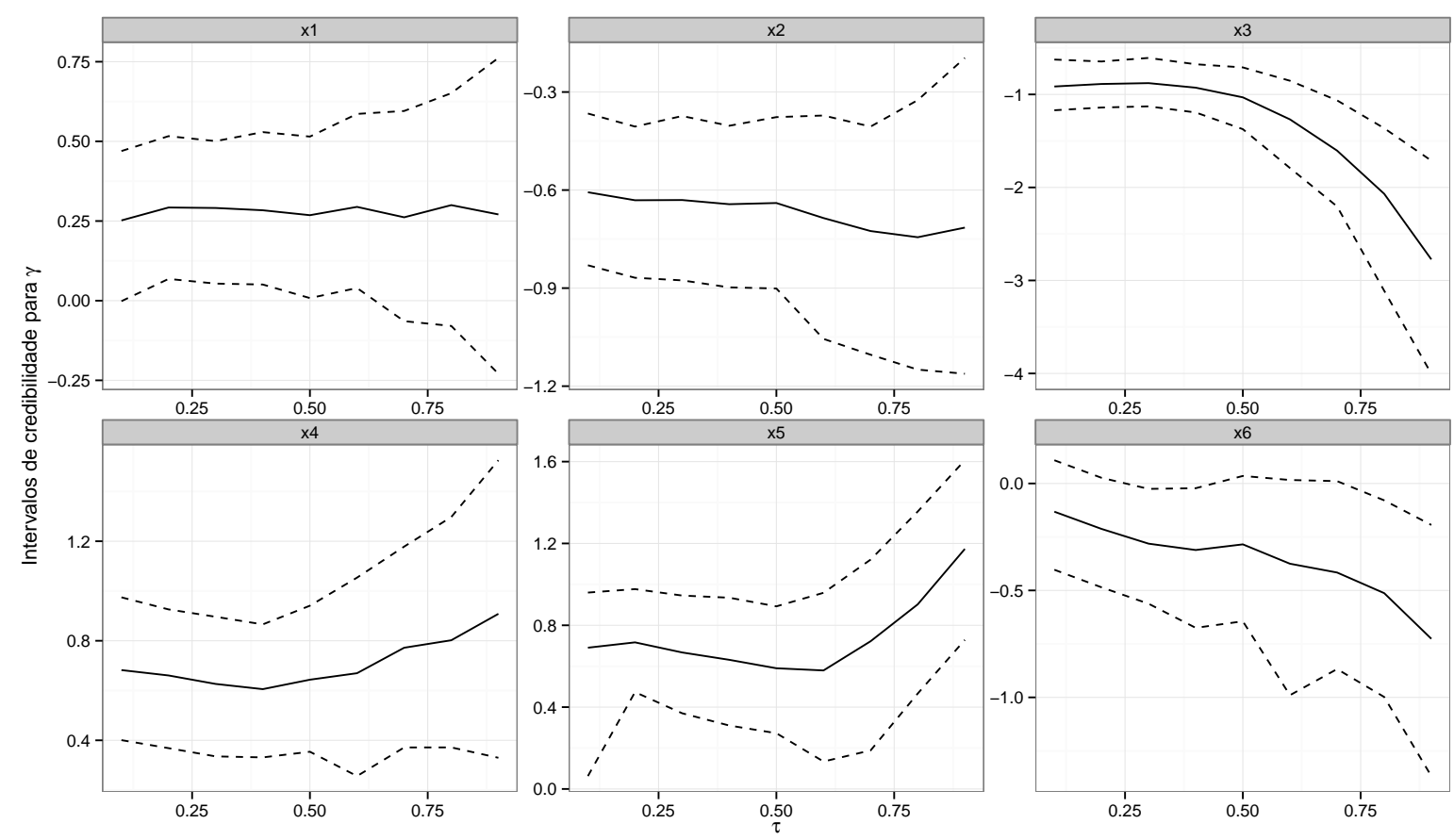

Figura 4.5: Média a posteriori e intervalos de credibilidade de $95 \%$ para $\gamma_{i}, i=1, \ldots, 6$.

de regressão quantílica inicialmente.

Ademais, é possível comparar a variação para cada variável no modelo de acordo com a probabilidade de uma observação ser censurada, que é um novo fator que foi adicionado pelo modelo proposto aqui para esse tipo de análise. Por exemplo, levando em consideração as variáveis renda que não é da mulher e anos de experiência, existem resultados interessantes quando grupos com diferentes probabilidades são comparados para dois valores de $\tau$.

Na Figura 4.6, estão apresentadas as distribuições de renda que não é da mulher separando as mulheres em dois grupos: com probabilidade de ser uma observação censurada acima ou abaixo da média para um quantil específico. Para $\tau=0,10$ a probabilidade média é 0,07 e para $\tau=0,50$ é 0,21. Enquanto não há uma diferença perceptível na distribuição dos dois grupos no quantil 0,10, existe uma diferença notável na distribuição para mulheres com probabilidade menor do que a média com relação a mulheres com probabilidade maior do que a média. As mulheres com maior probabilidade de serem classificadas como zeros verdadeiros, e consequentemente com probabilidade menor de serem consideradas censuradas, tem uma distribuição da renda com mais peso na cauda superior. É possível interpretar que essa renda, que é responsabilidade da mulher, pode ser vista como um incentivo à mulher 

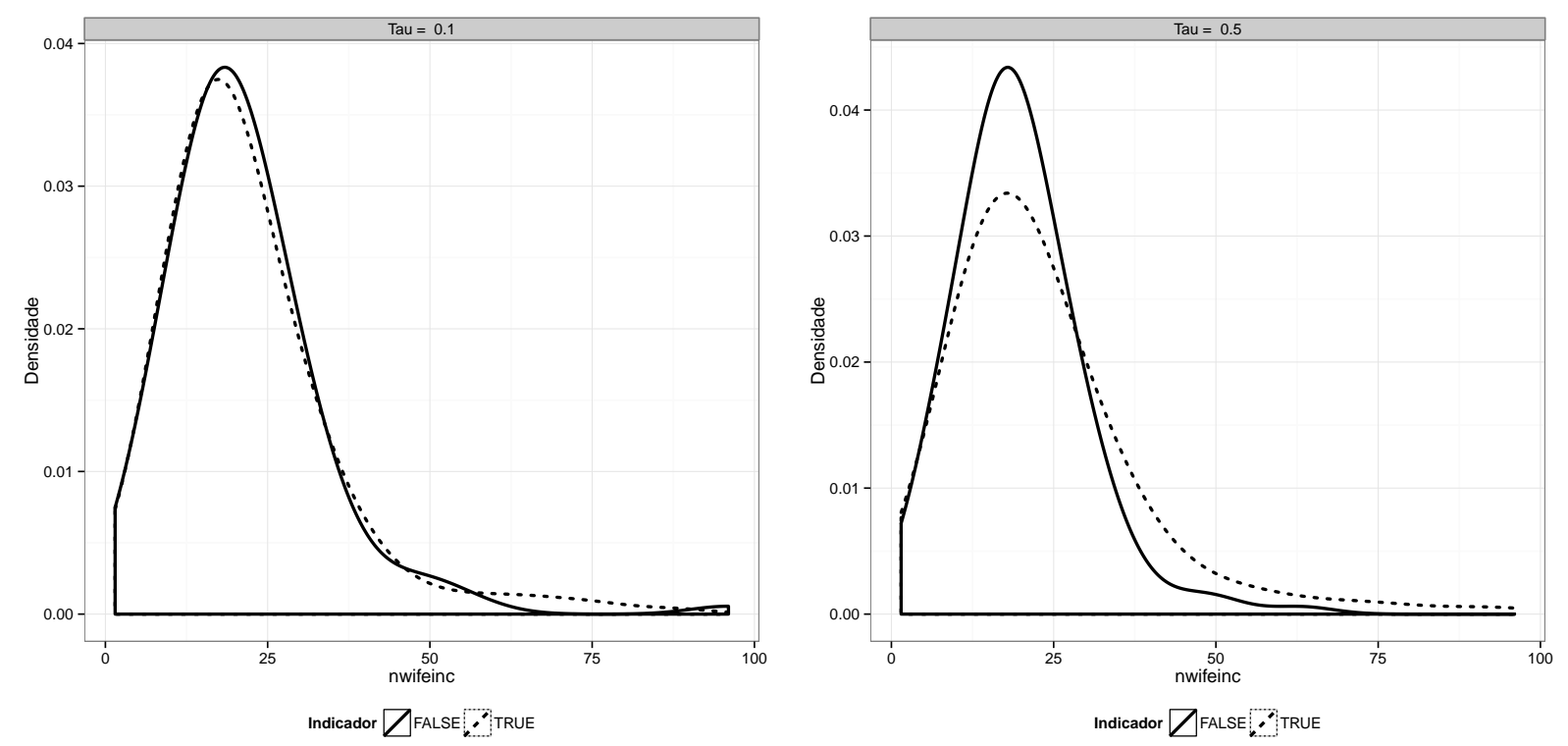

Figura 4.6: Densidade da variável $x_{1}$ separando por dois grupos de acordo com as respectivas probabilidade de censura em comparação com a probabilidade média em um dado quantil, para $\tau=0,1$ e $\tau=0,5$. As linhas sólidas são para o grupo acima da probabilidade média, enquanto as linhas pontilhadas são referentes ao grupo abaixo da probabilidade média.

não trabalhar.

Um resultado análogo é obtido quando a variável anos de experiência é utilizada, o que pode ser visualizado na Figura 4.7, mas agora considerando somente os quantis 0,5 e 0,9. Considerando as probabilidades de serem censuradas para $\tau=0,5$, não há uma diferença distinguível entre a distribuição dos anos de experiência para o grupo com probabilidade menor do que a média nesse quantil quando comparado com o grupo com probabilidade maior do que a média. Adicionalmente, para $\tau=0,9$, em que a média da probabilidade de ser censurada é 0,53 , o grupo com mulheres com probabilidade abaixo da média tem menos experiência em termos da quantidade de anos de experiência no mercado de trabalho, dado que a sua distribuição é concentrada abaixo de 20 anos de experiência. A distribuição para o outro grupo tem a moda por volta de 10 anos de experiência, porém uma boa parte dessa distribuição está concentrada acima de 20 anos de experiência, corroborando a diferença das densidades desses dois grupos. 

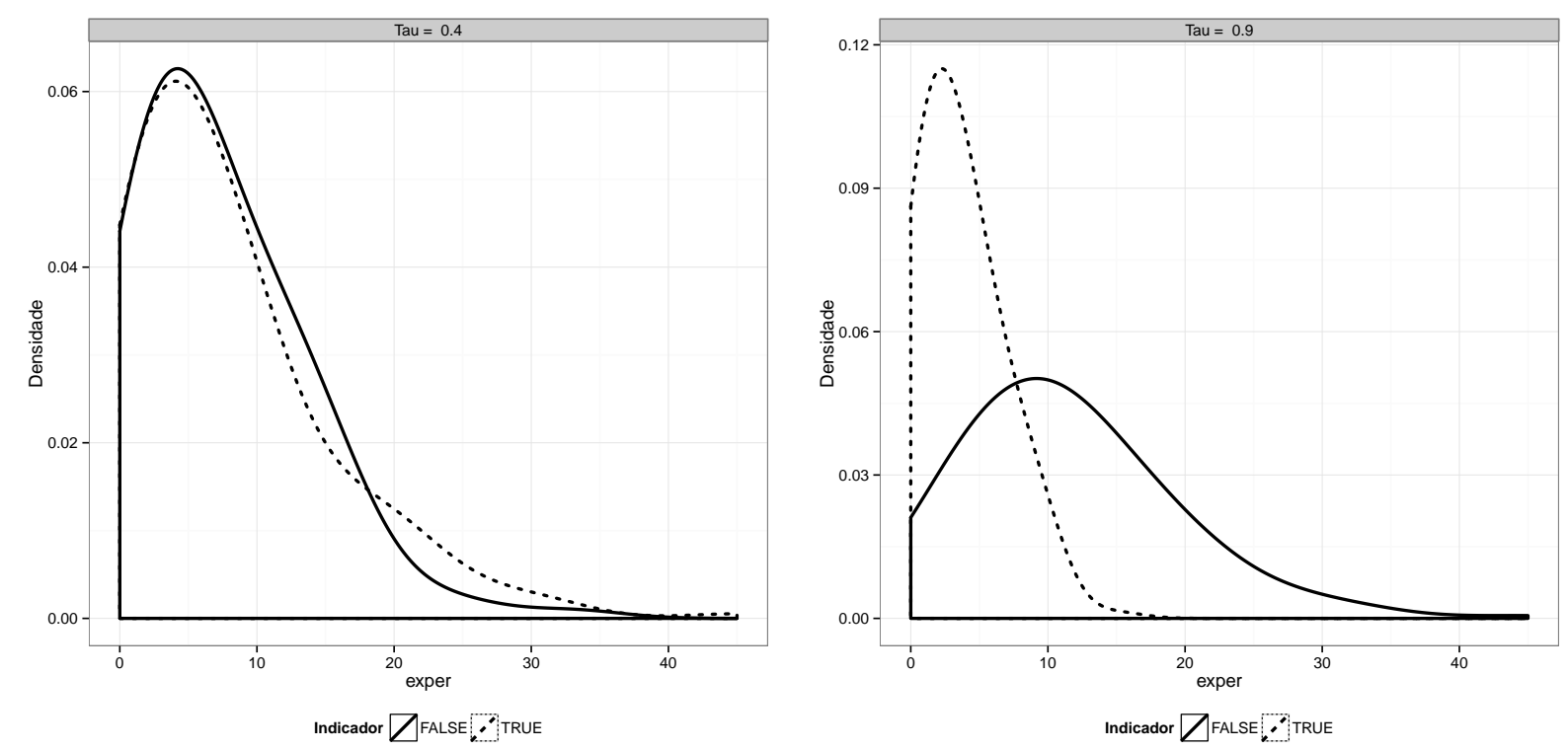

Figura 4.7: Densidade da variável $x_{3}$ separando por dois grupos de acordo com as respectivas probabilidade de censura em comparação com a probabilidade média em um dado quantil, para $\tau=0,5$ e $\tau=0,9$. As linhas sólidas são para o grupo acima da probabilidade média, enquanto as linhas pontilhadas são referentes ao grupo abaixo da probabilidade média.

\subsubsection{Gastos com bens duráveis no Brasil}

Uma segunda ilustração é apresentada aqui para o modelo proposto nesse capítulo usando dados sobre gastos com bens duráveis no Brasil, obtidos na "Pesquisa de Orçamentos Familiares (POF)“, que foi feita entre 2008 e 2009 e é uma pesquisa nacional que entrevistou mais de 50000 domicílios pelo país e está disponível em http://www.ibge.gov.br/home/ estatistica/populacao/condicaodevida/pof/2008_2009_encaa/microdados.shtm. Devido a limitações computacionais, já que no algoritmo MCMC a variável $v_{i}$ precisa amostrar em cada ponto da amostra, foram selecionados somente os dados do Estado do Maranhão, para preservar de alguma maneira o complexo plano amostral e também porque os dados desse estado apresentavam certa semelhança com os dados do país todo. Após fazer essa seleção, foram obtidas 2240 observações, das quais 1062 não tiveram nenhum gasto com bens duráveis no período.

Como covariáveis foram incluídas: gênero $\left(x_{1}: 0=\right.$ masculino, $1=$ feminino $)$, raça $\left(x_{2} 0\right.$ : branco, 1: não-brancos), idade em anos $\left(x_{3}\right)$, anos de educação $\left(x_{4}\right)$, uma variável indicadora sobre posse de cartão de crédito $\left(x_{5}: 0=\right.$ não, $\left.1=\operatorname{sim}\right)$. De forma similar à aplicação 


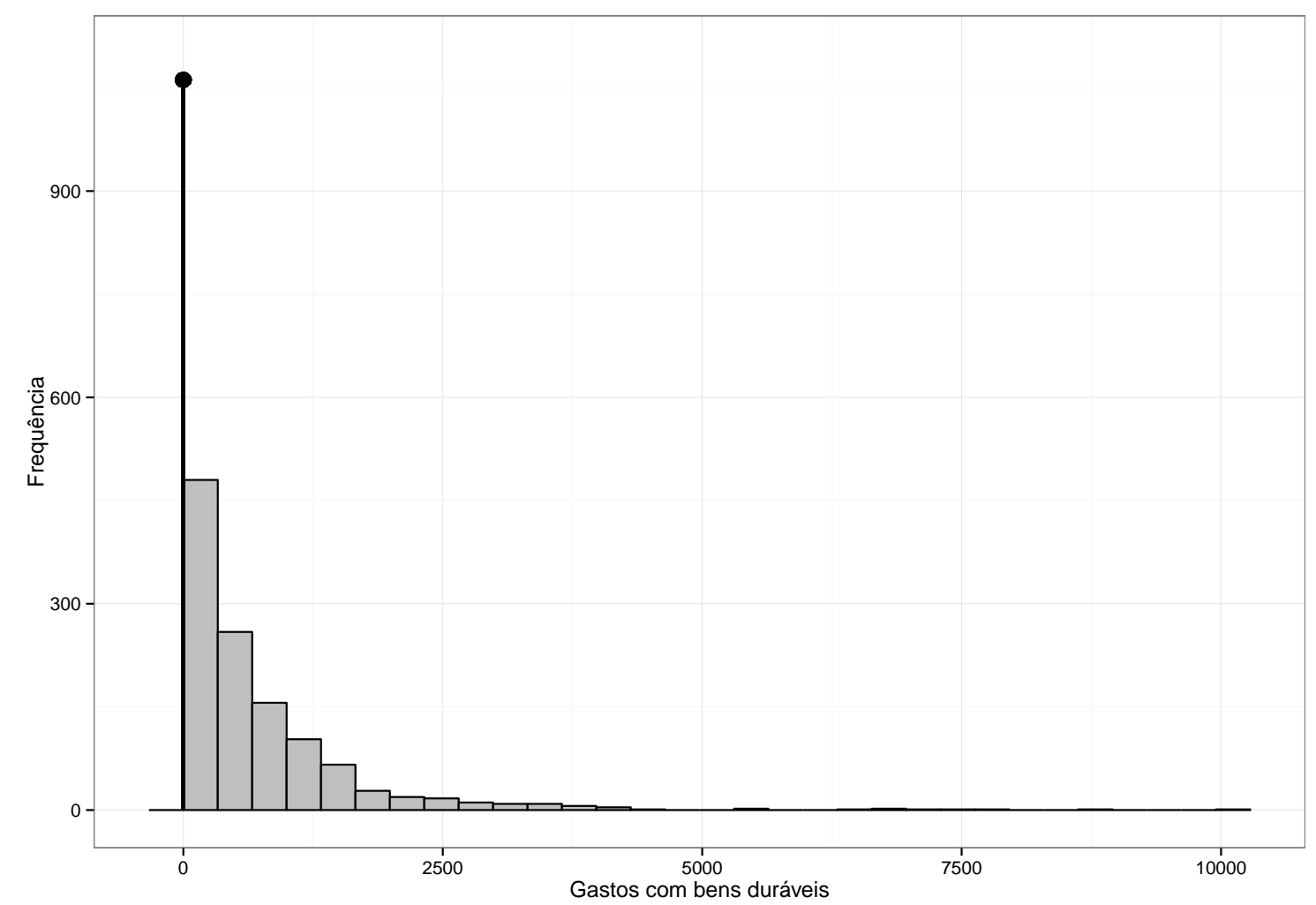

Figura 4.8: Distribuição de gastos com bens duráveis no Brasil com dados da POF, com uma massa pontual no zero, em reais.

anterior, foi utilizado um modelo logístico para analisar a probabilidade da resposta ser igual a zero, em que foram adicionadas todas variáveis e um intercepto. Também, todas variáveis foram incluídas para explicar a parte contínua do modelo. Decidiu-se por modelar a variável resposta transformada, com $\sqrt{Y}$, ao invés de $Y$ devido ao ganho de informação que foi obtido com essa transformação, já que antes de fazê-la, na análise para maiores quantis, todas as observações iguais a zero estavam sendo consideradas censuradas. Ainda que essa peculiaridade não tenha sido completamente corrigida depois da transformação, já que isso continua sendo ainda verificado nos resultados, há uma melhoria significativa usando a raiz quadrada dos gastos com bens duráveis. Logo, os seguintes modelos são considerados.

$$
\begin{aligned}
\log \left(\frac{p_{i}}{1-p_{i}}\right) & =\gamma_{0}+\gamma_{1} x_{i 1}+\gamma_{2} x_{i 2}+\gamma_{3} x_{i 3}+\gamma_{4} x_{i 4}+\gamma_{5} x_{i 5} \\
Q_{\sqrt{Y_{i}}}\left(\tau \mid x_{i}\right) & =\beta_{0}+\beta_{1} x_{i 1}+\beta_{2} x_{i 2}+\beta_{3} x_{i 3}+\beta_{4} x_{i 4}+\beta_{5} x_{i 5}
\end{aligned}
$$


Tabela 4.1: Estimativas da média a posteriori e intervalos de credibilidade com 90\% para $\gamma$ no modelo 4.8, para $\tau=0,50$

\begin{tabular}{lcc}
\hline Variável & Estimativa & Intervalo de credibilidade \\
Intercepto & $-2,14$ & {$[-2,88 ;-1,49]$} \\
Gênero & 0,02 & {$[-0,16 ; 0,18]$} \\
Raça & 0,16 & {$[-0,05 ; 0,36]$} \\
Idade & 0,08 & {$[-0,02 ; 0,18]$} \\
Educação & $-0,12$ & {$[-0,23 ;-0,01]$} \\
Cartão de crédito & 0,79 & {$[0,50 ; 1,09]$} \\
\hline \hline
\end{tabular}
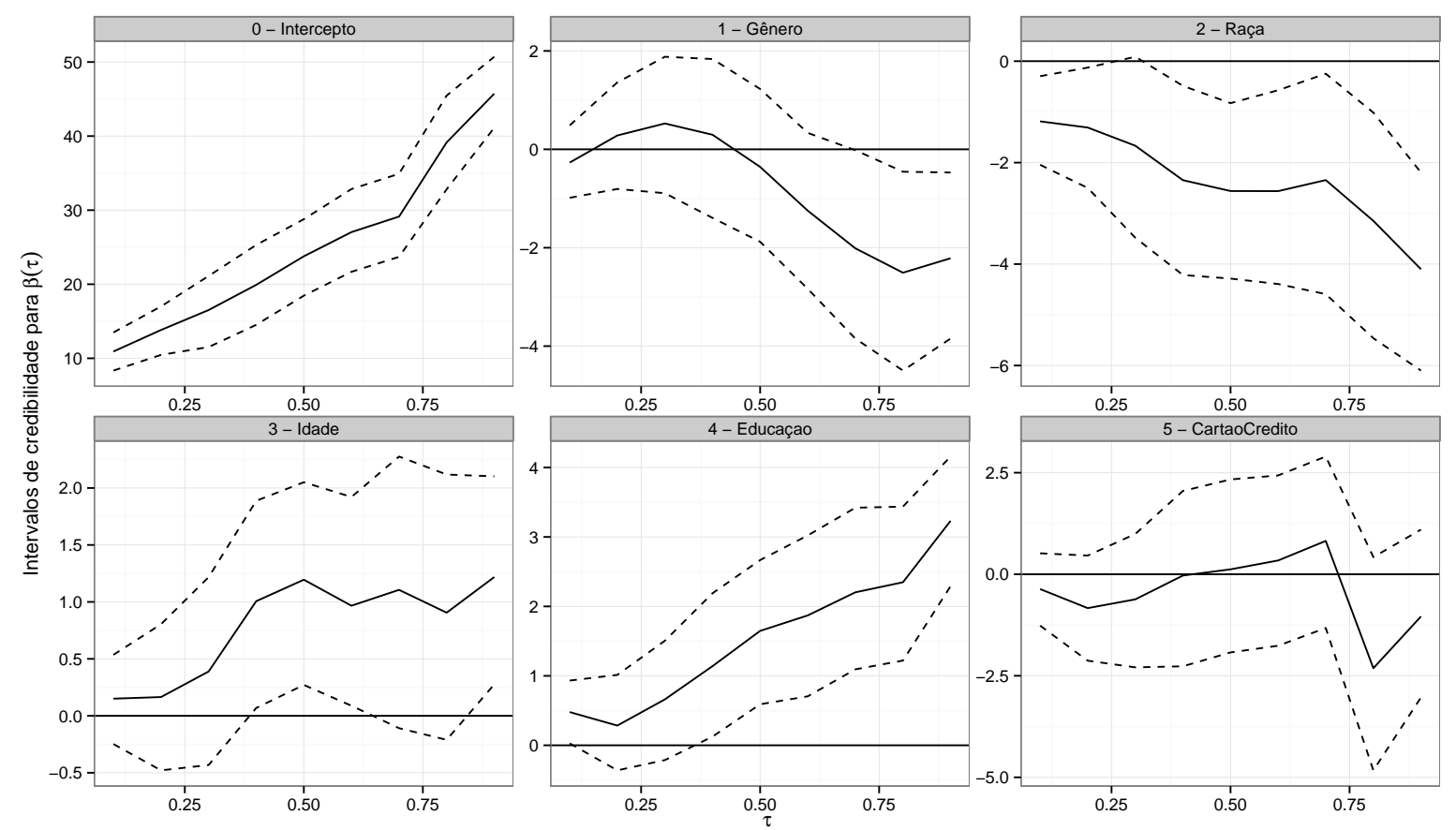

Figura 4.9: Estimativas da média a posteriori e intervalos de credibilidade de 90\% para $\beta(\tau)$

As conclusões do ajuste do modelo estão baseadas após gerar 50000 amostras do MCMC, das quais foram descartadas as primeiras 10000 observações, e em seguida foi selecionado um valor da amostra a cada 40 sorteios. Para obter as estimativas a posteriori, foi calculada a média a posteriori para cada parâmetro. Usando essas estimativas, como na Tabela 4.1 para o modelo da probabilidade $p_{i}$, é possível ver que as únicas variáveis significativas dados os seus intervalos de credibilidade são a variável indicadora de cartão de crédito e anos de educação, em que o primeiro tem um efeito negativo na probabilidade dos gastos serem iguais a zero, e o segundo tem efeito positivo, quando $\tau=0,50$. Em comparação, é estimado que as chances de ter zero gastos com bens duráveis em um certo período para uma pessoa que não tem cartão de crédito é 2,2 vezes as chances de uma pessoa com cartão de crédito. 
As estimativas da média a posteriori para a parte contínua são apresentadas na Figura 4.9. Usando os modelos de regressão quantílica, é possível checar que algumas variáveis têm efeito significativo somente em algumas partes da distribuição condicional da variável resposta. Nesse exemplo, vê-se que a diferença entre homens e mulheres é significante apenas na cauda superior, quando $\tau=0,80$ e $\tau=0,90$, com um efeito negativo nesse caso. De forma similar, as estimativas para anos de educação e raça são significantes para $\tau>0,30$, em que educação tem um efeito positivo nos gastos, e a variável raça é estimada ter um efeito negativo.

De forma análoga à aplicação anterior, também é possível comparar a probabilidade de uma observação ser considerada censurada para diferentes variáveis preditoras. Para $\tau=$ 0, 50, na Figura 4.10(a), a probabilidade da observação ser censurada é definitivamente maior para pessoas com cartão de crédito. Além disso, é possível analisar essa informação para outros quantis também. Como se nota na Figura 4.10(b), variando $\tau$ entre 0,1 e 0,7, é possível constatar que, em geral, as probabilidades para o grupo com cartão de crédito tem um aumento muito mais rápido quando se aumentam os quantis.

Não são apresentados os resultados para $\tau=0,8$ e $\tau=0,9$, porque a adição desses quantis dificultava a comparação entre os dois grupos, dado que para esses quantis a maior parte das observações é considerada censurada quando sua resposta é zero. Isso acontece devido ao peso que $F(0)$ tem no cálculo da probabilidade de uma observação ser censurada. Esse fator na probabilidade depende da escala dos dados e essa é a razão pela qual foi utilizada a transformação com a raiz quadrada antes de iniciar o ajuste do modelo. Deve-se lembrar que na aplicação anterior não foi necessária tal transformação. Deve-se notar novamente que para modelos de regressão quantílica a propriedade de equivariância da função quantílica permite que a modelagem seja feita na variável resposta transformada e que os quantis condicionais na escala original podem ser recuperados a partir do inverso da transformação utilizada, desde que essa função utilizada seja monótona.

Ainda sobre essa questão da maioria das observações serem consideradas censuradas num determinado quantil, para o modelo de duas partes há um pequeno problema quando isso acontece. Em particular, a inferência sobre o parâmetro $\gamma$ se diminui apenas à informação 


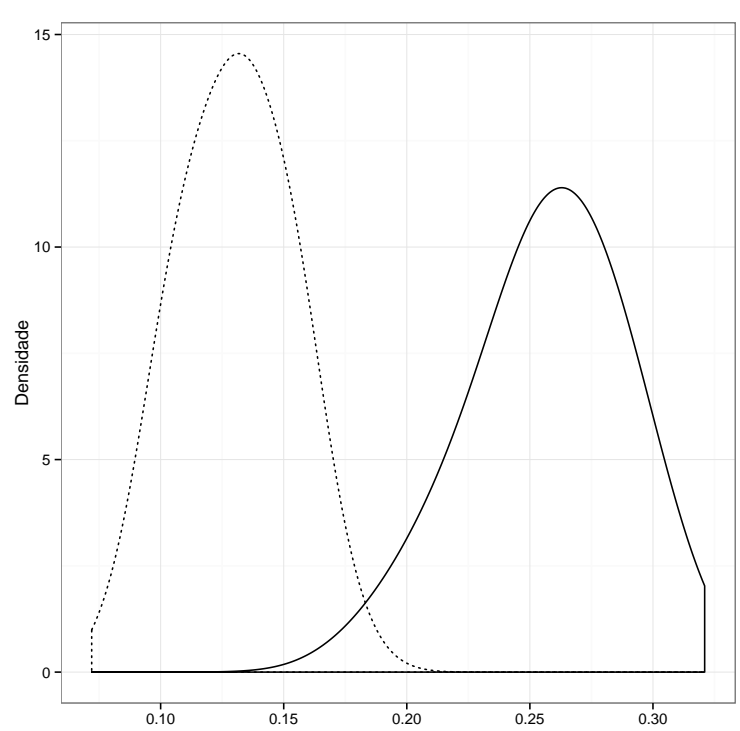

(a)

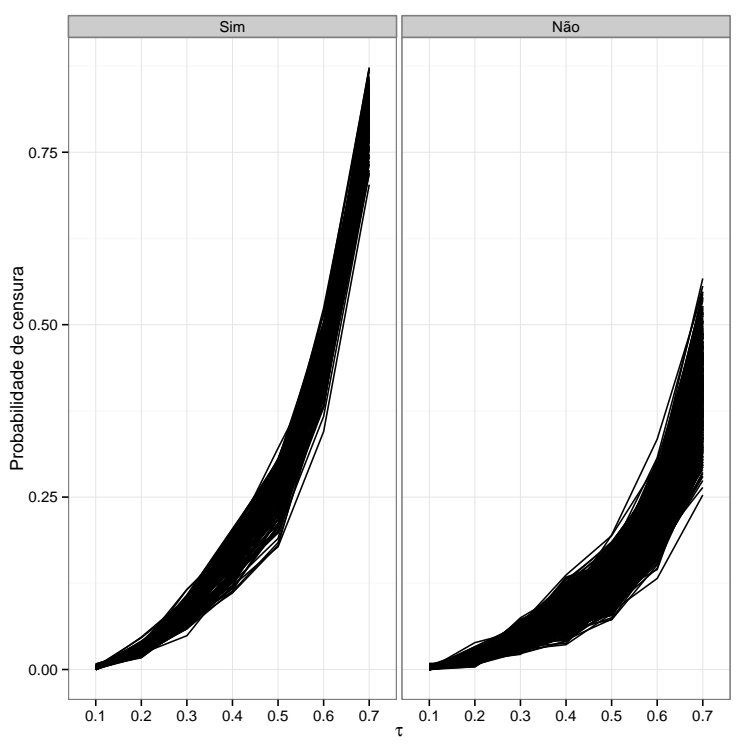

(b)

Figura 4.10: Comparações para as probabilidades das observações serem censuradas dada a variável indicadora Cartão de Crédito. (a) Densidades estimadas para $\tau=0,5$, sim $=$ linha sólida, $n \tilde{a} o=$ linha pontilhada. (b) Perfis da probabilidades para $\tau=0,1,0,2, \ldots, 0,7$.

a priori, uma vez que não há dados suficientes para atualizar o conhecimento sobre o parâmetro a posteriori. Nesse exemplo, outras transformações foram consideradas, porém a transformação com a raiz quadrada foi selecionada exatamente para que se fosse enfatizada essa característica desses modelos, e que isso sempre deve ser levado em consideração.

\subsection{Considerações finais}

Nesse capítulo, uma extensão do modelo de regressão quantílica Tobit bayesiano foi proposto para incluir a probabilidade de uma resposta igual a zero ser censurada, ao invés de considerar todas as observações censuradas desde o início, usando a distribuição Laplace assimétrica na verossimilhança para analisar os quantis condicionais da parte contínua do modelo. Foi utilizado um modelo de duas partes para estudar a probabilidade de $Y=0$, assumindo uma massa pontual no zero, e também utilizando um preditor linear para estudar os quantis condicionais para a variável resposta.

Foi mostrado como a probabilidade de uma observação ser censurada no modelo proposto 
é dependente do quantil de interesse, produzindo mais informação sobre se uma observação deve ser considerada realmente como censurada, por exemplo, comparando os perfis das probabilidades de diferentes observações e checando a sua variação para maiores ou menores $\tau$ 's. Em comparação com o método proposto por Moulton e Halsey (1995), em que a probabilidade não depende do quantil, no modelo sugerido é possível que essa probabilidade varie de acordo com os dados de interesse. Aqui $p$, a probabilidade de $Y=0$, deve ser interpretada como a proporção dos dados assumida ter sido gerada de uma distribuição degenerada no zero, quando se analisa um certo quantil de interesse.

Dois bancos de dados foram utilizados para ilustrar os métodos propostos. O primeiro, um banco de dados bastante utilizado na literatura de econometria sobre oferta de trabalho feminino, em que foi exposto como a probabilidade de uma observação ser considerada censurada dadas as covariáveis disponíveis afeta o modelo de forma distinta para $\tau$ 's diferentes. O segundo banco de dados tratava de gastos com bens duráveis no Brasil. Novamente, alguns resultados interessantes ficaram evidentes quando foram comparadas as probabilidades de censura para os grupos de pessoas com e sem cartão de crédito. Além disso, é importante mencionar que nosso modelo poderia também ser utilizado na análise de sobrevivência, quando existe a suposição de uma fração de indivíduos curados. Algumas pequenas modificações teriam que ser feitas para alterar a censura à esquerda no zero para censura à direita nesse caso. 


\section{Capítulo 5}

\section{Análise das eleições presidenciais no}

\section{Brasil via regressão quantílica}

\section{bayesiana espacial}

Nesse capítulo, uma extensão dos modelos de regressão quantílica é apresentada quando a resposta é reportada como uma proporção e a suposição de existência de correlação espacial é considerada. O modelo sugerido é ajustado aos dados da última eleição presidencial no Brasil, que ocorreu em 2014 e foi decidida por menos de $2 \%$ dos votos válidos, aproximadamente. Os modelos de regressão quantílica são utilizados para mostrar como variáveis sociodemográficas estão associadas com diferentes quantis na distribuição de votos nessa eleição acirrada. Para ajustar o modelo a esses dados, o processo Laplace assimétrico proposto por Lum e Gelfand (2012) é introduzido para incorporar essa dependência espacial no processo de modelagem. Para bancos de dados com alta dimensão, é sugerido o processo preditivo Laplace assimétrico. Por fim, esses modelos são ajustados aos dados do Estado de São Paulo para ilustração do método. 


\subsection{Introdução}

Como apresentado nos capítulos anteriores, os modelos de regressão quantílica são muito flexíveis, capazes de serem utilizados em diferentes tipos de análise, e ainda são mais eficazes na descrição da distribuição condicional da variável resposta, tendo em vista que estimam os efeitos em diferentes pontos dessa distribuição. Este método é particularmente mais informativo quando os dados apresentam heterocedasticidade, situação em que os modelos de regressão podem apontar para diferenças nos parâmetros da regressão em diferentes quantis.

Relembrando, para esses modelos assume-se que o quantil de ordem $\tau$ pode ser expressado através do seguinte modelo linear

$$
Q_{Y}(\tau \mid X)=X^{\prime} \beta(\tau)
$$

Conforme discutido nos capítulos anteriores, tal modelo pode ser estimado através do paradigma bayesiano usando a suposição da distribuição Laplace assimétrica. Diversas extensões desses modelos podem ser encontradas na literatura e algumas já foram citadas nos capítulos anteriores. Apenas para complementar, Waldmann e Kneib (2015) propuseram o uso desses modelos para respostas bivariadas. E Kneib (2012) discute a importância desses modelos no estudo da regressão que busca conhecimento na distribuição condicional além da média.

No Capítulo 2 discutiu-se como a regressão quantílica pode ser utilizada para analisar dados de proporção, se valendo da propriedade de equivariância, que permite modelar a variável resposta transformada e depois recuperar as estimativas dos quantis condicionais na escala original da variável resposta.

Além disso, tendo em vista esses dados de proporção outros trabalhos podem ser citados. Kieschnick e McCullough (2003) apresentam diferentes formas de analisar esse tipo de variável resposta, enquanto que Ferrari e Cribari-Neto (2004) propuseram uma forma direta de modelagem a partir da distribuição beta. Simas et al. (2010) estenderam esses modelos para considerar também uma estrutura não-linear para a média, assim como para o parâmetro 
de dispersão. E Branscum et al. (2007) propuseram uma versão bayesiana do modelo de regressão beta, de forma a evitar os resultados assintóticos utilizados no método frequentista, ao mesmo tempo que possibilita o uso de informação a priori no modelo.

Ademais, no presente capítulo, existe o interesse em especial nos dados da eleição presidenciais no Brasil, em que a presidente reeleita, Dilma Rousseff obteve a maioria do voto popular, mas com uma margem muito pequena. A vitória aconteceu por uma diferença de $2 \%$ dos votos, aproximadamente, e a distribuição dos votos apresenta uma correlação espacial, como pode ser visto na Figura 5.1. Esse resultado apertado aumenta o interesse em questões sobre como certas variáveis podem estar associadas à distribuição condicional dos votos. Nesse sentido, o uso dos modelos de regressão quantílica podem melhorar a qualidade dessa inferência, ao direcionar a análise para determinados quantis.

Na literatura sobre modelos que estudam essa estrutura espacial, pode-se citar o livro de Banerjee et al. (2003), que apresenta uma visão geral desses modelos do ponto de vista de modelos hierárquicos bayesianos, principalmente a partir de processos gaussianos, em que se modela essa correlação espacial através da distribuição normal multivariada. Além disso, Banerjee et al. (2008) propõem modelos espaciais para bancos de dados de alta dimensão, utilizando a esperança condicional de um processo gaussiano. Essa abordagem facilita o tratamento desse tipo de banco de dados, diminuindo o esforço computacional, ao evitar a inversão de matrizes de alta dimensão. No entanto, o foco nesses trabalhos está em descrever médias condicionais através desses modelos de regressão.

Na literatura de modelos de regressão quantílica, Lum e Gelfand (2012) propuseram uma adaptação da representação por mistura da distribuição Laplace assimétrica, para adicionar uma estrutura de correlação na distribuição normal que faz parte dessa representação, introduzindo um modelo de regressão quantílica bayesiano espacial, o qual pode ser útil para ajustar os dados das eleições presidenciais.

Ademais, a discussão feita no Capítulo 3, sobre a possibilidade do uso dos modelos de regressão quantílica para dados de proporção, ajuda a completar os requisitos necessários para analisar esses dados, que são descritos como a proporção de votos para um certo candidato 
por município no Brasil.

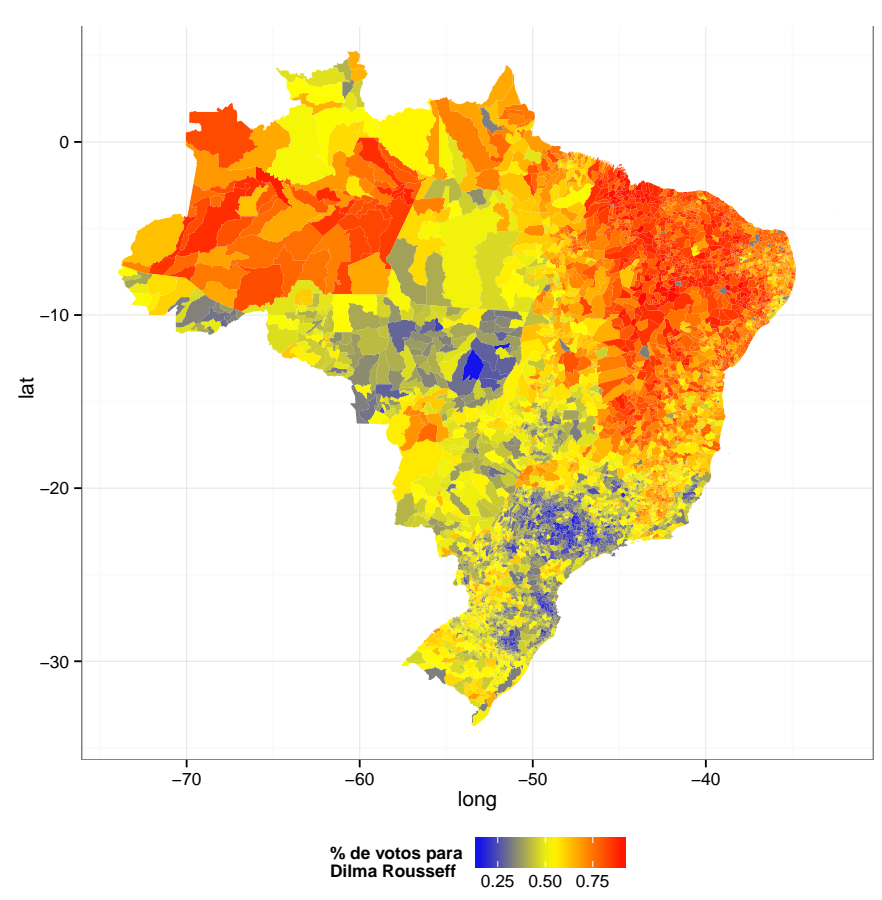

Figura 5.1: Proporção de votos para a presidenta reeleita Dilma Rousseff em cada município do Brasil.

Esse capítulo está organizado da seguinte maneira. Inicialmente, são apresentadas as alterações necessárias para introduzir os modelos de regressão quantílica bayesianos espaciais na Seção 5.2. Seguindo, na Seção 5.3, repassamos as transformações importantes na modelagem de dados de proporção, tendo em vista a propriedade de equivariância, e também os ajustes essenciais para o uso desses modelos em bancos de dados com muitas observações. Continuando, apresentamos a aplicação aos dados da eleição, destacando os principais resultados com o uso dos modelos de regressão quantílica. E por último, finalizamos com alguns comentários na Seção 5.5.

\subsection{Regressão quantílica espacial bayesiana}

Dados com algum tipo de referência espacial podem ter essa informação adicionada ao processo de modelagem, e com isso usualmente aumenta-se a complexidade do modelo. Na abordagem bayesiana, uma possível forma de modelar esse tipo de dados, sendo uma das 
opções mais utilizadas, é considerar um processo gaussiano ${ }^{1}, w(s)$, o qual pode ser definido assim

$$
w(s) \sim G P(0, C(s ; \lambda))
$$

em que se assume que esse processo tem média zero e as covariâncias entre duas observações nas localizações $s$ e $s^{\prime}$ podem ser modeladas pela função $C\left(s, s^{\prime} ; \lambda\right)$, em que $\lambda$ pode ser um vetor com os parâmetros utilizados para definir a função de covariância. De forma resumida, um processo gaussiano é definido como uma função aleatória, em que todas as possíveis distribuições de dimensão finita tem distribuição normal multivariada. No caso dos modelos de regressão espacial como em (5.1), é usual utilizar um processo com média zero, pois esse processo é utilizado como se fosse o erro do modelo de regressão linear simples, mas com essa estrutura espacial.

Conforme discutem Lum e Gelfand (2012), essa estrutura espacial não pode ser simplesmente adicionada no modelo de regressão quantílica, pois a interpretação dos parâmetros $\beta(\tau)$ ficaria prejudicada. Considerando o seguinte modelo linear para a variável resposta, com a localização $s$ incluída para ressaltar a natureza espacial do problema

$$
Y(s)=x(s)^{\prime} \beta(\tau)+\epsilon(s)
$$

em que o erro do modelo $\epsilon(s)$, a partir da representação por mistura da distribuição Laplace assimétrica tem distribuição normal, condicionalmente à variável latente $v$,

$$
\epsilon(s) \mid v \sim N\left(0, \psi^{2} \sigma v\right)
$$

No primeiro uso dessa representação por Kozumi e Kobayashi (2011), esses erros são considerados independentes entre as observações. Entretanto, tendo em vista o processo gaussiano como em (5.1), Lum e Gelfand (2012) perceberam a potencialidade dessa representação para adicionar uma estrutura de correlação entre as observações e ainda estudar os quantis condicionais da variável resposta com os modelos de regressão quantílica. Para isso,

\footnotetext{
${ }^{1}$ A notação considerará GP, de Gaussian process, para usar a mesma notação usualmente utilizada na literatura. Para referências, ver Rasmussen e Williams (2006).
} 
os autores definiram o processo Laplace assimétrico da seguinte forma

$$
\begin{aligned}
Y(s) & =X(s) \beta(\tau)+\epsilon(s), \\
\epsilon(s) & =\theta v(s)+\sqrt{\psi^{2} \sigma v(s)} Z(s), \\
Z(s) & \sim G P(0, C(s ; \lambda)), \\
v(s) & \sim \operatorname{Exp}(\sigma),
\end{aligned}
$$

em que a notação para $\epsilon(s)$ poderia ser $\epsilon(s, \tau)$ pois esse erro depende de $\theta$ e $\psi^{2}$ que são funções de $\tau$, mas optou-se por deixar somente a localização para simplificar a notação. A função exponencial ao quadrado

$$
c\left(s, s^{\prime} ; \lambda\right)=\exp \left\{-\lambda\left\|s-s^{\prime}\right\|^{2}\right\}
$$

pode ser utilizada para explicar modelar essa covariância. Essa função de covariância é interessante pois preserva a variância igual a 1 na diagonal principal da matriz $C(s ; \lambda)$, que é uma condição necessária para obter a distribuição Laplace assimétrica marginalmente, ou seja, em cada localização. Além disso, também é necessário que $v(s) \sim \operatorname{Exp}(\sigma)$ em todas localizações $s$. Lum e Gelfand (2012) discutiram algumas propostas para modelar $v(s)$ também considerando alguma forma de correlação, mas ao fim sugeriram a opção i.i.d., que é utilizada aqui também.

Ainda para modelos de regressão quantílica, Reich et al. (2011) propuseram um modelo espacial, usando bases polinomiais de Bernstein de forma a construir estimativas crescentes para os quantis condicionais.

\subsection{Regressão quantílica bayesiana espacial para dados de proporção}

A partir do interesse na modelagem da análise dos dados das eleições presidenciais no Brasil em 2014 e tendo em vista que a variável resposta é a proporção de votos para a 
presidenta eleita, é necessário discutir as alterações necessárias para adicionar a dependência espacial no modelo. O processo Laplace assimétrico definido na seção anterior é inicialmente direcionado a variáveis contínuas, dado que o suporte da distribuição Laplace assimétrica é R. A fim de contornar esse problema, a propriedade de equivariância da função quantílica que foi provada na Seção 3.2 pode ser utilizada novamente.

De forma breve, relembrando, tomando uma função contínua não-decrescente $h($.$) em \mathbb{R}$, então para qualquer variável aleatória, o seguinte é sempre verdade

$$
Q_{h(Y)}(\tau \mid x)=h\left(Q_{Y}(\tau \mid x)\right)
$$

Então, é possível modelar o quantil de ordem $\tau$ da variável transformada com o seguinte modelo linear,

$$
Q_{h\left(Y_{i}(s)\right)}\left(\tau \mid x_{i}(s)\right)=x_{i}(s)^{\prime} \beta(\tau)
$$

usando a representação espacial para localização $s$ e com a função inversa $h^{-1}$ é possível obter as estimativas dos quantis na escala original. Essa abordagem é a mesma que foi utilizada no Capítulo 3.

Para modelos espaciais, existe o interesse também em interpolar os resultados para localizações não observadas, $s_{0}$, por exemplo. Considerando o objetivo de estimar os quantis condicionais para essa nova localização, o quantil condicional para o erro nessa predição deve ser igual a zero. Condicionalmente nas outras localizações e as informações observadas na amostra, Lum e Gelfand (2012) mostram que

$$
Y\left(s_{0}\right)-x\left(s_{0}\right)^{\prime} \beta(\tau)-m\left(s_{0}\right) \sqrt{\frac{\pi \sigma}{2 \tau(1-\tau)}} \mid \sigma, \beta(\tau), \lambda, Y \sim A L\left(0, \frac{\sigma}{\sigma\left(s_{0}\right)}, \tau\right)
$$


em que

$$
\begin{aligned}
m\left(s_{0}\right) & =c^{\prime}\left(s_{0}, s ; \lambda\right) C^{-1}(s ; \lambda) Z \\
\sigma\left(s_{0}\right) & =1-c^{\prime}\left(s_{0}, s ; \lambda\right) C^{-1}(s ; \lambda) c\left(s_{0}, s ; \lambda\right) \\
Z & =\frac{\epsilon(\tau, s)-\theta v(s)}{\sqrt{\psi^{2} \sigma v(s)}}
\end{aligned}
$$

e $c\left(s_{0}, s ; \lambda\right)$ é o vetor coluna das correlações entre a nova localização $s_{0}$ e todas as outras localizações $s$ usadas para ajustar o modelo. Então, o estimador do quantil de ordem $\tau$ para a variável resposta nessa nova localização $s_{0}$ pode ser escrito como

$$
Q_{Y\left(s_{0}\right)}\left(\tau \mid x\left(s_{0}\right), \epsilon(\tau, s)\right)=x\left(s_{0}\right)^{\prime} \beta(\tau)+Q_{\epsilon\left(\tau, s_{0}\right)}(\tau \mid \epsilon(\tau, s))
$$

em que $Q_{\epsilon\left(\tau, s_{0}\right)}(\tau \mid \epsilon(\tau, s))$ pode ser considerado um interpolador quantílico espacial e é igual a $m\left(s_{0}\right) \sqrt{\frac{\pi \sigma^{2}}{2 \tau(1-\tau)}}$. Esse resultado é obtido integrando para fora $v\left(s_{0}\right)$, a variável latente na nova localização, e tomando que $E(\sqrt{V})=\sqrt{\pi \sigma} / 2$, quando $V \sim \operatorname{Exp}(\sigma)$.

\subsubsection{Ajuste do modelo}

Lum e Gelfand (2012) sugeriram elicitar a distribuição a priori para $\sigma$, o parâmetro de escala, definindo uma variância comum para todos os quantis. Decidiu-se por não considerar tal sugestão, tendo em vista a discussão do Capítulo 2, em que foi possível ver que a distribuição a posteriori de $\sigma$ se adapta a essa variância dos dados de forma automática. Para $\sigma$ então assumiu-se uma distribuição gama inversa a priori, com hiperparâmetros iguais a 3/2 e 0.005 .

Para $\beta(\tau)$ foi utilizada a distribuição normal novamente, já que mesmo adicionando a estrutura de correlação não há perda da conjugação com a verossimilhança.

A atualização a posteriori para a variável latente é feita notando que a distribuição posteriori de $v_{i}$ é proporcional a

$$
v_{i}^{-1 / 2} \exp \left\{-\frac{1}{2 \sigma \psi^{2}} u^{t} D(\sqrt{v}) C^{-1} D(\sqrt{v}) u-\frac{v_{i}}{\sigma}\right\}
$$


em que $u$ é um vetor $n \times 1$, com cada termo igual desse vetor igual a

$$
u_{i}=Y_{i}-x_{i}^{\prime} \beta(\tau)-\theta v_{i}
$$

e $D(\sqrt{v})$ é uma matriz diagonal com valores iguais a $\sqrt{v(s)}$. Para gerar valores da distribuição a posteriori dessas variáveis latentes, optou-se por utilizar um algoritmo de Metropolis com múltiplas tentativas ${ }^{2}$, proposto por Liu et al. (2000).

Sobre a função de covariância exponencial ao quadrado com parâmetro de decaimento $\lambda$, Lum e Gelfand (2012) sugerem adicionar um parâmetro $\alpha \in(0,1)$ da seguinte maneira

$$
c\left(s_{i}, s_{j} ; \lambda, \alpha\right)=(1-\alpha) \exp \left\{-\lambda\left\|s_{i}-s_{j}\right\|^{2}\right\}+\alpha \mathbb{I}(i=j),
$$

em que $\lambda>0$ e $\alpha$ é introduzido como um erro puro, ou seja, que não é devido a dependência espacial, porém que é limitado ao intervalo $(0,1)$ para manter a representação por mistura da distribuição Laplace assimétrica. Se esse parâmetro é incorporado ao modelo, então pode se utilizar uma distribuição uniforme a priori para $\alpha$. E a sua atualização a posteriori pode ser feita a partir de um passo Metropolis-Hastings, por exemplo, usando como proposta a distribuição beta, com parâmetro de precisão escolhido de forma a obter uma taxa de aceitação razoável e com média igual ao valor atual da cadeia.

Para $\lambda$, conforme sugerido por Lum e Gelfand (2012) é feita uma discretização do espaço paramétrico, considerando somente valores possíveis para esse parâmetro tendo em vista a variação dos dados.

Os detalhes das distribuições a posteriori dos outros parâmetros são similares àqueles apresentados na Seção 2.2, por isso não serão apresentados novamente. O artigo de Lum e Gelfand (2012) e a tese de Lum (2010) em que foi baseado o artigo também podem ser consultados para maiores informações. A rotina para ajuste desses modelos também está exemplificada no apêndice.

\footnotetext{
${ }^{2}$ Do inglês, Multiple-try Metropolis.
} 


\subsubsection{Processo Preditivo Laplace assimétrico}

O banco de dados para o qual existe o interesse em usar os modelos de regressão quantílica espacial é composto por mais de 5000 observações, quando considerados os votos disponíveis para todas as cidades do Brasil. Esse tipo de dados com essa quantidade enorme de observações espaciais torna impraticável o uso tanto dos processos gaussianos assim como do processo Laplace assimétrico, uma vez que em cada passo do MCMC é necessário inverter a matriz de covariância, com o custo computacional $O\left(n^{3}\right)$. E como esse processo é repetido uma grande quantidade de vezes, utilizar esse modelo se torna inviável.

Na literatura de processos gaussianos, Banerjee et al. (2008) propuseram uma modificação do processo gaussiano de forma a permitir o seu uso para bancos de dados de alta dimensão, a qual foi denominada de processo preditivo gaussiano. De forme resumida, os autores sugeriram condicionar o processo em apenas alguns pontos, chamados de nós, e utilizar a esperança condicional dado o processo nesses pontos, por isso foi chamado de processo preditivo. O mesmo conceito foi adaptado para os modelos de regressão quantílica por Lum e Gelfand (2012), produzindo o processo preditivo Laplace assimétrico (PPLA).

Para definir o PPLA, é necessário redefinir $\epsilon(s)$ como

$$
\begin{aligned}
\ddot{\epsilon}(s) & =\theta v(s)+\sqrt{\psi^{2} \sigma v(s)} \ddot{Z}(s) \\
\ddot{Z}(s) & =\ddot{w}(s)+\delta(s) \\
\ddot{w}(s) & =\tilde{w}(s)+\tilde{\delta}(s) \\
\tilde{w}(s) & =E\left(Z(s) \mid Z^{*}\right)=c^{t}\left(s, s^{*} ; \lambda\right) C^{*^{-1}} Z^{*} \\
Z^{*} & \sim N_{m}\left(0,(1-\alpha) C\left(s^{*}, s^{*^{\prime}} ; \lambda\right)\right) \\
\tilde{\delta}(s) & \sim N(0, \ddot{\sigma}(s)) \\
\ddot{\delta}(s) & =(1-\alpha)\left(c(s, s ; \lambda)-c^{t}\left(s, s^{*} ; \lambda\right) C^{*^{-1}} c\left(s, s^{*} ; \lambda\right)\right) \\
\delta(s) & \sim N(0, \alpha),
\end{aligned}
$$

em que $\tilde{w}(s)$ é o processo preditivo condicional a observação do processo em um conjunto de nós $s^{*}$ e $\tilde{\delta}(s)$ é adicionado para corrigir a subestimação da variância do processo original, 
conforme apresenta Finley et al. (2009).

Se for tomado que

$$
\ddot{\epsilon}(s) \sim N\left(\theta v(s), \psi^{2} \sigma D(\sqrt{v}) \Sigma_{\xi} D(\sqrt{v})\right)
$$

em que

$$
\Sigma_{\xi}=(1-\alpha) c^{t}\left(s, s^{*} ; \lambda\right) C^{*^{-1}} c\left(s, s^{*} ; \lambda\right)+D(\alpha+\ddot{\delta}(s))
$$

e $D(\alpha+\ddot{\delta}(s))$ é uma matriz diagonal. Para a inversão da matriz $\Sigma_{\xi}$ necessário no cálculo da verossimilhança, é possível utilizar a fórmula de Sherman-Morrison-Woodbury (Harville, 1997) para inversão de matrizes que afirma que

$$
(A+U W V)^{-1}=A^{-1}-A^{-1} U\left(W^{-1}+V A^{-1} U\right)^{-1} V A^{-1} .
$$

No caso da relação em $(5.2), A=D(\alpha+\ddot{\delta}(s))$, uma matriz diagonal que é facilmente invertida, $W=(1-\alpha) C^{*^{-1}}$ e $U=c^{t}\left(s, s^{*} ; \lambda\right)=V^{t}$. Dessa forma, evita-se inverter uma matriz com dimensão $n$ para fazer a inversão somente de uma matriz de dimensão $m$, que é a quantidade de nós escolhidos, e de uma matriz diagonal de dimensão $n$.

Outra quantidade de interesse no cálculo da verossimilhança é o determinante da matriz de covariância, que também pode ser simplificado considerando a forma da matriz $\Sigma_{\xi}$. Esse determinante então pode ser escrito como

$$
\operatorname{det}\left(\Sigma_{\xi}\right)=\frac{\operatorname{det}(D(\alpha+\ddot{\delta}(s)))}{\operatorname{det}\left(C^{*}\right)} \operatorname{det}\left(C^{*}+c(\lambda) D(\alpha+\ddot{\delta}(s))^{-1} c^{t}(\lambda)\right)
$$

\subsection{Eleição presidencial no Brasil}

Para aplicação desses modelos de regressão quantílica bayesiana espacial para dados de proporção, foram selecionados os dados das últimas eleições presidenciais no Brasil, que ocorreu no ano de 2014. Nesse ano em particular, no segundo turno, quando somente os dois candidatos finais, Dilma Rousseff e Aécio Neves permaneciam na disputa, o resultado final 
foi relativamente próximo dada a quantidade de pessoas que votaram.

A Figura 5.1 mostra o resultado para a proporção de votos para a presidenta reeleita Dilma Rousseff em cada município do Brasil. Os dados foram obtidos em http://www.tse. jus.br/eleicoes/estatisticas/repositorio-de-dados-eleitorais. É possível perceber que a presidenta obteve uma maior proporção de votos no Nordeste e Norte. E que há, de fato, uma dependência espacial entre os municípios. Tais características sugerem que um modelo de regressão quantílica espacial pode obter estimativas mais verossímeis na análise do que o modelo que deixa de considerar essa dependência espacial.

Como covariáveis para ajudar na explicação do modelo foram utilizadas variáveis do Censo de 2010, assim como algumas outras informações complementares, como valores pagos pelo programa federal de transferência de renda, chamado Bolsa- Família. Os dados desse programa social estão disponíveis em www.bolsafamilia.datasus.gov.br. Os dados do Censo de 2010 foram retirados de http://www.atlasbrasil.org.br/2013/pt/download. Porém, todas essas informações foram agrupadas e podem ser encontradas no pacote do $\mathrm{R}$ que foi implementado durante essa tese. No apêndice, é apresentado como fazer para acessar esses dados.

Apesar da apresentação do modelo preditivo na seção anterior, optou-se aqui por utilizar somente os dados do Estado de São Paulo, devido ao enorme tempo de computação para utilizar todos os dados na estimação dos parâmetros. Deve-se lembrar que para cada variável latente é necessário gerar valores da distribuição a posteriori em cada iteração do MCMC, o que deixa o procedimento bastante custoso computacionalmente. Porém, nos dados de São Paulo também é possível perceber a enorme correlação entre os municípios. Por esse motivo, o modelo de regressão quantílica espacial continua sendo ideal para a análise. Os dados somente do Estado de São Paulo podem ser vistos na Figura 5.2. É possível notar que na região central do Estado há uma concentração maior de votos para o candidato derrotado Aécio Neves, enquanto que nos arredores do Estado há um maior agrupamento de cidades com quantidade maior de votos para a candidata Dilma Rousseff. 


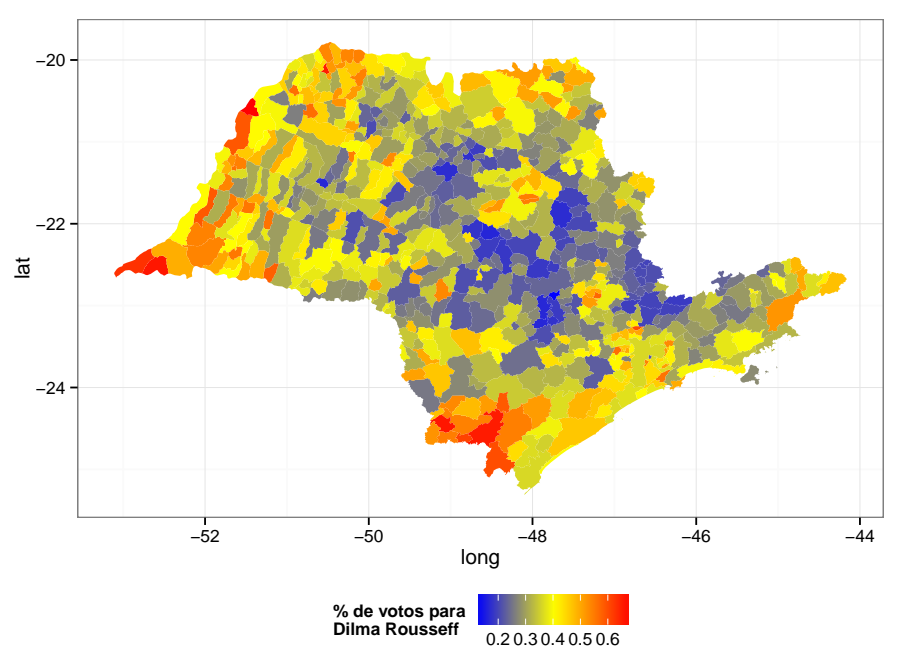

Figura 5.2: Proporção de votos para a presidenta reeleita Dilma Rousseff em cada município do Estado de São Paulo.

O seguinte modelo foi proposto para estudar a proporção de votos

$$
Q_{h(y)}(\tau \mid x)=\beta_{0}(\tau)+\beta_{1}(\tau) x_{1}+\beta_{2}(\tau) x_{2}+\beta_{3}(\tau) x_{3}+\beta_{4}(\tau) x_{4}+\beta_{5}(\tau) x_{5}
$$

em que $x_{1}$ é o índice de desenvolvimento humano (IDHM), $x_{2}$ é a média dos anos de estudo (E_ANOSESTUDO), $x_{3}$ é variação de Gini entre os anos 2000 e 2010 (GINI_DELTA), $x_{4}$ é a variação da renda per capita entre os anos de 2000 e 2010 (RDPC_DELTA), e $x_{5}$ é o valor médio recebido em média por cada família cadastrada no programa Bolsa Família. As distribuições de algumas dessas variáveis estão apresentadas na Figura 5.4

Para obtenção das estimativas foram geradas cadeias de tamanho 10000 para cada parâmetro do modelo. Em seguida, foram descartadas as primeiras 1000 observações para propósitos de aquecimento e depois foram consideradas os valores geradas a cada 9 iterações, em que foram obtidas 1000 amostras das distribuições a posteriori para análise. Para essa aplicação, o parâmetro $\alpha$ não foi adicionado ao modelo. As estimativas dos parâmetros da regressão quantílica podem ser observadas na Figura 5.5, em que foi calculada a média da distribuição a posteriori de cada parâmetro.

Para o parâmetro $\lambda$, utilizou-se uma discretização do espaço paramétrico para melhoria 


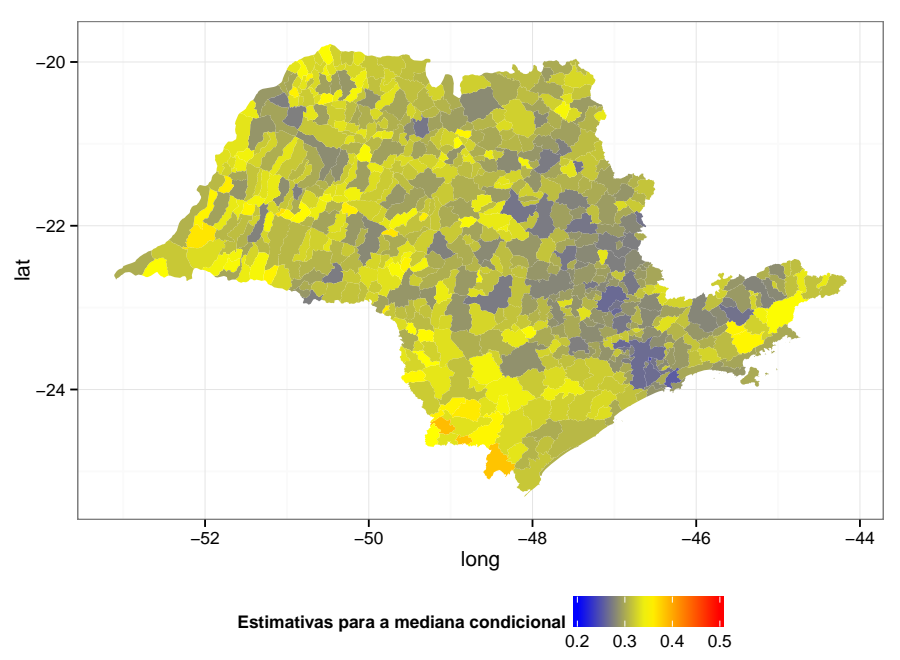

Figura 5.3: Estimativa da mediana condicional da proporção de votos para a candidata Dilma Rousseff, segundo o modelo de regressão quantílica espacial bayesiano ajustado.

no algoritmo MCMC, conforme sugerido por Lum e Gelfand (2012). E os valores obtidos a posteriori para esse parâmetro mostram maiores valores nas caudas da distribuição condicional. O que indicaria menor correlação entre as observações para maiores e menores quantis.

Analisando os resultados da Figura 5.5, é possível diferenciar as estimativas obtidas a partir do modelo bayesiano que não considera a dependência espacial e aquele em que foi adicionada essa informação ao processo de modelagem. Em particular, as estimativas pontuais para os dois modelos não se diferem de maneira tão grande. Contudo, os intervalos de credibilidade apresentam discrepâncias maiores, em que o modelo espacial aponta maior incerteza sobre os parâmetros, com intervalos de credibilidade mais largos, em especial, para os quantis mais próximos das caudas.

Com relação aos coeficientes estimados, não houve diferença nas conclusões para os coeficientes associados à variável IDH, em que para todos os quantis o coeficiente é negativo e significante dado o intervalo de credibilidade estimado. Todavia, para as variáveis RDPC_DELTA, GINI_DELTA e E_ANOSESTUDO houve diferença nos resultados quando comparadas as duas abordagens. Para a primeira variável, o modelo com independência su- 

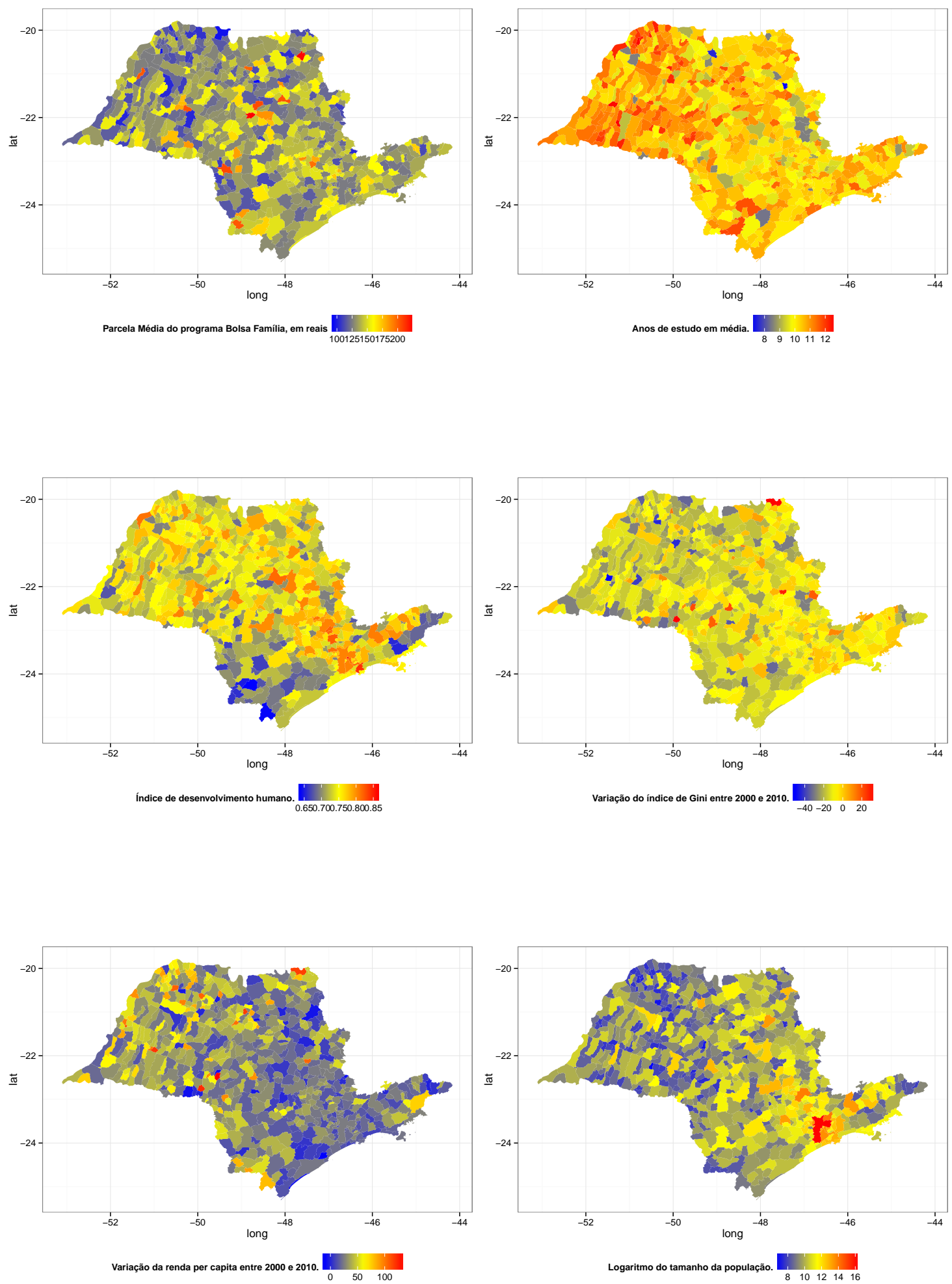

Figura 5.4: Distribuição das variáveis explicativas do modelo e também do tamanho da população nos municípios do Estado de São Paulo. 

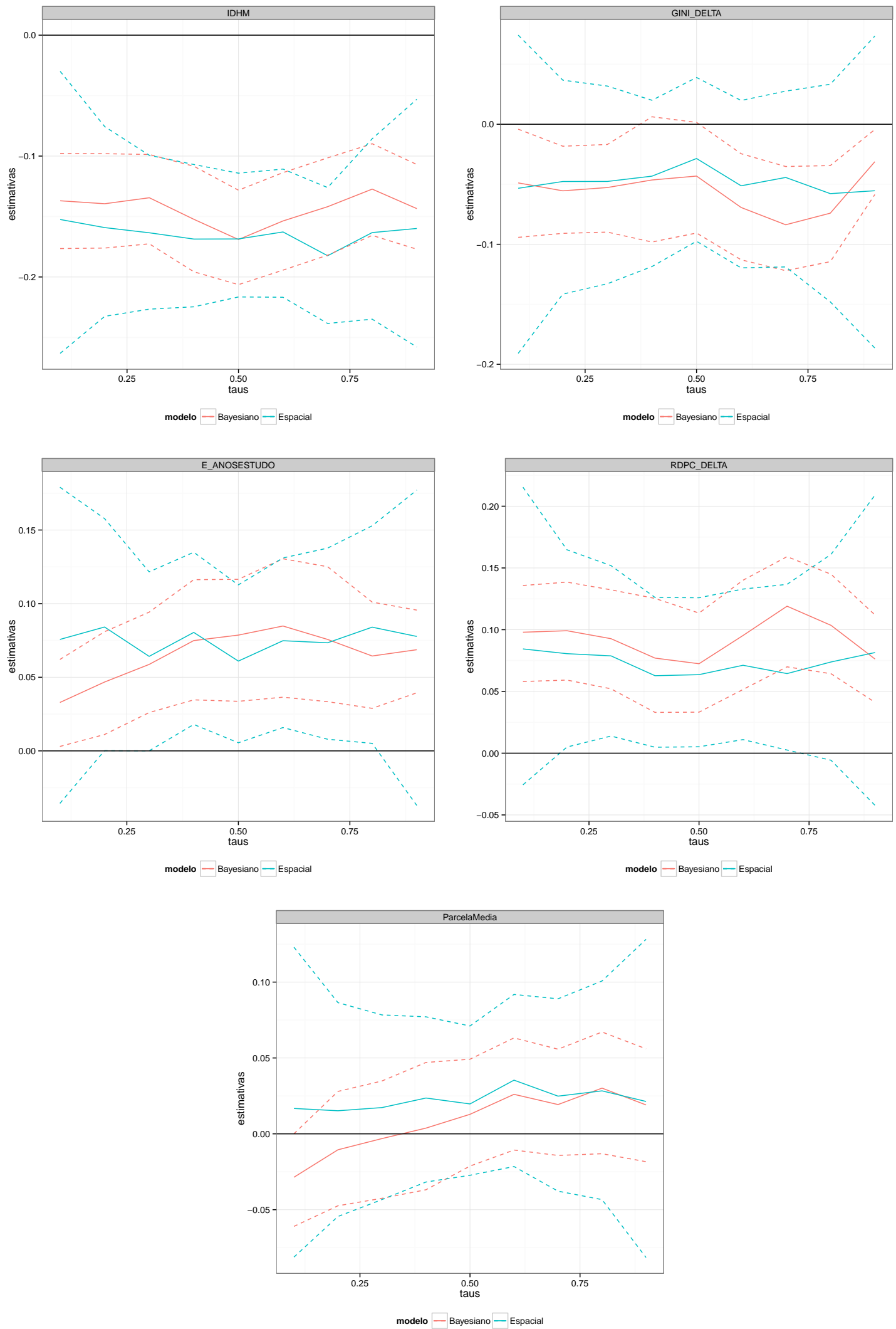

Figura 5.5: Estimativas pontuais e intervalares considerando o modelo de regressão quantílica bayesiano com dependência espacial e sem dependência espacial. Intervalos de credibilidade de $90 \%$. 
gere que o coeficiente do modelo associado a essa variável é sempre positivo e significante, enquanto que no modelo espacial somente os quantis centrais seriam considerados significantes. Situação semelhante ocorre com a variável anos de estudo, em que também os coeficientes são estimados significantes somente nos quantis centrais, devido a maior incerteza nas caudas. E para a variável GINI_DELTA, o modelo bayesiano com suposição de independência estima o efeito dessa variável para alguns quantis, principalmente mais próximos da cauda superior, sendo positivo e significante. Porém, para o modelo espacial não é possível obter essa mesma conclusão, uma vez que nenhum intervalo de credibilidade deixou de conter o zero. Para a variável sobre o programa federal Bolsa Família, não houve diferença nas conclusões, já que ambos os modelos estimam que essa variável não teve influência na variação da proporção de votos obtida pela candidata Dilma Rousseff.

Interpretando o significado dos sinais obtidos na estimação dos modelos e apresentados na Figura 5.5, pode se dizer que o índice de IDH teve efeito negativo na proporção de votos, de forma que aqueles municípios com maior IDH apresentaram menor proporção de votos. Além disso, a variável que mede a variação da renda per capita entre os anos de 2000 e 2010 teve um efeito positivo na proporção de votos, mostrando que quanto maior a melhoria nesse índice maior a quantidade de votos. E para a variável anos de estudo, o efeito dessa variável é positivo, denotando que quanto maior o número médio de anos de estudo da população do município maior a proporção de votos para a candidata vencedora nesse pleito.

Ademais, conforme já discutido anteriormente, a propriedade da equivariância da função quantílica permite que transformações sejam utilizadas para modelar a variável resposta. E usando o inverso da função utilizada na transformação é possível obter as estimativas do modelo para os diferentes quantis na escala original. Para o exemplo das eleições presidenciais, a Figura 5.3 apresenta as estimativas da proporção de votos para a mediana condicional da proporção de votos para a candidata Dilma Rousseff. Em média, a mediana condicional foi calculada em 0,352, valor próximo do valor real observado nos municípios do Estado de São Paulo igual a 0,346.

Ainda sobre essa análise dos dados das eleições presidenciais, é evidente que existe o interesse dessa mesma análise para os dados de todo o Brasil, para comparação e análise 
das variáveis que tiveram mais relação com a vitória de uma e com a derrota do outro candidato. Considerando esse modelo de regressão quantílica será possível avaliar o efeito dessas variáveis nos diferentes quantis e identificar relações que só poderiam ser verificadas propondo modelos que vão além da média condicional. Tais resultados não foram adicionados aqui nessa tese devido ao tempo de processamento, que, mesmo utilizando o processo preditivo, ainda precisa de muito tempo para obtenção das cadeias do algoritmo MCMC proposto. Porém, para futura publicação dessa aplicação, pretende-se que sejam apresentados os resultados para todo o Brasil.

\subsection{Discussão}

Nesse capítulo, foi acentuado o potencial dos modelos de regressão quantílica, em que, com o objetivo de estudar as variáveis que poderiam estar associadas com a proporção de votos para a presidente eleita nas eleições de 2014, pode-se verificar a variação dos parâmetros do modelo ao longo de diferentes quantis. Mais uma vez, esses modelos demonstram sua importância, já que buscam avaliar não somente uma posição central na distribuição condicional, mas sim diversos pontos dessa distribuição, construindo no processo uma visão mais completa dessas relações. Em particular, para esse banco de dados, o modelo de regressão quantílica espacial apresentou maior incerteza sobre os parâmetros em comparação com o modelo que supõe independência.

De forma geral, a abordagem bayesiana se mostrou importante em sua flexibilidade de assumir a distribuição Laplace assimétrica na verossimilhança, com a adição das correlações entre as localizações podendo ser facilmente incorporada no processo de modelagem. A propriedade de equivariância novamente foi relevante em permitir modelar essa proporção de votos a partir da distribuição Laplace assimétrica. Além disso, o processo preditivo foi essencial para ajustar o modelo para esse banco de dados com muitas observações espaciais. 


\section{Capítulo 6}

\section{Conclusão e estudos futuros}

\subsection{Considerações finais}

Conforme pode ser verificado nessa tese, os modelos de regressão quantílica servem a diferentes tipos de problemas, dependendo do limite de variação da variável resposta e de suposições que possam ser feitas acerca desta. Além disso, usando a abordagem bayesiana a distribuição Laplace assimétrica se mostrou capaz de se ser utilizada para aproximar os quantis condicionais de variáveis resposta em diversos cenários. É importante sempre checar as suposições do modelo e avaliar se é necessária alguma transformação nos dados. Porém, a partir da propriedade de equivariância da função quantílica verificou-se que é possível modelar a variável transformada e ainda observar as estimativas na escala original dessa variável de interesse.

Nessa tese, foram estudados alguns aspectos da inferência bayesiana nessa classe de modelos. Primeiramente, utilizando da representação por misturas da distribuição Laplace assimétrica, em que uma variável latente é adicionada no processo de modelagem, foi proposto o estudo da distribuição a posteriori dessa variável com a finalidade de identificar prováveis observações aberrantes, ou aquelas que se distanciam das demais, de acordo com a explicação do modelo. Essa proposta foi aplicada em um banco de dados sobre índices de Gini nos Estados brasileiros, medidos nos últimos três censos, em que foi possível identificar algumas 
observações como outliers.

Considerando dados de proporção, foi proposto também a utilização de modelos de regressão quantílica bayesianos, considerando inclusive a possibilidade de uma quantidade não desprezível de observações exatamente iguais a zero ou um. Um algoritmo MCMC foi discutido nesse caso e uma aplicação com dados sobre proporção de domicílios com acesso à eletricidade foi utilizado para ilustrar a inferência utilizando esses modelos.

Nessa tese, também foram propostos modelos de regressão quantílica para dados contínuos com um componente discreto em zero, em que parte dessas observações é considerada censurada e a outra parte é dita pertencer a uma massa pontual no zero. A aplicação desse modelo em dados sobre gastos com bens duráveis no Brasil apresentou resultados muito interessantes, tendo em vista a inferência sobre a possibilidade de censura nos diferentes quantis.

Por último, a aplicação desses modelos de regressão quantílica no banco de dados sobre eleições presidenciais no Brasil, reforça a facilidade com que esses modelos podem ser adaptados para diferentes cenários. Nesse caso, foi apresentado como a dependência espacial pode ser adicionada ao processo de modelagem, a partir do processo Laplace assimétrica. Nessa tese foi feita uma revisão desses modelos, apresentando as mudanças que devem ser consideradas para dados de proporção.

Para todos os modelos desenvolvidos, foi construído um pacote estatístico baquantreg, que está descrito no apêndice, com exemplos de todas as análises feitas aqui nessa tese. Em especial, esse pacote permite a estimação de modelos de regressão quantílica espaciais, que são de enorme interesse na literatura e para o qual não havia software disponibilizado para sua estimação.

\subsection{Trabalhos futuros}

Alguns estudos podem ser considerados para análise futura, tendo em vista os modelos apresentados nessa tese: 
- para todos os modelos sugeridos nessa tese, em especial o modelo em que a massa pontual no zero pode tanto pertencer à distribuição contínua quanto à distribuição discreta no zero, podem ser estudados métodos de seleção de variáveis ou de seleção de modelos. Em particular, os métodos utilizando a priori-potência (Alhamzawi e Yu, 2012; Chen et al., 2000; Ibrahim e Chen, 2003) poderiam ser sugeridos;

- para todos os modelos propostos, poderia ser adicionado um componente não-linear, de forma a enriquecer a explicação dos quantis condicionais da variável resposta;

- as proposições de modelos de regressão quantílica, com modelos semi- paramétricos ou não-paramétricos, têm crescido na literatura e uma análise interessante seria uma comparação entre essas duas abordagens, com apontamento de limitações e vantagens de cada uns dos métodos;

- algumas medidas de influência poderiam ser estudadas para esse modelo, de forma a complementar as medidas propostas aqui nessa tese.

- outras distribuições de probabilidades, além da distribuição Laplace assimétrica podem ser consideradas para os modelos propostos, com o intuito de construir modelos mais robustos. (ver Wichitaksorn et al., 2014). 


\section{Apêndice A}

\section{Manual sobre pacote baquantreg}

Inicialmente, para instalar o pacote desenvolvido com todos os programas da tese, é necessário instalar o pacote devtools que possibilita a instalação do código a partir do Github.

library (devtools)

Em seguida, o pacote pode ser instalado a partir do seguinte comando.

install_github ("brsantos/baquantreg")

Um comentário é importante aqui para mencionar que o pacote foi testado e instalado somente em máquinas Linux. Embora seja possível que o conjunto de comandos funcione no Windows não foi feito nenhum teste nesse sistema operacional.

O pacote deve ser carregado para que todas as funções e todos os bancos de dados estejam disponíveis. E para acessar o manual para obter mais informações sobre os dados disponíveis e parâmetros que controlam o ajuste dos modelos, deve-se fazer

library (baquantreg)

help (package = "baquantreg")

Dessa forma, todos os processos de estimação propostos aqui nessa tese ficam disponíveis. Inclusive todos os bancos de dados também podem ser reutilizados para outras análises. Por exemplo, para carregar os dados estudados no segundo capítulo sobre índices de Gini nos estados brasileiros pode-se utilizar o seguinte comando 
data("Brazilgini")

E para obter mais informações sobre os dados, com descrição de cada campo, basta fazer ?Brazilgini

\section{Capítulo 2}

O ajuste do modelo de regressão quantílica usual pode ser feito com os seguintes comandos

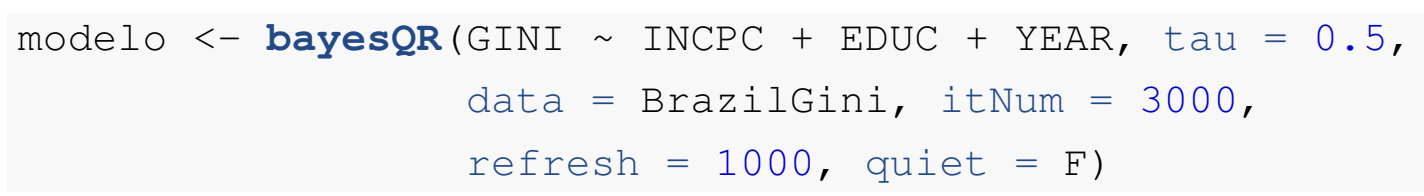

E também é possível ajustar o modelo considerando mais quantis e sem imprimir mensagens para acompanhar o andamento do MCMC.

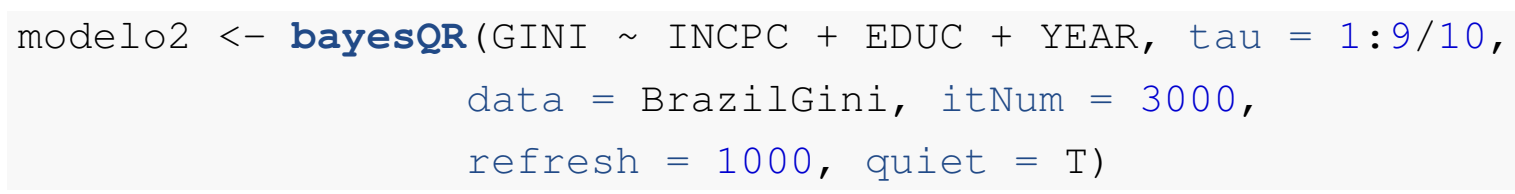

Para saber mais detalhes da função, e como alterar alguns argumentos, é só fazer ?bayesQR

E para obter um resumo do modelo, pode se utilizar a função summary:

resumo <- summary (modelo2)

Para fazer o gráfico com as estimativas e o respectivo intervalo de credibilidade, plot (resumo)

Para fazer o gráfico das estimativas a posteriori de $\sigma$ 


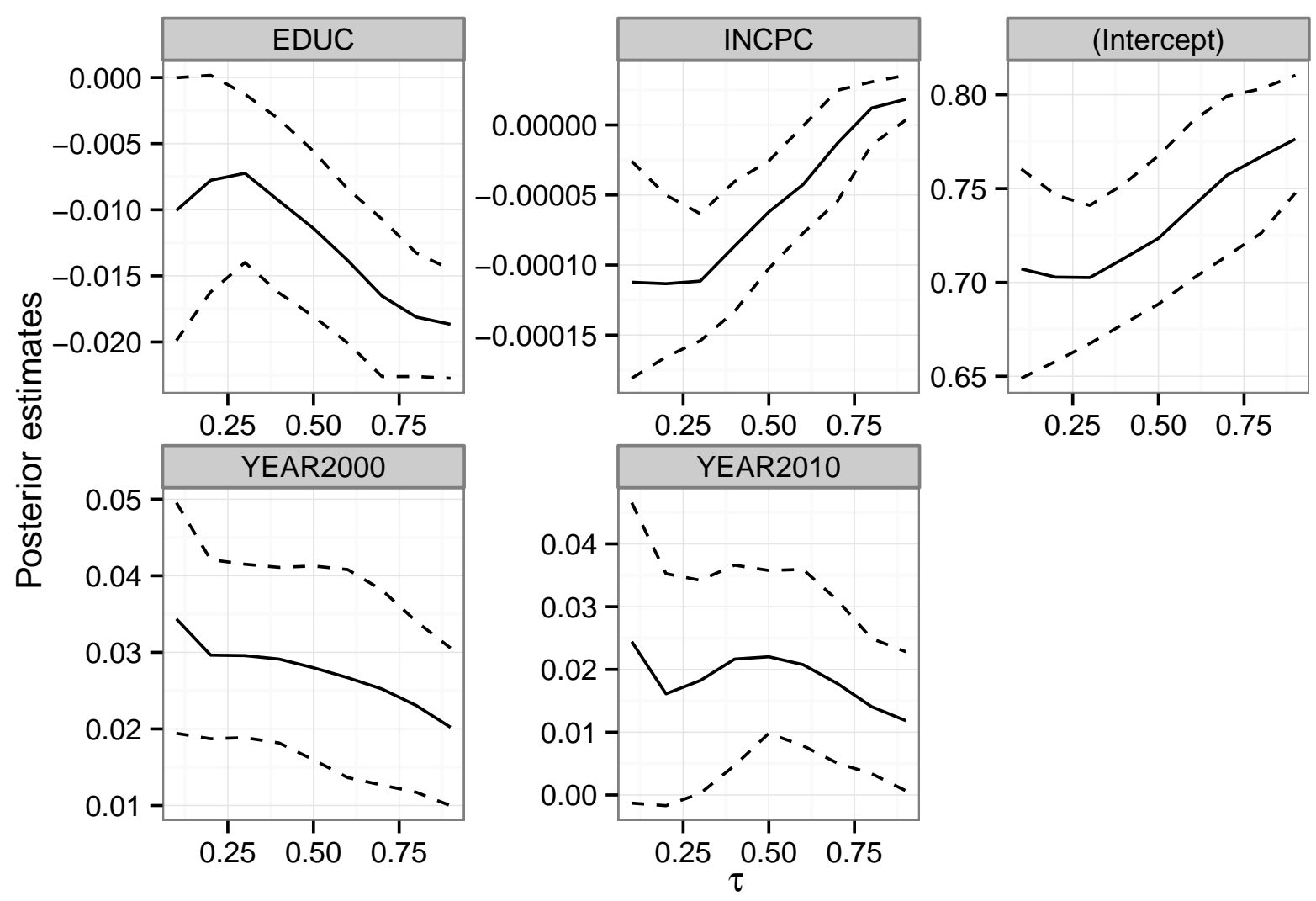

Figura A.1: Gráfico com o sumário dos parâmetros da regressão quantílica

plot (resumo, sigma $=$ TRUE)

Os gráficos da probabilidade a posteriori de cada observação ser um outlier podem ser feitos com os seguintes comandos

dadosProb <- proboutlier (modelo2, burnin = 500)

\#\# [1] "The observation with greater mean probability is: 81"

O gráfico similar, porém usando a divergência de Kullback-Leibler pode ser obtido fazendo

dadosKL <- latentKL (modelo2, burnin = 500)

\#\# [1] "The observation with greater Kullback-Leibler divergence from the o

Para visualizar as trajetórias das cadeias das variáveis latentes, para verificar se alguma variável possa estar distante das outras, o seguinte comando pode ser utilizado 


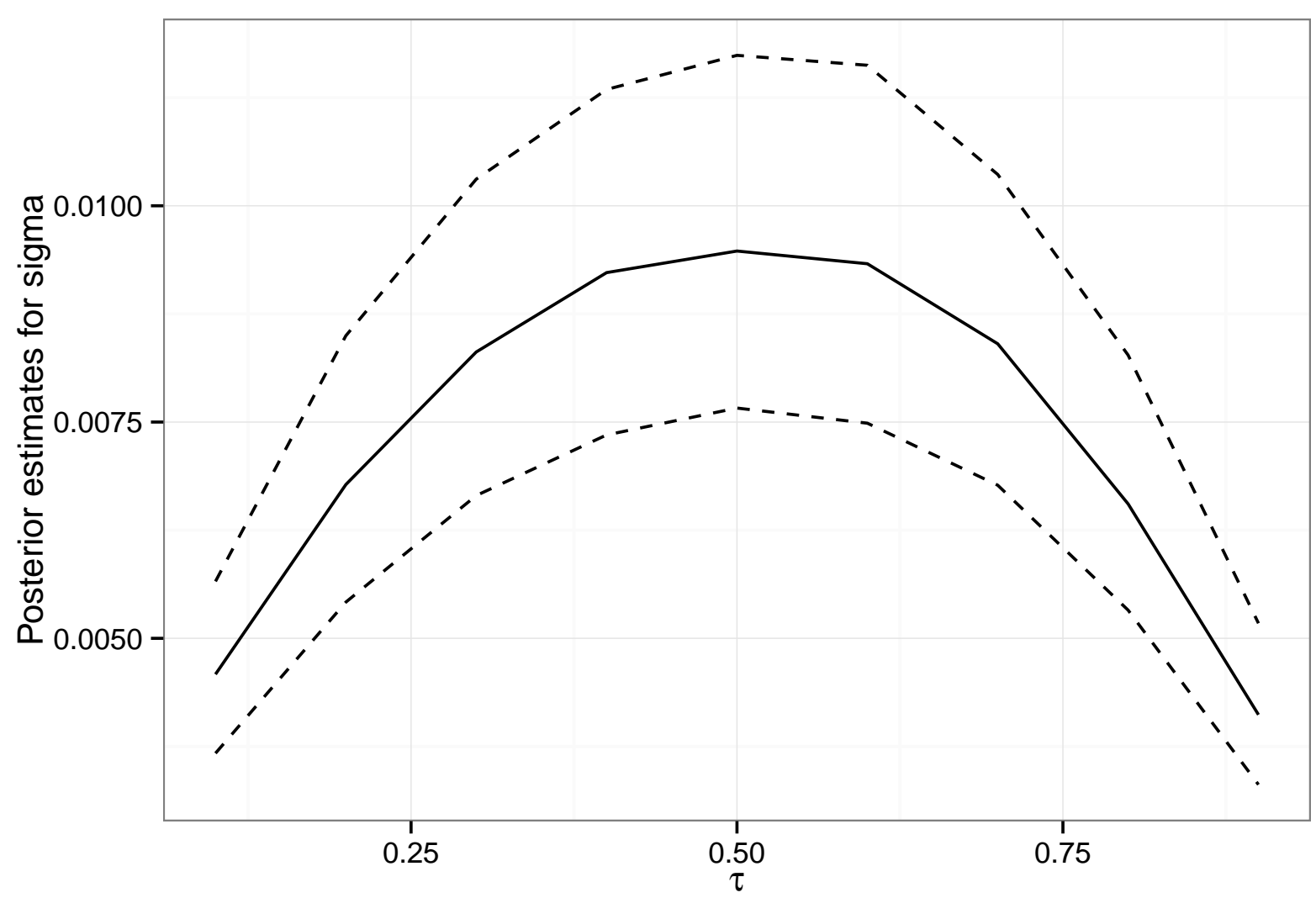

Figura A.2: Gráfico com as estimativas a posteriori para sigma

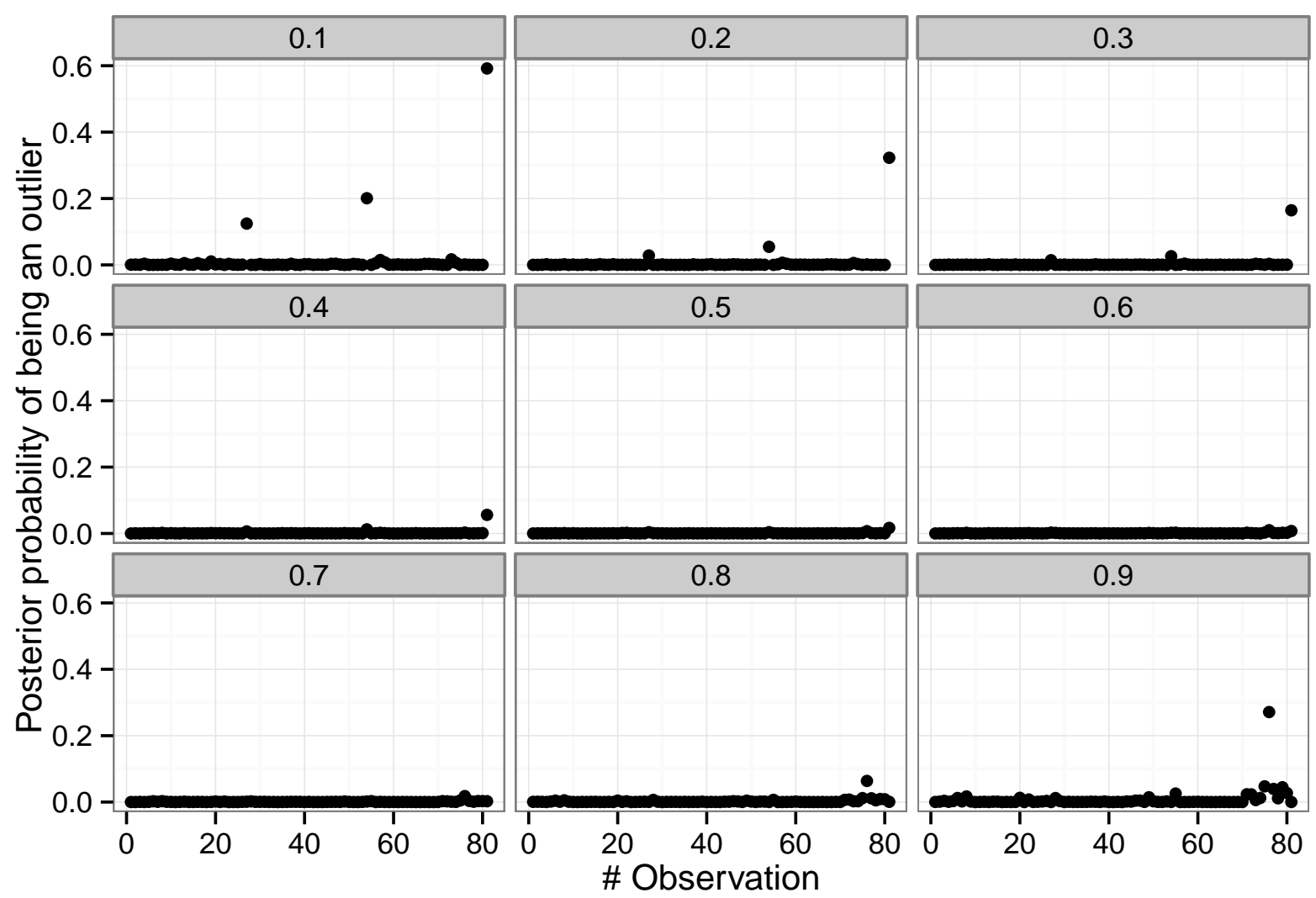

Figura A.3: Gráfico com as probabilidades de uma observação ser outlier a posteriori 


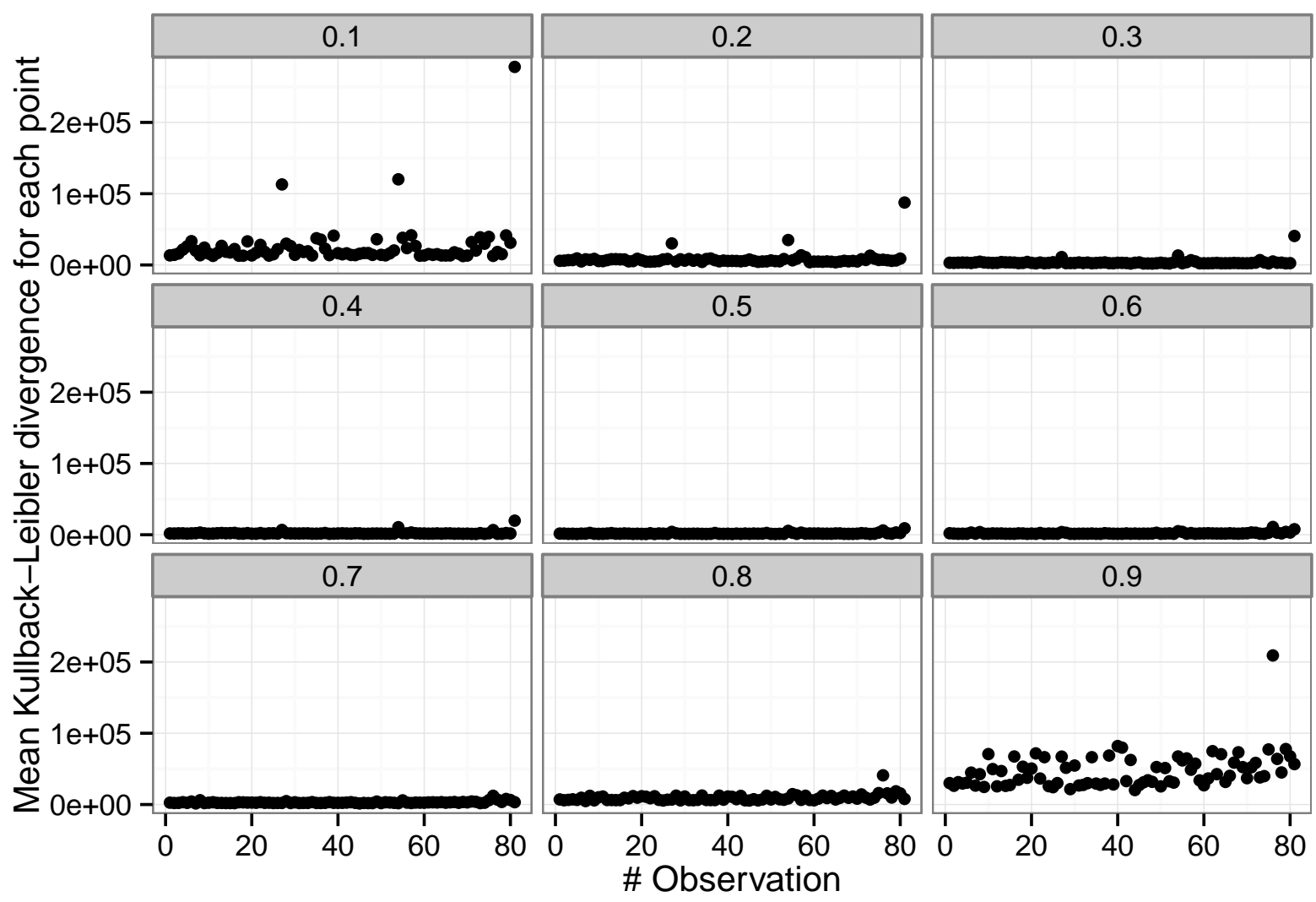

Figura A.4: Gráfico da divergência de Kullback-Leibler para observações aberrantes

plotvfit (modelo, burnin = 1000)

Porém, nesse gráfico não é possível diferenciar as diferentes variáveis latentes de forma satisfatória. Se o interesse é comparar as cadeias das diferentes variáveis latentes, então podemos utilizar a densidade da distribuição a posteriori de uma variável e contrastar com o resumo de todas as outras variáveis, com a seguinte função

dadosComp <- plotComparison(modelo, observation $=50$, plotComp $=\mathrm{T}$ )

Se o usuário verificar que as cadeias geradas ainda não alcançaram a distribuição estacionária, então é possível aumentar o tamanho da cadeia a partir do modelo gerado, fazendo modelo $<-$ update $($ modelo, itNum $=200$ )

\section{Capítulo 3}

Os dados de acesso a energia elétrica estão disponíveis no pacote. Para carregá-los na área de trabalho, basta fazer 


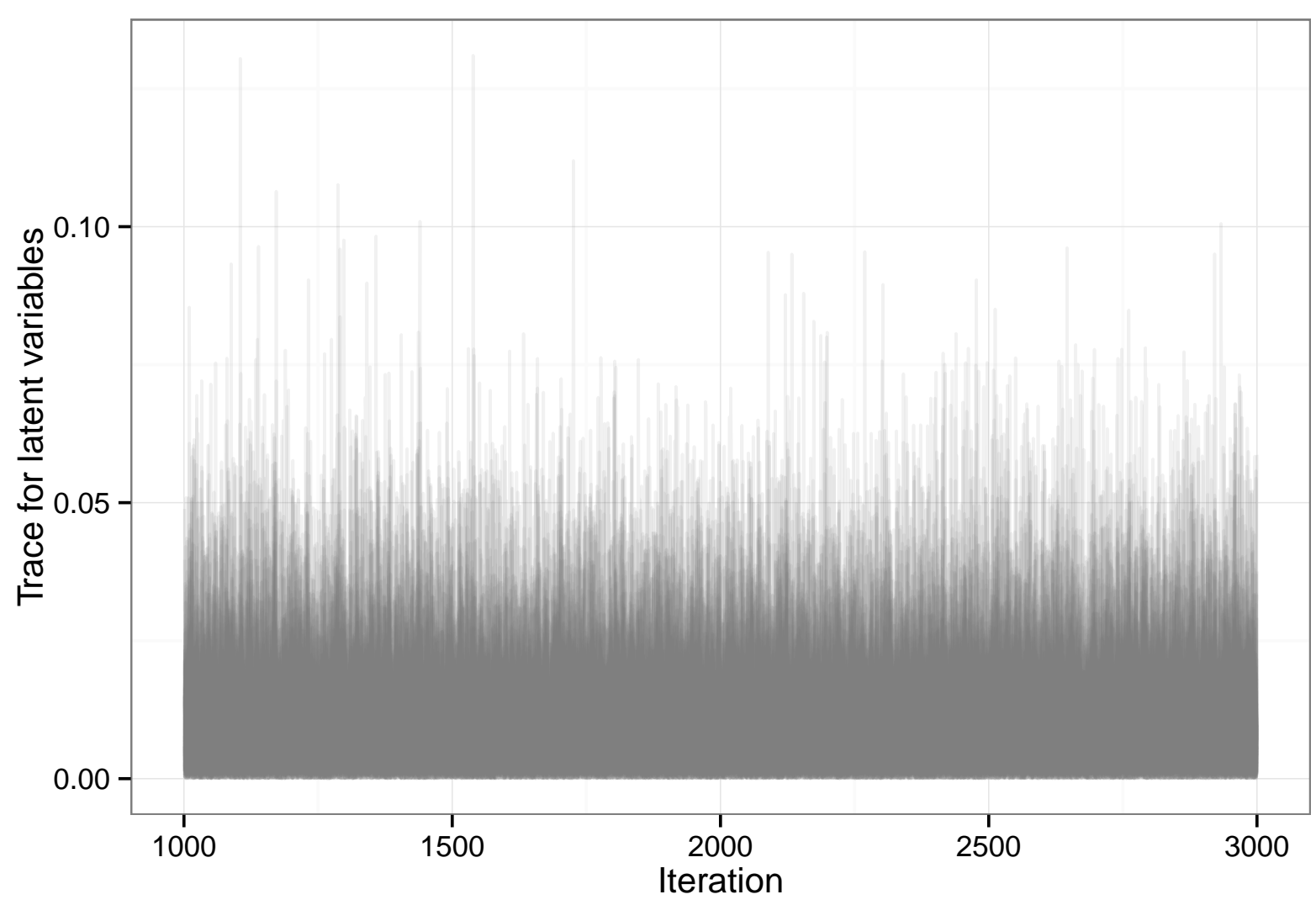

Figura A.5: Gráfico da cadeias das variáveis latentes.

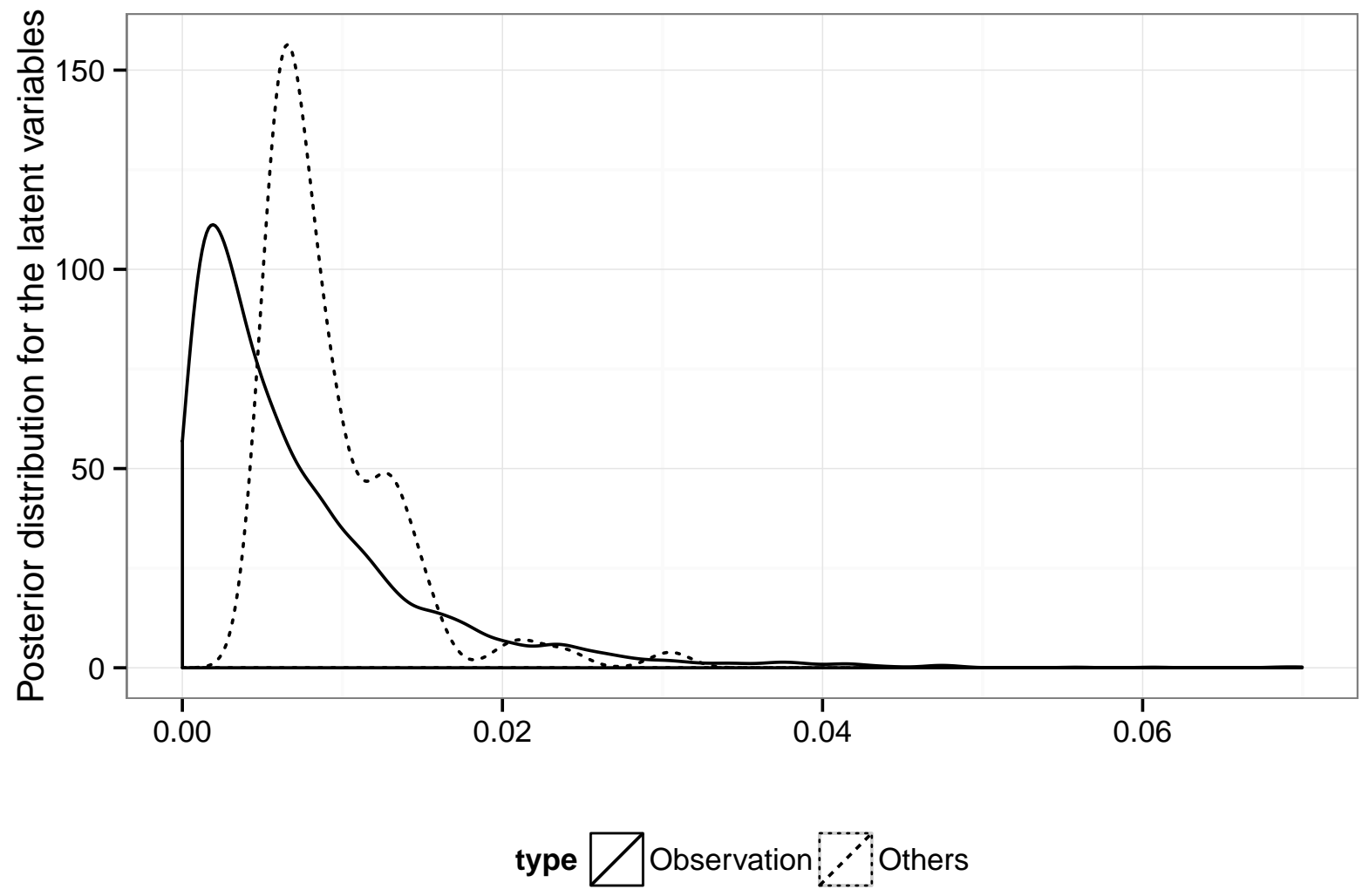

Figura A.6: Gráfico com a comparação da densidade de uma variável latente com todas as outras no modelo 
data ("Brazilelectricity")

Para ajustar o modelo de duas partes

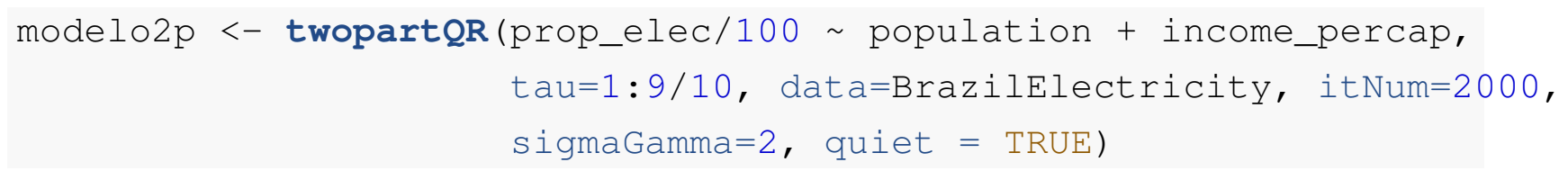

Se julgar que a cadeia ainda não convergiu, pode-se utilizar a função update para aumentar a cadeia, com

modelo2p <- update (modelo2p, 200, sigmaGamma $=2$ )

Para mais detalhes sobre os argumentos de update é só fazer

?update.twopartQR

E também é possível obter as estimativas das médias a posteriori de cada parâmetro usando a função summary,

resumo $2 \mathrm{p}<-$ summary (modelo2p)

E o gráfico com as estimativas também pode ser obtido combinando a função summary com a função plot.

plot (summary (modelo2p))

\section{Capítulo 4}

Os dados sobre gastos com bens duráveis também estão disponíveis no pacote. Para carregá-los na área de trabalho, o seguinte comando pode ser utilizado

data ("BrazilDurableGoods")

A descrição dos campos pode ser obtida fazendo 


\section{?BrazilDurableGoods}

E para ajustar o modelo de regressão quantílica Tobit bayesiano com inflação de zeros, é só usar o comando.

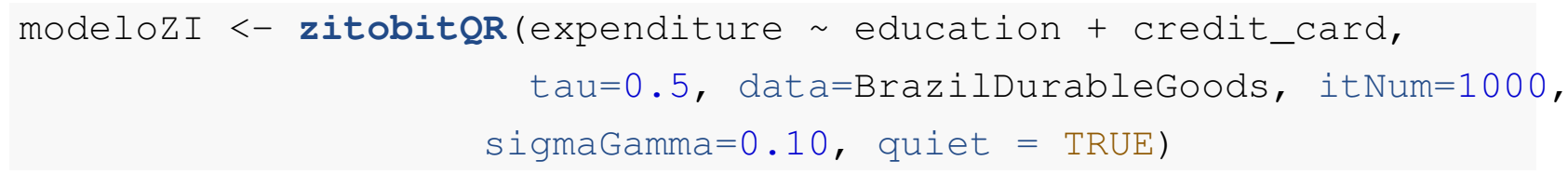

Para esse modelo não foi construída uma função update, pois nesse caso a variável indicadora de censura não é salva, para evitar o uso excessivo de memória física do computador. Ao invés disso, é salvo somente a probabilidade de censura para cada observação.

Para fazer os gráficos comparando as densidades da probabilidade de censura comparando diferentes níveis de uma variável categórica, o seguinte comando pode ser utilizado

plotCensoring (modelozI, "credit_card")

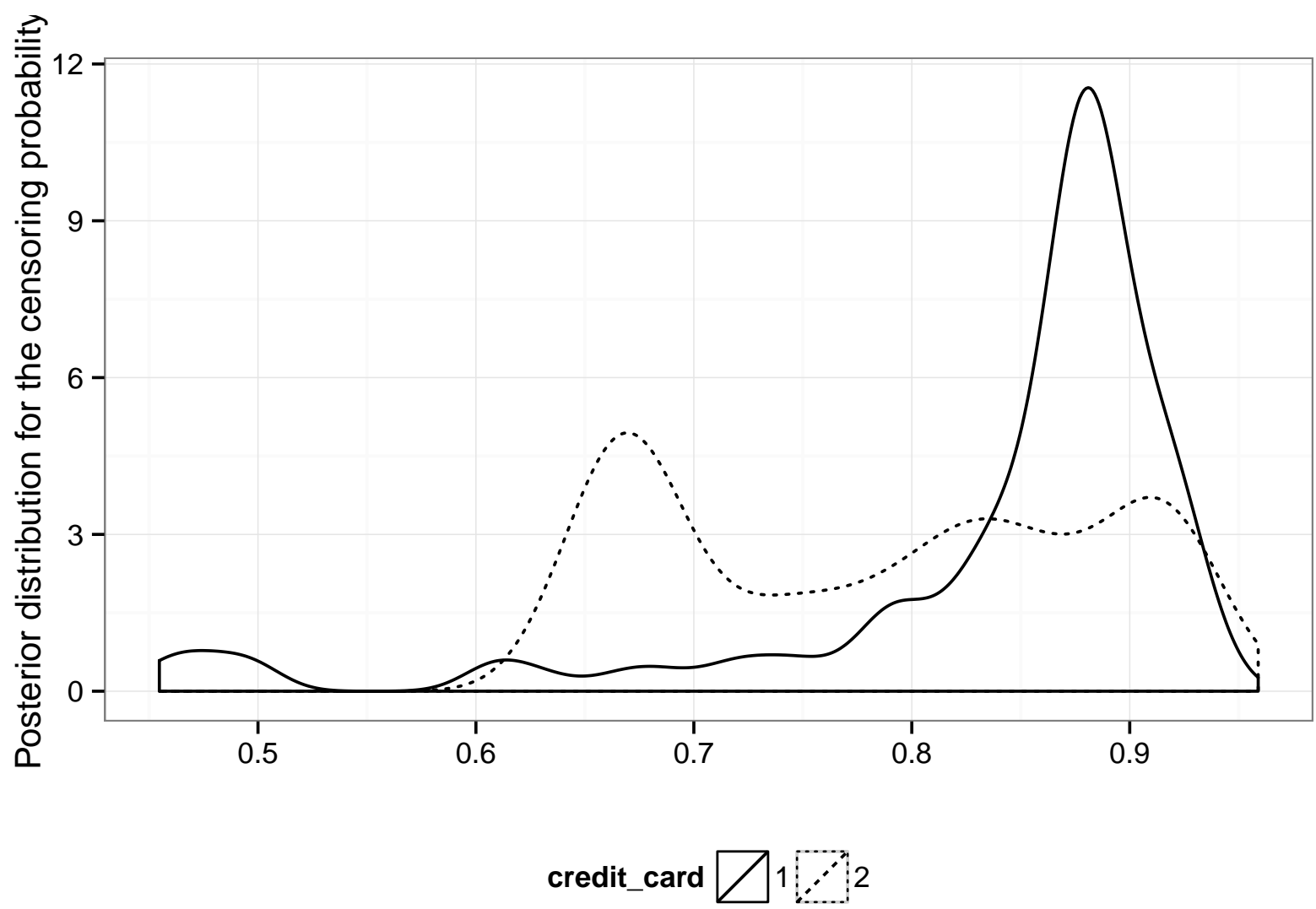

Figura A.7: Gráfico com a comparação da densidade da probabilidade de censura dada a variável cartão de crédito.

O resultado obtido aqui difere daquele apresentado na tese devido tanto ao número de iterações do MCMC quanto também das variáveis utilizadas, que foram selecionadas apenas para exemplificar o resultado. 
Da maneira similar àquela feita para os comandos do capítulo anterior, também é possível utilizar as funções summary e plot para obter as estimativas dos modelos estimados

summary (modelozI)

plot (summary (modelozI))

\section{Capítulo 5}

O banco de dados sobre as eleições também está disponível no pacote e pode ser carregado com o comando

data ("Brazilelection2014")

E para ver as descrição de cada variável, é só fazer

?BrazilElection2014

Para ajustar o modelo somente para os dados de São Paulo, é necessário separar essas observações inicialmente.

dadosSP <- subset (BrazilElection2014, $\mathrm{UF}==35$ )

Antes de ajustar o modelo, é necessário fazer a transformação da variável resposta usando a transformação logito, que pode ser realizada da seguinte forma usando o pacote dplyr

library (dplyr)

dadosSP <- mutate (dadosSP, Resposta = log (percVotes/(1-percVotes)))

Em seguida, dependendo da quantidade de observações é possível utilizar o processo Laplace assimétrico.

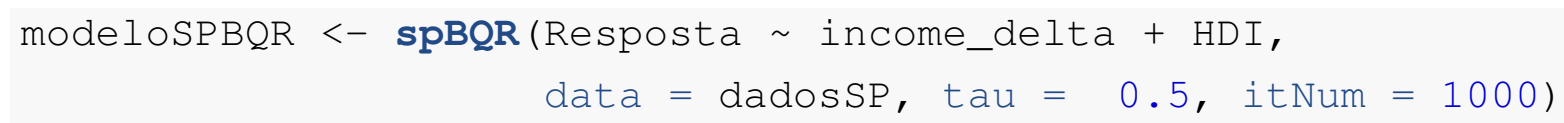

E para usar o processo preditivo é necessário utilizar a função sppBQR, em que precisamos informar o número de nós que serão utilizados no processo de estimação. 


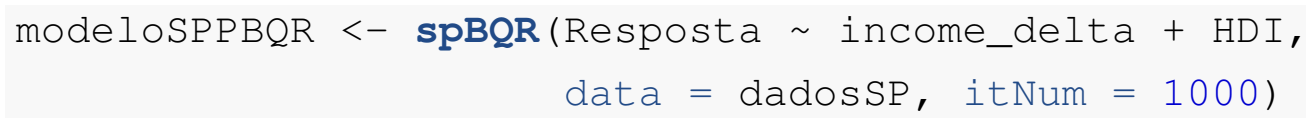

Para ambos os modelos, é possível utilizar a função summary para obtenção das estimativas, como também a função plot para fazer o gráfico com as bandas de credibilidade nos diferentes quantis.

plot (summary (modeloSPPBQR)) 


\section{Referências Bibliográficas}

Albert, J. e Chib, S. (1993), "Bayesian Analysis of Binary and Polychotomous Response Data," Journal of the American Statistical Association, 88, 669-679. Citado na pág. 53

Alhamzawi, R. e Yu, K. (2012), "Variable selection in quantile regression via Gibbs sampling," Journal of Applied Statistics, 39, 799-813. Citado na pág. 30, 91

- (2013), "Conjugate priors and variable selection for Bayesian quantile regression," Computational Statistics $\&$ Data Analysis, 64, 209-219. Citado na pág. 31

Banerjee, S., Carlin, B. P., e Gelfand, A. E. (2003), Hierarchical Modeling and Analysis for Spatial Data, Monographs on Statistics and Applied Probability 101, Chapman and HallCRC, $1^{\text {a }}$ ed. Citado na pág. 73

Banerjee, S., Gelfand, A. E., Finley, A. O., e Sang, H. (2008), "Gaussian predictive process models for large spatial data sets," Journal of the Royal Statistical Society. Series B, 70, 825-848. Citado na pág. 73, 80

Barndorff-Nielsen, . (1978), "Hyperbolic Distributions and Distributions on Hyperbolae," Scandinavian Journal of Statistics, 5, 151-157. Citado na pág. 11

Benoit, D. e Van den Poel, D. (2012), "Binary quantile regression: a Bayesian approach based on the asymmetric Laplace distribution," Journal of Applied Econometrics, 27, 1174-1188. Citado na pág. 48

Branscum, A. J., Johnson, W. O., e Thurmond, M. C. (2007), "Bayesian beta regression: applications to household expenditure data and genetic distance between foot-and-mouth disease viruses," Australian \& New Zealand Journal of Statistics, 49, 287-301. Citado na pág. 73

Chai, H. S. e Bailey, K. R. (2008), "Use of log-skew-normal distribution in analysis of continuous data with a discrete component at zero," Statistics in Medicine, 27, 3643-3655. Citado na pág. 54

Chen, M., Ibrahim, J., e Shao, Q. (2000), "Power prior distributions for generalized linear models." Journal of Statistical Planning Inference, 84, 121-137. Citado na pág. 91

Chib, S. (1992), "Bayes inference in the Tobit censored regression model," Journal of Econometrics, 51, 79-99. Citado na pág. 54

Cragg, J. (1971), "Some Statistical Models for Limited Dependent Variables with Application to the Demand for Durable Goods," Econometrica, 39, 829-844. Citado na pág. 29, 50, 51, 54,61 
Diebolt, J. e Robert, C. (1994), "Estimation of Finite Mixture Distributions through Bayesian Sampling," Journal of the Royal Statistical Society. Series B, 56, 363-375. Citado na pág. 29

Dunson, D. B., Pillai, N., e Park, J.-H. (2007), "Bayesian density regression," Journal of the Royal Statistical Society: Series B, 69, 163-183. Citado na pág. 2

Elsner, J. B., Kossin, J. P., e Jagger, T. H. (2008), "The increasing intensity of the strongest tropical cyclones," Nature, 455, 92-95. Citado na pág. 30

Ferrari, S. e Cribari-Neto, F. (2004), "Beta Regression for Modelling Rates and Proportions," Journal of Applied Statistics, 31, 799-815. Citado na pág. 29, 34, 35, 72

Finley, A. O., Sang, H., Banerjee, S., e Gelfand, A. E. (2009), "Improving the performance of predictive process modeling for large datasets," Computational Statistics and Data Analysis, 53, 2873-2884. Citado na pág. 81

Gelman, A., Carlin, J. B., Stern, H. S., e Rubin, D. B. (2003), Bayesian data analysis, CRC press. Citado na pág. 39

Harville, D. A. (1997), Matrix Algebra From a Statistician's Perspective, Springer-Verlag. Citado na pág. 81

Ibrahim, J. e Chen, M. (2003), "On the optimality properties of the power prior," Journal of the American Statistical Association, 98, 204-213. Citado na pág. 91

Ji, Y., Lin, N., e Zhang, B. (2012), "Model selection in binary and tobit quantile regression using the Gibbs sampler," Computational Statistics and Data Analysis, 56, 827-839. Citado na pág. 31

Karlis, D. (2002), "An EM type algorithm for maximum likelihood estimation of the normal-inverse Gaussian distribution," Statistics $\&$ Probability Letters, 57, 43-52. Citado na pág. 11

Khare, K. e Hobert, J. P. (2012), "Geometric ergodicity of the Gibbs sampler for Bayesian quantile regression," Journal of Multivariate Analysis, 112, 108-116. Citado na pág. 5, 32

Kieschnick, R. e McCullough, B. D. (2003), "Regression analysis of variates observed on (0, 1): percentages, proportions and fractions," Statistical Modelling, 3, 193-213. Citado na pág. 72

Kneib, T. (2012), "Beyond mean regression," Statistical Modelling, 13, 275-303. Citado na pág. 50,72

Koenker, R. (2005), Quantile Regression, Cambridge University Press. Citado na pág. 5, 30, 33

- (2013), quantreg: Quantile Regression, r package version 5.05. Citado na pág. 40

Koenker, R. e Bassett, G. (1978), "Regression Quantiles," Econometrica, 46, 33-50. Citado na pág. $2,5,7,30,31$

Koenker, R. e Machado, J. (1999), "Goodness of Fit and Related Inference Processes for Quantile Regression," Journal of the American Statistical Association, 94, 1296-1310. Citado na pág. 5,32 
Kottas, A. e Gelfand, A. E. (2001), "Bayesian Semiparametric Median Regression Modeling," Journal of the American Statistical Association, 96, 1458-1468. Citado na pág. 6

Kottas, A. e Krnajajić, M. (2009), "Bayesian Semiparametric Modelling in Quantile Regression," Scandinavian Journal of Statistics, 36, 297-319. Citado na pág. 6

Kozumi, H. e Kobayashi, G. (2011), "Gibbs sampling methods for Bayesian quantile regression," Journal of Statistical Computation and Simulation, 81, 1565-1578. Citado na pág. 5, 8, $30,31,32,55,58,61,75$

Kullback, S. e Leibler, R. A. (1951), "On Information and Sufficiency," The Annals of Mathematical Statistics, 22, 79-86. Citado na pág. 14

Liu, J. S., Liang, F., e Wong, W. H. (2000), "The Multiple-Try Method and Local Optimization in Metropolis Sampling," Journal of the American Statistical Association, 95, 121-134. Citado na pág. 79

Lum, K. (2010), "Bayesian Spatial Quantile Regression." Tese de Doutorado, Duke University. Citado na pág. 79

Lum, K. e Gelfand, A. (2012), "Spatial Quantile Multiple Regression Using the Asymmetric Laplace Process," Bayesian Analysis, 7, 1-24. Citado na pág. 30, 71, 73, 75, 76, 77, 78, 79, 80, 84

Luo, Y., Lian, H., e Tian, M. (2012), "Bayesian quantile regression for longitudinal data models," Journal of Statistical Computation and Simulation, 82, 1635-1649. Citado na pág. 31

McCullagh, P. e Nelder, J. (1989), Generalized Linear Models, Chapman and Hall. Citado na pág. 1

Moulton, L. H. e Halsey, N. A. (1995), "A mixture model with detection limits for regression analyses of antibody response to vaccine," Biometrics, 51, 1570-1578. Citado na pág. 54, 70

Mroz, T. A. (1987), "The sensitivity of an empirical model of married women's hours of work to economic and statistical assumptions," Econometrica, 765-799. Citado na pág. 61

Ospina, R. e Ferrari, S. L. (2012), "A general class of zero-or-one inflated beta regression models," Computational Statistics \& Data Analysis, 56, 1609-1623. Citado na pág. 29, 30, 36

Rasmussen, C. E. e Williams, C. K. I. (2006), Gaussian Processes for Machine Learning, MIT Press. Citado na pág. 75

Reich, B. J., Fuentes, M., e Dunson, D. B. (2011), "Bayesian Spatial Quantile Regression," Journal of the American Statistical Association, 106, 6-20. Citado na pág. 6, 76

Rigby, R. A. e Stasinopoulos, D. M. (2005), "Generalized Additive Models for Location, Scale and Shape," Journal of the Royal Statistical Society, Series C., 54, 507-554. Citado na pág. 1

Santos, B. (2012), "Modelos de regressão quantílica," Dissertação de Mestrado, Universidade de São Paulo. Citado na pág. 7

Santos, B. e Elian, S. (2015), "Influence measures for quantile regression models," Communications in Statistics - Theory and Methods, 44, 1842-1853. Citado na pág. 6 
Schnabel, S. K. e Eilers, P. H. (2009), "Optimal expectile smoothing," Computational Statistics $\&$ Data Analysis, 53, 4168-4177. Citado na pág. 2

Simas, A. B., Barreto-Souza, W., e Rocha, A. V. (2010), "Improved estimators for a general class of beta regression models," Computational Statistics $\&$ Data Analysis, 54, 348-366. Citado na pág. 29, 72

Sriram, K., Ramamoorthi, R., e Ghosh, P. (2013), "Posterior Consistency of Bayesian Quantile Regression Based on the Misspecified Asymmetric Laplace Density," Bayesian Analysis, 8, 479-504. Citado na pág. 5, 36, 52

Taddy, M. A. e Kottas, A. (2010), "A Bayesian Nonparametric Approach to Inference for Quantile Regression," Journal of Business $E$ Economic Statistics, 28, 357-369. Citado na pág. 6

Tanner, M. e Wong, W. (1987), "The calculation of posterior distributions by data augmentation," Journal of the American Statistical Association, 82, 528-540. Citado na pág. 32

Tobin, J. (1958), "Estimation for Relationship for limited dependent variables," Econometrica, 26, 24-36. Citado na pág. 50, 54, 61

Tokdar, S. T. e Kadane, J. B. (2011), "Simultaneous Linear Quantile Regression: A Semiparametric Bayesian Approach," Bayesian Analysis, 6, 1-22. Citado na pág. 6

Waldmann, E. e Kneib, T. (2015), "Bayesian bivariate quantile regression," Statistical Modelling, 15, 326-344. Citado na pág. 72

Wichitaksorn, N., Choy, S., e Gerlach, R. (2014), "A generalized class of skew distributions and associated robust quantile regression models," Canadian Journal of Statistics, 42, 579-596. Citado na pág. 91

Yang, Y., Wang, H. J., e He, X. (2015), "Posterior Inference in Bayesian Quantile Regression with Asymmetric Laplace Likelihood," International Statistical Review. Citado na pág. 5, 8

Yu, K., Chen, C. W., Reed, C., e Dunson, D. B. (2013), "Bayesian variable selection in quantile regression," Statistics and Its Interface, 6, 261-274. Citado na pág. 34

Yu, K., Lu, Z., e Stander, J. (2003), "Quantile Regression: Applications and Current Research Areas," Journal of the Royal Statistical Society. Series D (The Statistician), 53, 331-350. Citado na pág. 30

Yu, K. e Moyeed, R. (2001), "Bayesian quantile regression," Statistics \& Probability Letters, 54, 437-447. Citado na pág. 5, 7, 8, 10, 30, 32 